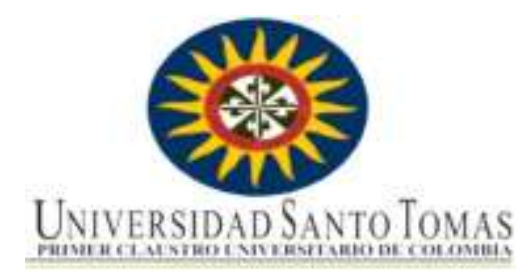

\title{
PROPUESTA DE UNA ESTRATEGIA DE COMUNICACIÓN PARA LA PROMOCIÓN DE LA ALIMENTACIÓN SALUDABLE DE MUJERES GESTANTES.
}

\section{ANDREA CONSTANZA BORBÓN GUEVARA}

\author{
Universidad Santo Tomás
}

Maestría en Comunicación, Desarrollo y Cambio Social

Bogotá, Colombia

2018 



\section{PROPUESTA DE UNA ESTRATEGIA DE COMUNICACIÓN PARA LA PROMOCIÓN DE LA ALIMENTACIÓN SALUDABLE DE MUJERES GESTANTES.}

\section{ANDREA CONSTANZA BORBÓN GUEVARA}

Trabajo de investigación presentado como requisito parcial para optar al título de:

Magister en Comunicación, Desarrollo y Cambio Social

Directora: Ibeth Molina Molina

Doctora en Ciencias Sociales

Línea de Investigación:

Comunicación, salud, medio ambiente y sostenibilidad

Universidad Santo Tomás

Facultad de Comunicación Social

Bogotá, Colombia

2018 


\section{AGRADECIMIENTOS}

A la vida que es bella....

A mi estrella mayor en el cielo que día a día me guía y protege y siempre decía:

Estudie, que es lo único que le puedo dar.

A mi estrella mayor en la tierra que con su ejemplo y su tenacidad me enseñó más que cualquier maestra

A mi familia osos de la casa que son mi energía, mi porqué y mí para qué

Al equipo del INS que me enseñaron a dar grandes pasos, a mi tutora Ibeth que me guío con su paciencia y dulzura.

A todos los que de una u otra manera intervinieron en mi camino de una nutricionista en la Comunicación, el Desarrollo y el Cambio Social 
Resumen

La presente investigación tiene por objeto proponer una estrategia de comunicación dirigida a la promoción de la alimentación saludable de las mujeres gestantes pertenecientes al programa familias en acción de la Secretaría Distrital de Integración Social a partir del conocimiento de sus prácticas alimentarias y consumo de medios. El proceso se realizó en el marco de la comunicación estratégica, en el cual mediante procesos participativos, surgieron aspectos interesantes como la importancia de vincular a los actores influyentes en la decisión del consumo de alimentos como son las madres de las gestantes, sus abuelas y compañeros y luego de los profesionales de la salud y líderes sociales. En la estrategia propuesta se incluyen unos ejes comunico - educativos que buscan fortalecer capacidades de los actores para que por medio de la consejería adquieran habilidades comunicativas para escuchar, observar, generar confianza y dar apoyo y un eje comunicativo donde, mediante el uso de redes sociales, se refuerzan mensajes claves. La propuesta se basa en la comunicación y salud, unión clave para buscar transformaciones reales que perduren en el tiempo, en el desarrollo para empoderar y autogenerar estrategias viables a partir de ideas propias y cambio social en el cual las gestantes y los actores claves son quienes determinan que necesitan y cómo conseguir lo que requieren, buscando resultados poblacionales a partir de sus realidades $\mathrm{y}$ potencialidades.

Palabras claves: Gestantes, estado nutricional, comunicación, desarrollo y cambio social, comunicación estratégica. 


\section{Introducción}

Acorde a la Encuesta Nacional de Situación Nutricional, aproximadamente el $50 \%$ de las mujeres gestantes presentan algún grado de malnutrición sea por exceso, como obesidad y sobrepeso o por déficit como baja ganancia de peso gestacional. Esta situación repercute en problemas de salud tanto de la madre como del bebé afectando en especial el crecimiento y desarrollo de los niños. En varios casos la principal causa de esta situación es la inadecuada alimentación de las gestantes y sus familias, derivada de cultura y hábitos alimentarios, disposición y posibilidad de adquirir alimentos nutritivos así como de la selección de los mismos. Es por esto que desde el Instituto Nacional de Salud, COLCIENCIAS y la Secretaría Distrital de Integración Social, se realizó una investigación longitudinal con una muestra representativa de las 20 localidades del distrito sobre las prácticas alimentarias de las mujeres gestantes pertenecientes al programa familias en acción y con el ánimo de utilizar ésta información para proyectar acciones de salud pública que contribuyan a mejorar la situación nutricional de las gestantes, se realizó está investigación en el marco de la comunicación, el desarrollo y el cambio social, lo cual implicó conocer cómo se alimentan las gestantes y porqué consumen esos alimentos, como se informan sobre alimentación saludable y quienes son los actores claves que influyen el consumo de los alimentos. A partir de ésta realidad y acorde a la metodología de comunicación estratégica se realizó una propuesta para la promoción de la alimentación saludable participativa, sostenible, teniendo en cuenta a las gestantes y los actores claves como sujetos y no como objetos de intervención dignos de cambiar donde a través de unos ejes comunicativos y comunico-educativos se proponen acciones participativas para el cambio, transformaciones que perduren en el tiempo y que contribuyan al desarrollo de la sociedad y al mejoramiento de la situación alimentaria de nuestra población. A continuación, se presenta el resultado de la investigación en mención, requisito para optar al título de maestra en comunicación, desarrollo y cambio social. 


\section{Contenido}

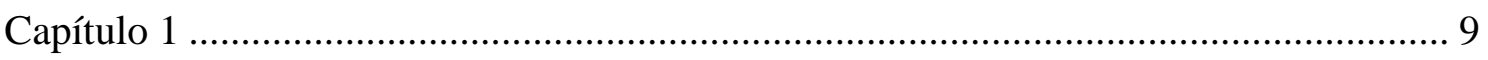

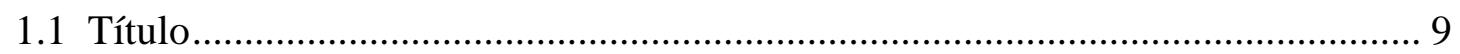

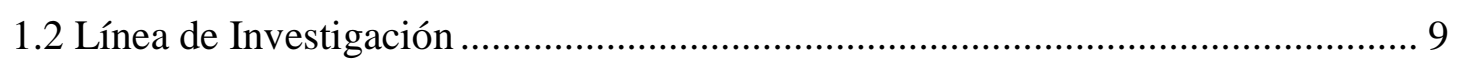

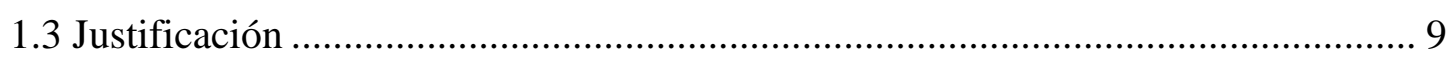

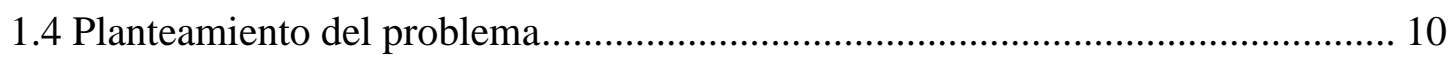

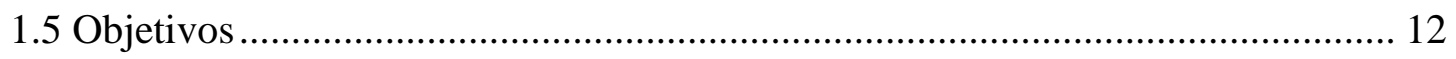

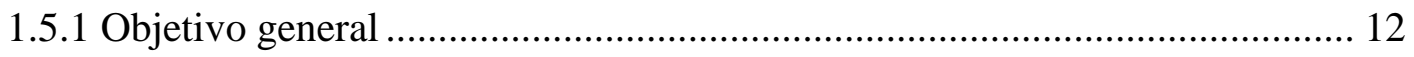

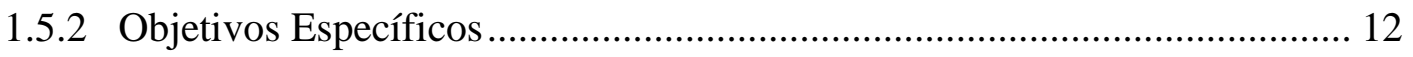

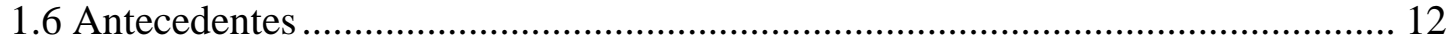

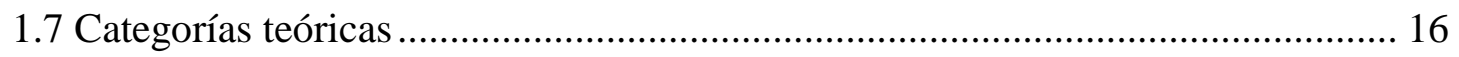

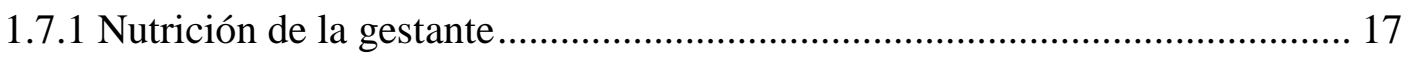

1.7.2 Comunicación, desarrollo y cambio social ................................................. 21

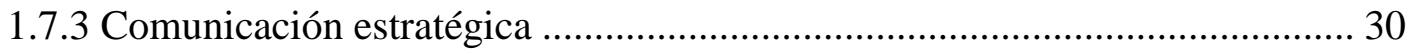

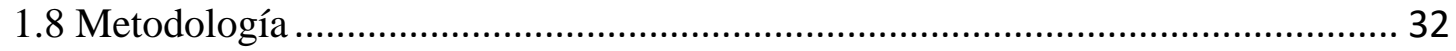

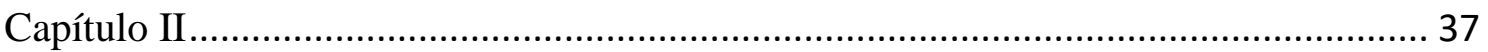

2. Características sociales y alimentarias de las mujeres gestantes .............................. 37

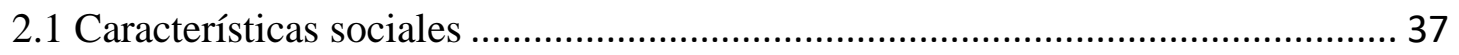

2.2 Caracterización de las prácticas alimentarias ...................................................... 45

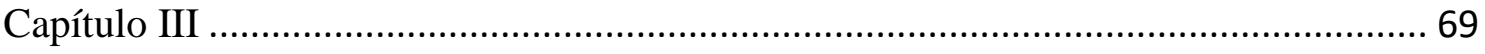

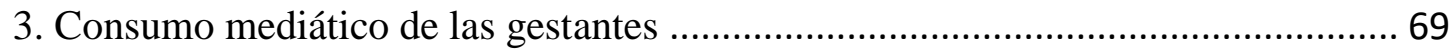

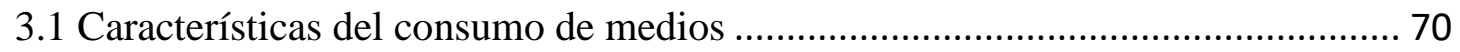

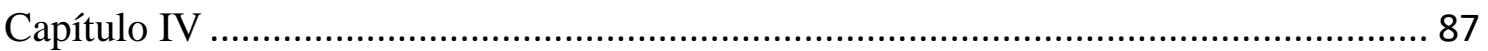

4. Estrategia de comunicación para la promoción de la alimentación saludable ...........87 87

4.1 Propuesta de estrategia de comunicación ........................................................ 103

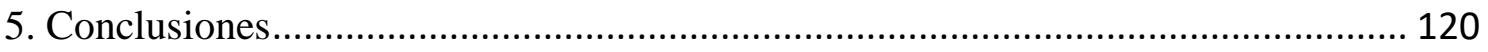

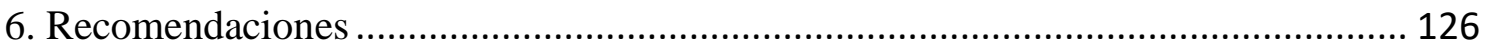

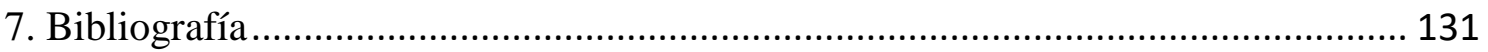




\section{Índice de tablas}

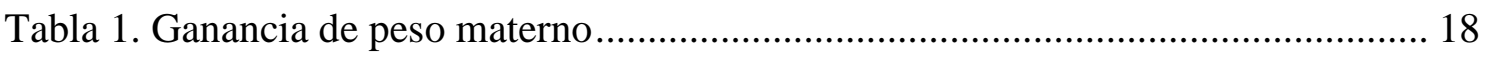

Tabla 2. Población de gestantes evaluadas en el componente de consumo ..................... 46

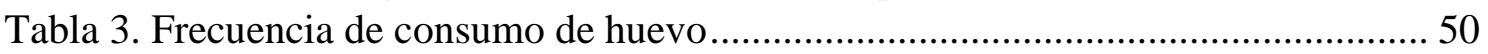

Tabla 4. Consumo de fuentes de proteína en las gestantes.......................................... 51

Tabla 5. Consumo de vísceras por las gestantes........................................................ 52

Tabla 6. Descripción del análisis agrupado de consumo de frutas y verduras en gestantes

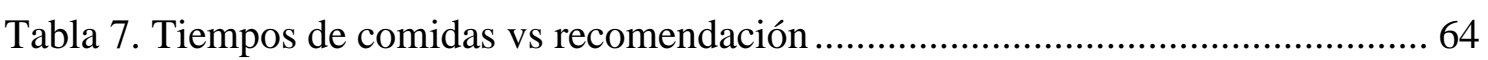

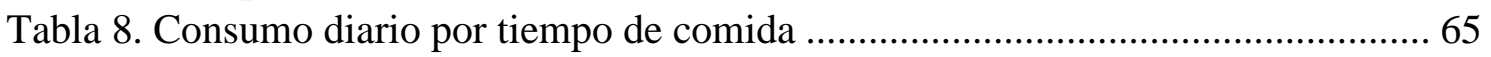

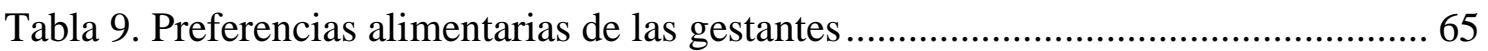

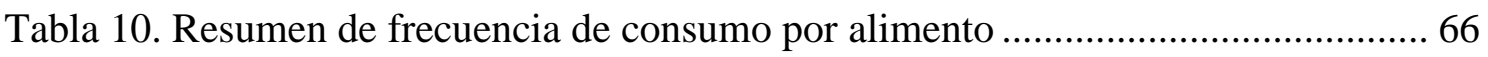

Tabla 11. Población de gestantes participantes en la encuesta del consumo de medios 69

Tabla 12. Población de gestantes participantes en encuesta de consumo de internet y

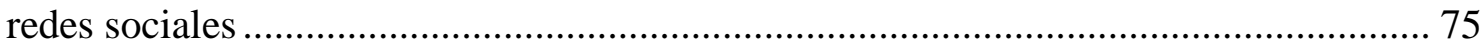

Tabla 13. Resumen de los componentes del proceso de Información, Educación y

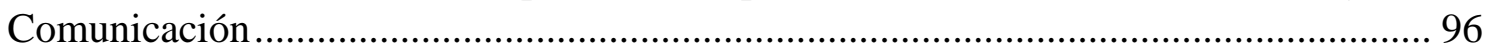

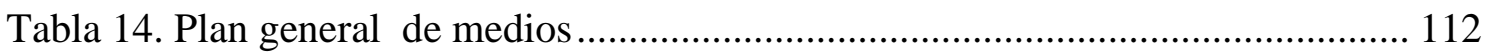

Tabla 15. Ciclo de envío de la información a las gestantes........................................... 113

Tabla 16. Ejemplo del desarrollo del plan de medios dirigido a las gestantes ............ 113

Tabla 17. Plan de medios para familiares ................................................................... 115

Tabla 18. Ciclo de envío de la información a los familiares ..................................... 115

Tabla 19. Ejemplo del desarrollo del plan de medios dirigido a los familiares ........... 116

Tabla 20. Proceso de monitoreo y evaluación ......................................................... 118 


\section{Índice de ilustraciones}

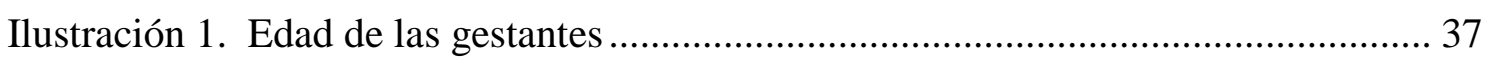

Ilustración 2. Número de personas que conforman el hogar .......................................... 38

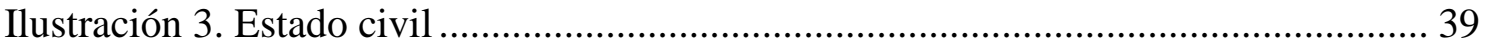

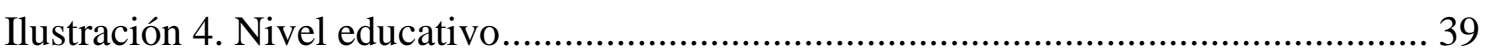

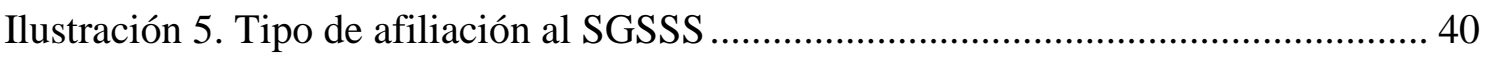

Ilustración 6. Actividad económica de las gestantes ..................................................... 41

Ilustración 7. Estrato de la vivienda …………………………………………….... 41

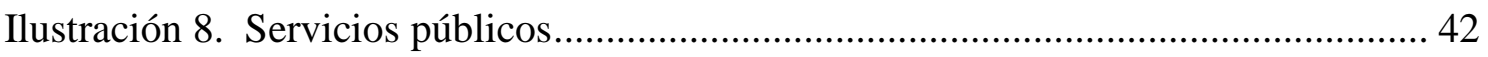

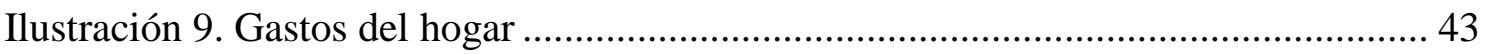

Ilustración 10. Participación en apoyos alimentarios ...................................................... 44

Ilustración 11. Distribución de la frecuencia de consumo de leche en las gestantes ..... 48

Ilustración 12. Distribución de la frecuencia de consumo de derivados lácteos en las

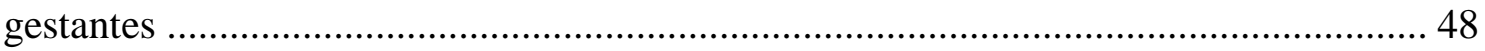

Ilustración 13. Consumo de fuentes de proteína en las gestantes por tipo de frecuencia

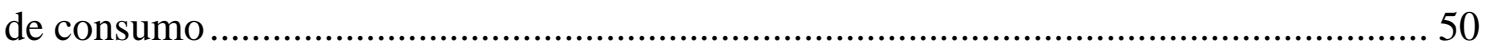

Ilustración 14. Consumo de leguminosas secas en las gestantes.................................... 53

Ilustración 15. Consumo de fuentes de carbohidratos por grupos de edad ..................... 54

Ilustración 16. Consumo de azúcar, miel y panela......................................................... 55

Ilustración 17. Frecuencia de consumo de gaseosas o refrescos por las gestantes.......... 56

Ilustración 18. Consumo de dulces y golosinas en las gestantes.......................................56

Ilustración 19. Consumo de verduras cocidas y crudas en las gestantes por subcategoría

de frecuencia.................................................................................................... 59

Ilustración 20. Consumo de frutas enteras y en jugo por subcategorías de frecuencia. . 59

Ilustración 21. Consumo de alimentos integrales ......................................................... 60

Ilustración 22. Consumo de alimentos fuentes de grasas............................................. 61

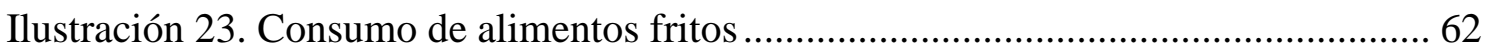

Ilustración 24. Consumo de comidas rápidas en la población de estudio ......................... 62

Ilustración 25. Consumo de snacks y/o productos de paquete ......................................... 63

Ilustración 26. Consumo de medios con relación a la edad de la gestante....................... 71

Ilustración 27. Preferencia de medios para recibir cualquier tipo de información......... 72

Ilustración 28. Medio que utiliza para buscar u obtener información sobre alimentación

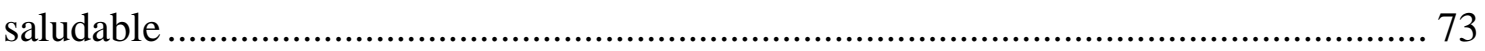

Ilustración 29. Medio que preferiría para recibir información sobre alimentación saludable.

Ilustración 30. Interés en recibir información sobre alimentación saludable

independiente del medio................................................................................... 74

Ilustración 31. ¿Ha buscado información sobre alimentación saludable en You Tube? 77

Ilustración 32. ¿Qué palabras usa para la búsqueda? ..................................................... 77

Ilustración 33. ¿Busca información sobre alimentación en Google? .............................. 78

Ilustración 34. Palabras utilizadas para la búsqueda en Google..................................... 79

Ilustración 35. ¿Tiene cuenta de Facebook?................................................................ 80 
Ilustración 36. ¿Cuántas veces al día utiliza facebook? 80

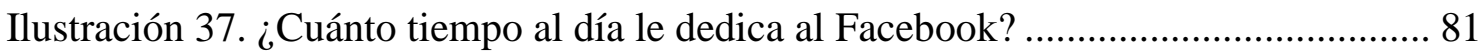

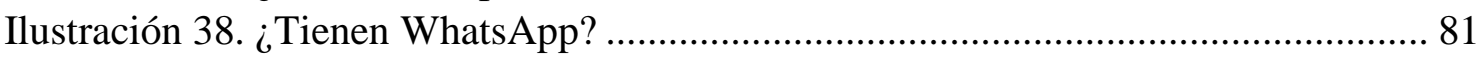

Ilustración 39. ¿Usa WhatsApp para consultar sobre alimentación saludable? .............. 82

Ilustración 40. ¿Qué temas consulta con sus contactos en WhatsApp? ........................ 82

Ilustración 41. ¿A quién consulta en caso de dudas relacionadas con alimentación? .... 83

Ilustración 42. Mapa de Actores de las Mujeres Gestantes ......................................... 93

Ilustración 43. Estructura general de la propuesta de la Estrategia de Comunicación. 104 


\section{Anexos}

1. Instrumento para caracterizar prácticas alimentarias

2. Instrumento para caracterizar el consumo de medios

3. Instrumento para caracterizar el consumo de internet y redes sociales

4. Guía grupo focal 


\section{Capítulo 1}

\subsection{Título}

Propuesta de una estrategia de comunicación para la promoción de la alimentación saludable de mujeres gestantes.

\subsection{Línea de Investigación}

El estudio propuesto se enmarca en la línea de investigación de la Maestría de Comunicación, Desarrollo y Cambio Social de la Universidad Santo Tomás denominada “Comunicación, salud, medio ambiente y sostenibilidad", dado que se involucra la salud y en este caso, la alimentación saludable de las gestantes, en el marco del derecho de la alimentación como principio fundamental para contribuir al desarrollo humano desde la perspectiva de las gestantes como actores sociales. Esta investigación se enfoca en las prácticas alimentarias de las mujeres gestantes y en la elaboración de una propuesta de comunicación pública en salud, teniendo en cuenta el contexto cultural, la comprensión de las gestantes y su manera de ver y concebir el cuerpo y la salud, con el fin propiciar el empoderamiento de esta población frente a su problemática y ofrecer una alternativa de comunicación en salud para la promoción de la alimentación saludable.

\subsection{Justificación}

El presente trabajo presenta los resultados de la investigación resultante de mi labor como Coinvestigadora en el marco de una investigación desarrollada por Colciencias, el Grupo de Nutrición del Instituto Nacional de Salud, la Secretaría Distrital de Integración Social y la Asociación Colombiana para el avance de la ciencia - ACAC, denominada "Efecto de las prácticas alimentarias de mujeres gestantes y sus hijas e hijos hasta los 24 meses de edad sobre el estado nutricional, en una población atendida por la Secretaría Distrital de Integración Social de la Alcaldía mayor de Bogotá", la cual busca profundizar en el conocimiento sobre la alimentación de las gestantes y sus hijos menores de 24 meses para, a partir de su análisis con relación a factores sociodemográficos, culturales, de salud, alimentarios y del estado nutricional, poder contribuir al fortalecimiento de políticas y estrategias de intervención y atención acordes a la realidad de la población. 
Dada la importancia de la alimentación saludable en la mujer gestante y sus efectos en el estado nutricional y de salud de la población infantil que repercuten en las condiciones físicas y psicológicas de la madre y del niño hasta su vida adulta, es fundamental realizar estudios que exploren estos aspectos.

Uno de los principales problemas identificados en la población gestante es la malnutrición, ya sea por déficit o por exceso, lo cual repercute en el estado de salud y de nutrición de sus hijos. Es por esto, que en mi labor de coinvestigadora pretendo, a partir de la valoración de las prácticas alimentarias y de comunicación de las gestantes beneficiarias de un programa social, establecer cuál sería la mejor estrategia de comunicación para promover la alimentación saludable en estas mujeres, contribuyendo así al fortalecimiento de las acciones en salud pública para la promoción de la alimentación y salud de las gestantes. Se propone entonces la creación colectiva de una estrategia que incluya la participación de la población beneficiaria, bajo la premisa, que invertir en su salud no es solo correcto sino que también ayuda a lograr sociedades estables, pacíficas y productivas a favor del desarrollo de un país.

\subsection{Planteamiento del problema}

La Encuesta Nacional de Situación Nutricional Colombia - ENSIN 2010, estudio poblacional de cobertura nacional con representatividad urbana y rural (Salud, Profamilia, \& ICBF, 2010), muestra que el 16\% y el 34.6\% de las gestantes en Colombia presentan bajo peso y exceso de peso para la edad gestacional respectivamente. Esto significa que aproximadamente la mitad de las mujeres gestantes del país no tiene un adecuado estado nutricional, repercutiendo en la salud tanto de ellas como de sus hijos.

Durante el embarazo, las necesidades nutricionales son mayores, en comparación con otras etapas de su vida. La alimentación de la gestante debe proporcionarle todos los macro y micronutrientes para que al crecer el óvulo fertilizado, se convierta en un feto viable y luego que tenga un nacimiento a término. Mientras la madre se va nutriendo, brinda nutrientes al feto en crecimiento y al mismo tiempo prepara su tejido mamario para la lactancia (Latham, 2002). Además la evidencia muestra que las mujeres con ganancias insuficientes o excesivas de peso presentan un mayor riesgo de tener retardo en el crecimiento intrauterino, bajo peso al nacer, mortalidad perinatal y mayor porcentaje de complicaciones al nacimiento (Hernandez, 2014). 
La principal causa del inadecuado estado nutricional es la inseguridad alimentaria, desde dificultades en la disponibilidad y en el acceso a los alimentos, hasta problemas con el consumo y aprovechamiento biológico. Se requiere por lo tanto el diseño, implementación y desarrollo de iniciativas intersectoriales que aborden el carácter multifactorial de los problemas de alimentación, que contribuyan a que las mujeres gestantes tengan un adecuado estado nutricional y de salud, teniendo en cuenta los grandes retornos económicos y sociales de invertir en una alimentación adecuada tanto en las gestantes como en los niños y niñas menores de 2 años (Perczek \& Corredor, 2014).

Una de las estrategias más costo efectivas y necesarias para la promoción de la alimentación saludable de la gestante es mediante la comunicación efectiva que va más allá de la transmisión vertical y unidireccional de información e implica la participación activa de la comunidad para construir una estrategia de comunicación saludable de ellos y para ellos, haciéndola propia, especial y única, que aporte al cambio social y al desarrollo humano de la población (Martinez, 2012). Es así como desde el campo de la comunicación, desarrollo y cambio social, se aportarán elementos técnicos que permitan, por una parte, contribuir a mejorar las condiciones de vida de los sujetos sociales, mediante la inclusión, participación y valoración de sus realidades alimentarias y por otro lado busca brindar alternativas de promoción de la alimentación saludable a las entidades marco de la investigación principal, mediante la identificación de elementos de la comunicación, que perfilen una estrategia integral que permita el fortalecimiento de conocimiento de mujeres gestantes para que sean parte de procesos transformadores de la vida de sus hijos y la vida de los demás en su contexto social y cultural.

Sin embargo, tanto a nivel territorial, como a nivel nacional e internacional, cada vez son más las campañas de promoción de la alimentación saludable dirigidas a las mujeres gestantes que son creadas en oficinas y centros de diseño sin tener en cuenta el marco real de esta población, es decir, no son escuchadas, no se comparte con ellas, no se abre debate y no se tiene en cuenta a las comunidades, sus conceptos de desarrollo, sus problemas, por lo tanto los resultados no son reales, porque no están los procesos relacionados con su identidad ni están pensados para el fortalecimiento de los grupos poblacionales. La comunicación, desarrollo y cambio social, le apuesta por el contrario, a contribuir al impulso que requieren las comunidades para que ellos mismos, a partir de su realidad, de su sentir y de su vivir, identifiquen sus problemas y potencialicen sus capacidades para establecer soluciones viables que genere cambios y mejoras en su calidad de vida. 
Dado lo anterior y con el objeto de brindar elementos que ayuden al mejoramiento del estado nutricional de las gestantes y a la salud de sus hijos, surge la pregunta ¿Cómo promover la alimentación saludable de las gestantes, a través de una estrategia comunicativa, teniendo en cuenta sus prácticas de alimentación, su consumo de medios y la participación de esta población en la construcción de la propuesta?

\subsection{Objetivos}

\subsubsection{Objetivo general}

Promover la alimentación saludable de mujeres gestantes a través del diseño de una estrategia comunicativa.

\subsubsection{Objetivos Específicos}

Identificar las prácticas alimentarias de un grupo de gestantes beneficiarias del Servicio de Atención Integral a la Primera Infancia en el Ámbito Familiar de la Secretaría Distrital de Integración Social, estableciendo conductas de riesgo objeto de intervención frente a la alimentación.

Caracterizar las prácticas comunicativas e informativas relacionadas con la alimentación de un grupo de gestantes beneficiarias del Servicio de Atención Integral a la Primera Infancia en el Ámbito Familiar de la Secretaría Distrital de Integración Social. - $\quad$ Establecer una propuesta de estrategia de comunicación que contribuya con la promoción de la alimentación saludable de la población gestante.

\subsection{Antecedentes}

La promoción de la alimentación saludable de las gestantes es un proceso que busca brindar a las mujeres embarazadas y sus familias, herramientas, habilidades y competencias para alimentarse de manera adecuada, con el objeto de proporcionar los nutrientes necesarios a la madre y al hijo que les permitan gozar de una buena salud. Estas acciones contribuyen a prevenir eventos que conlleven a la enfermedad, mediante la adopción y mantenimiento de buenas prácticas alimentarias. Para esto se requiere de trabajos multidisciplinarios que contribuyan a que las acciones de promoción sean efectivas y generen comportamientos que beneficien a la población. 
Se realizó una revisión bibliográfica de las acciones de promoción de la alimentación saludable en mujeres gestantes, con el ánimo de conocer qué procesos y resultados se habían desarrollado, en el marco de las estrategias de comunicación que buscaban contribuir a mejorar la alimentación de las mujeres gestantes.

Un estudio realizado en Madrid, España en el año 2015, denominado "La divulgación radiofónica de la alimentación y nutrición”, buscaba explicar el papel que pueden tener los medios de comunicación y en especial la radio comunitaria, en la divulgación de conocimientos científicos relacionados con la alimentación y la nutrición, encontró que éstas acciones permitieron popularizar conocimientos en la población radioescucha. Al finalizar se evidenció la recordación de los mensajes y puesta en práctica de lo aprendido en relación a alimentación y nutrición y se recomendó que para este tipo de programas se unieran los profesionales de las dos áreas, comunicación y salud, para mejorar los resultados de la experiencia. De igual manera se mostró el interés y posibilidad que ofrece la radio para cumplir su función educativa y transmitir contenidos fiables y rigurosos adaptados al público en general y que pueden ayudar a mejorar los hábitos alimentarios y de salud de la población (Bernabeu-Peiró, 2015).

Un trabajo realizado en México en 2010, se enfocó en la importancia de desarrollar acciones que eviten consecuencias negativas derivadas de la inadecuada alimentación como la malnutrición en el periodo de la gestación y resaltó que la alimentación es una actividad no sólo biológica, nutricional y médica, sino también un fenómeno social, psicológico, económico, simbólico, religioso y cultural. Por lo tanto, al conocer las formas de obtención y distribución de los alimentos, así como las prácticas de preparación y consumo de los mismos, los hábitos de consumo y las creencias sobre la alimentación, brindan información útil para mejorar la comunicación y elaborar recomendaciones efectivas a las mujeres, lo cual puede ayudar a promover cambios de conducta durante el embarazo y concluye que a pesar que las gestantes cuentan con los conocimientos correctos frente a una alimentación saludable, en la realidad es muy difícil cumplir con la teoría por las dificultades para cambiar hábitos alimentarios y recomiendan ampliar la información de promoción de alimentación saludable a la pareja y a la madre, dada la gran influencia que tienen estas personas sobre ellas (Sánchez-Jiménez, Sámano, Pinzón, Balas, \& Perichart, 2010) 
Por otra parte, una investigación realizada en Canadá en 2010, cuestionaba si las mujeres de este país podían lograr un embarazo en forma, para lo cual registraba diariamente y durante una semana, el nivel de actividad física y los comportamientos alimentarios relacionados con la ganancia de peso gestacional, concluyendo que había más mujeres con una ganancia de peso gestacional por encima de lo normal y que en general, el estilo de vida de las gestantes es inactivo, así como también, resalta la importancia de los mensajes de salud pública y la promoción de estilos de vida saludable para reducir obesidad en mujeres gestantes. Finalmente, recomienda que las estrategias de comunicación deben estar enfocadas en tres temas primordiales: promover una adecuada ganancia de peso gestacional, mantener un Índice de Masa Corporal adecuado y procurar la actividad física para contribuir a tener un embarazo saludable (Tamara R. Cohen, 2010).

De igual manera un trabajo de investigación realizado en Líbano, resaltó la importancia de dar consejería a las gestantes para ayudar a que las mujeres en edad reproductiva tengan un adecuado peso preconcepcional y una adecuada ganancia de peso durante el embarazo (Rym El Rafei, 2015)

En Colombia hay algunos estudios relacionados con la promoción de la alimentación saludable y la comunicación, como el realizado en Bogotá en el año 2008, donde unos investigadores de comunicación de la Universidad Javeriana analizaron la experiencia en los programas de promoción y prevención de la salud. Como resultado, se encontró una evidente falta de creatividad para cautivar al público y persuadirlo, pues las acciones comunicativas funcionan bajo un mismo patrón: folletos, charlas y talleres y se resalta la función de las estrategias comunicativas orientadas a la información, movilización y educación, dejando por fuera las funciones de construcción del sentido y la comunicación para el cambio social, las cuales podrían aportar a la comprensión de las problemáticas y a la posterior concientización de la comunidad de la importancia de tener hábitos saludables. También referencia que la salud no recibe la importancia que merece en los medios de difusión masiva como la televisión, siendo frecuente información de salud pero en espacios pequeños que no permiten profundizar en los temas y dejan muchas inquietudes en los televidentes. Lo mismo pasa en la radio donde se tratan temas que son tendencia en salud y acorde a resultados de últimas investigaciones pero sin un alto grado de profundidad. Por el contrario, la prensa fue el medio por el cual se brindó información ampliada con relación a salud, ya que tuvo en cuenta la opinión y sugerencias de expertos 
y otros puntos de vista. A partir de lo anterior, se pudo concluir la falta de estrategias de divulgación de los programas de promoción y prevención de las entidades por los diferentes canales de comunicación, recomendando dar a conocer la oferta de servicios y los programas; de igual manera evidenciaron la ineficacia de campañas publicitarias elaboradas dentro de las instituciones y fuera de los contextos sociales y culturales, que impiden generar cambios (Torrez \& Chavez, 2008).

Por otra parte, es importante mencionar que existen ejemplos de planes de comunicaciones, que van más allá de un plan de medios, como el desarrollado en el marco del Programa de Cero a Siempre de la Presidencia de la República, quienes con el objeto de divulgar las políticas, los lineamientos, los estándares de calidad y la ruta de atención integral a la Primera Infancia, así como posicionar su marca, la cual reúne las acciones del sector público y privado para el beneficio de los niños y las niñas menores de 5 años, crearon una estrategia que incluye:

- Plan Padrino, para apoyo en la construcción y adecuación de infraestructura para educación;

- Creación de alianzas público privadas para la consecución de los objetivo

- Elaboración del convenio entre la alta consejería presidencial para programas especiales y Discovery Latino América uniendo esfuerzos para la promoción de pautas de crianza y hábitos saludables por medio de la difusión de la campaña: "Kids en Acción”, en la cual se realizaron y divulgaron mensajes sensibilizadores para la adopción de hábitos saludables, la sana alimentación de los niños y la importancia de la actividad física. Esto se desarrolló mediante cápsulas informativas presentadas por "La guarida secreta", Doki y sus amigos y a través de algunos capítulos de "Yummy Tonnies trasmitiendo una campaña atractiva, dinámica y útil para toda la familia.

- Firma de convenio con la firma Pacific Rubiales para la creación de un centro de desarrollo infantil (Alarcón, 2013)

Otro ejemplo similar se encuentra en el programa de educación nutricional de la Fundación Alpina en el Municipio de Sopó, el cual inició con un diagnóstico poblacional en el año 2011, para luego proponer la realización de acciones a nivel educativo, con tiendas escolares, con madres comunitarias, en tiendas veredales y en el fomento de huertas caseras. Al finalizar el desarrollo de la estrategia, los resultados evidenciados fueron cambios favorables, no solo a nivel de alimentación sino a nivel integral: 
autoestima, confianza, habilidades comunicativas, capacidad para buscar soluciones y construcción del tejido social (Sanchez, 2012)

Específicamente para la promoción de la alimentación saludable pero en hogares comunitarios, investigadores de la Universidad de la Sabana utilizaron la metodología "Investigación - acción participativa, IAP" para promover el consumo de frutas y verduras en los niños vinculados a 5 hogares comunitarios del Municipio de Sopó. Para esto incluyeron a los niños y las niñas, sus padres, las madres comunitarias y personal de la administración municipal relacionado con la salud y la educación quienes al finalizar el estudio comprendieron la importancia del consumo de una alimentación saludable, se motivaron para incrementar el consumo de frutas y verduras, mejoraron el consumo de alimentos sanos y finalmente se pudo articular la propuesta con el sector salud y educativo del municipio y se reconoció la importancia del trabajo conjunto por una mejor nutrición de los niños del municipio (Erwin Hernández-Rincón, 2015. )

Los anteriores estudios evidencian la necesidad de investigar a profundidad sobre estrategias de comunicación dirigidas a las mujeres gestantes, donde el medio para realizar las acciones de promoción, así como información clave para el contenido de los mensajes surja de la realidad de estas mujeres y esto se puede lograr mediante el análisis de la situación alimentaria y sus prácticas comunicativas. De esta manera, al incluir a las mujeres y sus actores claves en el proceso de elaboración de la estrategia, puede influir en la apropiación, aceptación y finalmente en adopción de cambios en los hábitos alimentarios que mejoren la salud de la madre y el hijo.

\subsection{Categorías teóricas}

Para elaborar una propuesta de estrategia de comunicación para la promoción de la alimentación saludable dirigida a las gestantes, es necesario profundizar en varios aspectos: como primera medida, se requiere indagar sobre la importancia de la adecuada alimentación y buena nutrición durante esta etapa particular de cambios fisiológicos y formación de una nueva vida. En segundo lugar, y dado que la investigación se desarrolla en el marco de la maestría de Comunicación, Desarrollo y Cambio Social, es necesario comprender algunos conceptos relacionados con comunicación y salud, así como con las estrategias de comunicación para la promoción de la salud y por último, es necesario hacer énfasis en la comunicación estratégica como herramienta clave para contribuir al desarrollo y el cambio social. 


\subsubsection{Nutrición de la gestante}

La alimentación saludable es un determinante para la buena salud de cualquier ser humano, pero en el caso de las gestantes, es primordial ya que al garantizar una adecuada alimentación y un buen estado nutricional, se contribuye a procurar el bienestar del binomio madre e hijo y de las futuras generaciones. Por esto es fundamental garantizar un buen estado nutricional de la mujer antes y durante el embarazo. Lo anterior tiene su fundamento en que durante la gestación el gasto de calorías y nutrientes son mayores, por lo cual se debe promover, evaluar y monitorear el consumo de alimentos, suplementos nutricionales y la ganancia de peso, con el objeto principal de garantizar una alimentación diaria que cubra las necesidades nutricionales de la mujer durante este periodo, responda a las demandas nutricionales específicas de la embarazada, almacene la grasa necesaria para favorecer la producción de leche materna y promueva el adecuado crecimiento y desarrollo fetal que permita alcanzar un peso y composición corporal óptimos, al término de los 9 meses del embarazo. (Manjarrez, Parra, Parra, \& Zapata, 2014)

El estado nutricional inadecuado en una mujer gestante es muy riesgoso, tanto para la salud y vida de la mamá como para su hijo. El término malnutrición aplica tanto para el exceso que incluye sobrepeso y obesidad, como para el déficit que incluye malnutrición por deficiencia de macro y micro nutrientes. Las gestantes con un exceso en la ganancia de peso gestacional tienen una mayor probabilidad de desarrollar hipertensión, preclampsia, diabetes mellitus tipo 2, parto prematuro, hemorragia postparto. Por otra parte, el hijo de una mujer gestante con sobrepeso u obesidad puede presentar hipoglucemia infantil y especialmente incremento en el riesgo de resucitación neonatal. En el caso de las gestantes con bajo peso, estas tienen incrementado el riesgo de sufrir anemia, deficiencia de micronutrientes e inadecuadas reservas para la lactancia materna y los hijos de estas mujeres tienen mayor probabilidad de tener retardo en el crecimiento intrauterino, insuficiente o bajo peso al nacer, ictericia, infecciones, síndrome de dificultad respiratoria, problemas metabólicos y hematológicos, malformaciones congénitas, lento potencial de crecimiento y mayor riesgo de enfermedades cardio metabólicas. (Manjarres, Parra, Parra, \& Zapata, 2014)

Es por esto que las acciones de promoción de una alimentación saludable son fundamentales, debido a que influyen en un peso adecuado tanto en la preconcepción 
como durante el embarazo, aportando así al buen desarrollo de la gestación y del niño en formación.

En Colombia, las "Guías de práctica clínica para la prevención y detección temprana y tratamiento de las complicaciones del embarazo, parto y puerperio" del Ministerio de Salud y Protección Social 2013, sugieren el uso de la metodología propuesta por Atalah para la vigilancia nutricional de la gestante ya que permite calcular la ganancia total de peso que debe alcanzar una mujer, acorde al Índice de Masa Corporal (IMC) pregestacional, lo cual permite hacer un monitoreo particular para cada mujer durante el embarazo, utilizando los criterios que se muestran en el tabla 1.(Restrepo, S. Manjarres L., 2014)

Tabla 1. Ganancia de peso materno

\begin{tabular}{|l|l|l|l|}
\hline \multicolumn{5}{|l|}{ Ganancia de peso materno según IMC pregestacional } \\
\hline $\begin{array}{l}\text { Clasificación del } \\
\text { IMC pregestacional }\end{array}$ & $\begin{array}{l}\text { Valores } \\
\text { referencia de IMC }\end{array}$ & $\begin{array}{l}\text { Ganancia de peso } \\
\text { g/ semana }\end{array}$ & $\begin{array}{l}\text { Ganancia de peso } \\
\text { total (Kg) }\end{array}$ \\
\hline Enflaquecida & $<20$ & $400-600 \mathrm{~g}$ & $12-18 \mathrm{kilos}$ \\
\hline Normal & $20.0-24.9$ & $330-430 \mathrm{~g}$ & $10-13 \mathrm{kilos}$ \\
\hline Sobrepeso & $25-29.9$ & $230-330 \mathrm{~g}$ & $7-10$ kilos \\
\hline Obesidad & $>=30$ & $200-230 \mathrm{~g}$ & $6-7$ kilos \\
\hline
\end{tabular}

Fuente: (Restrepo M, 2011)

Es así, como la malnutrición durante la gestación ha ido aumentando rápidamente, afectando a mujeres de todas las edades. A nivel mundial la prevalencia de desnutrición materna está en un rango entre el $10 \%$ al $19 \%$, siendo más común en poblaciones pobres. Las mujeres gestantes también presentan riesgo de deficiencia de micronutrientes, incluyendo deficiencias de hierro, ácido fólico, riboflavina y vitaminas A, D, B6, y B12. De los anteriores, las gestantes presentan mayor deficiencia de hierro afectando a 56 millones de embarazadas. Por otra parte, la prevalencia de sobrepeso y obesidad durante el periodo gestacional ha ido incrementándose rápidamente, tanto en países desarrollados como en desarrollo, afectando a mujeres de todas las edades. Por ejemplo, en Estados Unidos la prevalencia presenta rangos entre el 10\% al $39 \%$, en Brasil la prevalencia es de $22 \%$ y en algunos países de áfrica alcanza un 14\%. (Sarmiento, Ramírez, Samper, Paula Pinzón, \& Olarte, 2001) 
En un estudio realizado en Colombia, donde se evaluó el impacto del estado nutricional por déficit o exceso de peso de la mujer, desde la edad fértil y durante la gestación sobre la programación metabólica del neonato, se encontró que el estado nutricional de la mujer, antes y durante el embarazo, marcan las características del metabolismo de los hijos en la vida posnatal. Es así como una mujer desnutrida, con baja masa grasa y muscular tiene un mayor riesgo de tener hijos con bajo peso al nacer, los cuales, en edad adulta tiene un riesgo aumentado de sufrir diabetes, hipertensión y síndrome metabólico. Por su parte, una mujer obesa durante la gestación ejerce efectos fuertes en el desarrollo y la función de órganos reguladores del metabolismo de su hijo, afectando principalmente páncreas, cerebro, tejido adiposo, musculo y vasos sanguíneos. (Tarazona, 2013)

En la Encuesta Nacional de Situación Nutricional Colombia - ENSIN 2010, se encontró que una de cada seis mujeres gestantes presentó bajo peso, de las cuales, las más afectadas fueron las gestantes adolescentes (28.6\%) y las mujeres que tenían de 19 a 24 años (20.8\%). Por otra parte, el $24.8 \%$ de las gestantes tenía sobrepeso y el $9.8 \%$ obesidad, es decir que 34,6 \% presentó algún grado de exceso de peso para la edad gestacional; estas cifras fueron más frecuentes en embarazadas de 25 a 49 años. Estos datos evidencian que aproximadamente la mitad de las mujeres gestantes en Colombia, presentan algún grado de malnutrición, ya sea por déficit o por exceso de peso, lo cual conlleva a problemas de salud tanto de la madre como del hijo.

Adicionalmente se encontraron cifras altas de mujeres en edad fértil y gestantes con anemia, incrementando riesgos de hemorragias posparto. La encuesta ENSIN encontró que 1 de cada 5 mujeres embarazadas tenía anemia y de estas el 57.3\% presentó anemia por déficit de hierro. La prevalencia total de anemia en las gestantes fue cercana al $18 \%$, presentando mayores prevalencias las mujeres de nivel 1 del SISBEN. Lo anterior ubica a Colombia en similar situación de países como Guatemala, Bahamas, México y Barbados. Solo Salvador presenta cifras más altas. (Profamilia, 2010)

En un estudio realizado en Bogotá en el año 2011 (Sarmiento, Ramírez, Samper, Paula Pinzón, \& Olarte, 2001), se comparó el IMC con algunas características sociodemográficas de 1700 mujeres gestantes encontrando diferencias $p(<0.02)$ en relación al estado nutricional de las mujeres gestantes, dependiendo si eran adolescentes (13 - 19 años) o adultas (20 - 49 años). Se observó que las adolescentes presentaron mayor bajo peso para la edad gestacional (31\%) comparada con las mujeres adultas (14.5 
\%). En relación al sobrepeso se encontró que las adultas presentaron un mayor porcentaje (37.3\%) comparadas con las adolescentes (18\%). Se concluyó que el bajo peso para la edad gestacional en gestantes adolescentes y el sobrepeso en gestantes adultas de Bogotá coexiste como la doble carga nutricional, donde se puede encontrar en una misma familia los dos problemas de malnutrición.

Por lo anterior, se deben reforzar las políticas públicas para promover un peso saludable antes y durante la gestación y prevenir tanto el bajo peso para la edad gestacional como el sobrepeso y la obesidad, dadas las complicaciones para la salud de la madre y del hijo.

La promoción de la alimentación de las mujeres gestantes, se basa en la recomendación de una alimentación variada, equilibrada y fraccionada, ENSIN (Profamilia, 2010) permite observar que un gran número de gestantes no consumen una alimentación acorde a las recomendaciones de alimentos que proveen los nutrientes esenciales para una gestación saludable, donde los requerimientos de energía y nutrientes son especiales. En el consumo de lácteos se observó que una de cada 3 gestantes de 13 a 49 años no consumen productos lácteos a diario $(4.3 \%)$. En relación a las frutas, 2 de cada 7 gestantes no consumen fruta a diario $(42.2 \%)$ y en las verduras se evidenció que 2 de cada 3 mujeres no tiene como hábito consumirlas a diario (55.4\%). Finalmente, una de cada 7 mujeres no comió carne o huevo a diario ( $73.3 \%$ y $66.7 \%$ respectivamente). Todos los anteriores comportamientos son más marcados en gestantes jóvenes y de niveles bajos del SISBEN. En contradicción con lo anterior, los cereales y los azúcares son altamente consumidos a diario, $92 \%$ y $94.6 \%$ respectivamente y los alimentos fritos fueron consumidos por el $32.4 \%$ de las mujeres a diario.

Esta realidad tiene consecuencias en la deficiencia de macro y micronutrientes importantes en la gestación para prevenir malformaciones y enfermedades tanto en la madre como en el hijo. Por lo tanto, es importante el consumo de los micronutrientes (calcio, hierro, ácido fólico), como también la alimentación saludable con alimentos variados y en cantidades adecuadas para cubrir las necesidades especiales durante la gestación.

Por esto, se han implementado variadas estrategias desde salud pública como la suplementación y fortificación con micronutrientes así como también iniciativas de información, educación y comunicación en alimentación saludable, sin embargo y a pesar de las campañas no se han evidenciado cambios en los hábitos alimentarios, por lo cual 
se requiere diseñar estrategias de comunicación que procuren cambios alimentarios basado en la identificación de las prácticas alimentarias, de consumo mediático de las mujeres gestantes haciéndolas participes del proceso de validación de las propuestas.

\subsubsection{Comunicación, desarrollo y cambio social}

El enfoque de comunicación que se propone en esta investigación no tiene nada que ver con prácticas publicitarias, mercadeadas o periodísticas, así como tampoco con comunicación unida a gobernanza de las élites o a legitimar políticas de exclusión. Por el contrario es la comunicación como medio para superar problemas sociales colectivos, propiciando la transformación social, la articulación ciudadana, las redes sociales mediante modelos y estilos de comunicación más horizontales y participativos donde el objetivo final está orientado al empoderamiento, la democracia participativa y la movilización para generar entornos de convivencia saludables e inclusivos (Tufte, 2015)

Con relación al concepto de desarrollo este se encuentra relacionado con el objeto de cada cual por alcanzar un estándar de vida que satisfaga sus ideales de existencia. La comunicación en el desarrollo es un instrumento que ayuda a pensar sobre lo que las comunidades consideran que es el desarrollo, permite estrategias de intercambio de ideas, análisis de situaciones y establecimiento de caminos a seguir; es un medio para promover cambios en el nivel político, social, comunitario e individual.

Algunos investigadores Europeos y latinos, como los registrados en el libro de Marcelo Martínez Húmida y Francisco Sierra Caballero “Comunicación y Desarrollo, Prácticas comunicativas y empoderamiento local" (Onofrio, 2012), parten de definir el desarrollo como "humano, integral y sostenible" definiéndolo como "proceso de expansión de las capacidades de las personas que amplían sus opciones y oportunidades" (p. 315). Por otra parte definen comunicación como “interacción social consistente en compartir informaciones y significados, que en cuanto proceso, refuerzan la construcción en común" (p.315). Por lo tanto la comunicación y el desarrollo juntos son dos elementos que se benefician y potencializan mutuamente, ya que en este contexto la comunicación se convierte en una herramienta facilitadora para el proceso de desarrollo de las capacidades que las personas y comunidades, en el marco de la participación, el empoderamiento, la toma de decisiones y las acciones por el bien propio y el bien común. 
Según Obregón, (2011) la comunicación en los procesos de desarrollo se enmarca en varios paradigmas. El paradigma dominante basado en un modelo de modernización donde el desarrollo es un proceso homogenizador y los medios de comunicación transmiten información mediante líderes de opinión. Se caracteriza por su enfoque vertical y su naturaleza etnocéntrica. Otro paradigma mencionado por el autor es el de la Dependencia, que cuestiona el desarrollo capitalista, enuncia un modelo socialista y busca alternativas de desarrollo que permitan frenar la desigualdad entre los países. Es una teoría caracterizada por no tener en cuenta las situaciones internas de los países que influyen en su nivel de desarrollo. El último paradigma es el Alternativo, que representa el paso de un modelo de desarrollo capitalista a uno humanista, e incluye la participación de los actores sociales y locales. Tiene en cuenta causas estructurales de pobreza y subdesarrollo, tiene carácter social, promueve empoderamiento, participación, movilización y decisión. Esta teoría se caracteriza por ser muy romántica y utópica, así como por la dificultad para establecer niveles de participación reales por parte de la comunidad (p. 2 - 5). De acuerdo a lo anterior, la evolución de la comunicación para el desarrollo y bajo el paradigma alternativo, permite a las comunidades asumir sus realidades, apropiarlas y generar cambios efectivos que surgen de la unión de sus propios esfuerzos, ideas y medios.

En relación con la comunicación y el cambio social, Obregón también considera que "la comunicación para el cambio social se ha posicionado como una propuesta que pretende centrar la atención en el rol movilizador y empoderador de la comunicación" (p. 6), definiendo en este marco, la comunicación para el cambio social como "proceso de diálogo privado y público, a través del cual las gentes deciden quiénes son, qué quieren y cómo pueden obtenerlo" (p. 6). En otras palabras, implica que las personas y poblaciones pasen de ser objeto de intervenciones a ser sujetos de su propio cambio, usando elementos de diálogo, debate, compartir dudas, miedos, conocimientos y experiencias para avanzar y persuadir a la gente a hacer algo y a decidir en conjunto la mejor manera de seguir y contribuir a pasar los obstáculos que bloquean su desarrollo.

Es así como, la comunicación, desarrollo y cambio social han evolucionado a través del tiempo iniciando como la manera en que los campesinos, obreros, estudiantes, mineros, jóvenes e indígenas reclamaban mayor participación política y empezaban a desarrollar sus propias herramientas de comunicación porque no tenían la posibilidad de acceso a los medios masivos de difusión privados o públicos para expresar sus mensajes, dando pie 
para la creación de radios comunitarias, boletines, obras de teatro y hasta programas de televisión en canales locales.

Por su parte, Gumucio- Dragón (2014 a) definió la comunicación, desarrollo y cambio social como el "Proceso de dialogo público y privado, a través del cual la propia gente determina lo que es, lo que necesita y cómo conseguirlo" (p. 592). A la vez, en el Consenso de Roma 2006, se dio el siguiente concepto: "La comunicación para el desarrollo, es un proceso social basado en el diálogo que utiliza una amplia gama de instrumentos y métodos. Tiene que ver con buscar un cambio a distintos niveles, lo que incluye escuchar, crear confianza, compartir conocimientos y habilidades, establecer políticas, debatir, aprender, a fin de lograr un cambio sostenido y significativo. No se trata de relaciones públicas o comunicación empresarial” (Dragón, 2014 b, pág. 598)

La comunicación, el desarrollo y el cambio social, no establecen sistemas con herramientas, mensajes o técnicas fijos, porque es un proceso de participación y fortalecimiento comunitario de largo plazo, de colectivos con intereses comunes, para contribuir al desarrollo y cambio social y se hace sostenible por ser un proceso estratégico y participativo donde las comunidades se apropian de sus proceso de comunicación, se concentran en el debate, el diálogo y la negociación y los resultados buscados no son individuales, sino que están relacionados con fortalecer la identidad cultural, la confianza, el compromiso y el empoderamiento. Sin embargo para que este proceso sea válido es importante cumplir las siguientes condiciones: Participación y apropiación comunitaria, lengua y pertinencia cultural, generación de contenidos locales, usar la tecnología apropiada y contribuir a la conformación de redes. (Dragón, 2014 c, p. 295)

Lo anterior significa que en este enfoque, las comunidades son quienes toman decisiones de los problemas que los afectan a través del diálogo, diferenciando los procesos tradicionales donde no había participación democrática, donde las decisiones eran impuestas y no tomadas de manera horizontal y donde no se valoraba la identidad, la cultura ni el carácter dialógico de las relaciones. Es un enfoque abierto, de construcción colectiva donde el proceso es más importante que el producto y los resultados buscados tienen relación con el fortalecimiento organizativo, recuperación de la memoria, identidad colectiva y crecimiento de vida democrática.

En este sentido, en el marco de esta investigación donde se quiere establecer una estrategia de comunicación para la promoción de la alimentación saludable para mujeres 
gestantes, es necesario iniciar el proceso mediante un conocimiento previo del contexto social, cultural, económico, familiar, educativo y alimentario de estas mujeres y a partir de ese conocimiento, establecer un proceso de dialogó con ellas para identificar las causas de su comportamiento alimentario, sus ideales, sus pensamientos, sus tradiciones y sus intereses. Lo anterior, con el fin de contar con elementos útiles que permitan diseñar una estrategia de comunicación para este grupo poblacional que sea particular y apropiado a sus características.

Para esto, es necesario también revisar las diferentes metodologías que algunos autores han propuesto para el uso de la comunicación como un elemento clave para la promoción de la salud y la prevención de la enfermedad.

Comunicación y salud: La comunicación para la salud fue establecida como una disciplina por la Asociación Internacional de Comunicación en el año 1975 y desde allí ha evolucionado de manera sustancial, especialmente en la facultades de la salud más que en las de comunicación. Esta disciplina inicio abordando temas relacionados con la promoción de la disminución del uso del cigarrillo, la prevención del VIH y el cáncer y el propósito inicial era el análisis de audiencias, el diseño de mensajes y la evaluación de intervenciones comunicativas. Sin embargo, según Tufte "durante muchos años estuvieron ausentes las ciencias sociales y en especial la sociología, la antropología, el estudio de los medios y la ciencia política, lo cual conllevaba a no tener en cuenta procesos propios de la globalización, el desarrollo de una sociedad de riesgo y los cambios en las relaciones sociales que tienen implicaciones en la salud, el bienestar y en la vida cotidiana de los ciudadanos comunes" (Tufte, 2015, pág. 40).

Lo anterior ha significado la revisión del desarrollo de la comunicación y la salud articulando de manera efectiva las ciencias sociales y las ciencias de la salud en el análisis de los determinantes sociales, a la vez que se van abordando temas relacionados con la globalización y la mediatización de los últimos tiempos. Para este estudio, se revisaron varias estrategias con las que se dispone en relación a la comunicación y salud, para posteriormente poder establecer cuál es la más conveniente acorde a las características del grupo poblacional y a los objetivos propuestos.

Históricamente, acorde con lo referido por Beltrán, el uso de los medios de comunicación individuales o de grupos masivos, así como tradicionales y modernos, ha sido una herramienta de apoyo al logro de comportamientos colectivos funcionales para el 
cumplimiento de los objetivos de los programas de salud pública. Dicha información difundida, busca crear conciencia sobre aspectos específicos de la salud individual y de las comunidades así como sobre la importancia de la salud en el desarrollo (Mosquera, 2003, p. 2).

Por otra parte Gumucio Dragón, defiende la necesidad de concebir la comunicación para la salud con el enfoque comunitario donde los procesos se basen en el diálogo, lo anterior debido a que el autor considera que la comunicación en los campos de la promoción de la salud, se han limitado a hacer propaganda o simple difusión de información, concentrando los recursos en medios masivos o en espacios que tienen impacto en las ciudades más no en las áreas rurales. (Mosquera, 2003, p. 2) Esto indica la necesidad de avanzar de las estrategias mediáticas donde la población es objeto pero no sujeto de transformaciones y cambios reales.

Mario Mosquera por su parte, afirma que la comunicación para la salud puede poner estos temas en la agenda pública, reforzar los mensajes sanitarios, estimular a las personas para que busquen más información y en algunos casos aportar para la adopción de hábitos alimentarios saludables. Para lo anterior utiliza cuatro elementos claves en el proceso de comunicación: audiencia, mensaje, canal y fuente, además le suma dos elementos claves para este caso, un gran componente de investigación y otro de participación. Lo anterior, implica un proceso más complejo que va más allá de la transmisión pasiva de un mensaje dado por un emisor y recibido por un receptor, considerando un contenido técnico específico transmitido acorde a las particularidades dadas por la comunidad a quien se quiere llegar (Mosquera, 2003 a). Lo anterior ratifica que la comunicación para la salud avanza y une elementos técnicos y científicos pero le suma también el componente particular de las comunidades incluyendo su participación activa en los procesos.

Así mismo ese autor afirma que los programas efectivos de comunicación en salud identifican y le dan prioridad a la segmentación de audiencias, dan mensajes precisos, elaborados a partir de fuentes científicas y logran llegar a las audiencias a través de canales de comunicación familiares, es decir, a través de medios que son utilizados por los receptores a los cuales va dirigida la información técnica. De igual manera, considera que la comunicación para la salud puede adoptar muchas formas, como la comunicación de masas, los multimedia, narraciones de historias, teatro y canciones, esto quiere decir 
que para comunicar un mensaje, se tiene la libertad de utilizar el canal que desee con el objeto de llevar el mensaje al público, no existe la rigidez de tener que usar un tipo específico de medio. $\mathrm{Y}$ en tiempos modernos, es más común que las culturas y las personas afectadas por los problemas participen activamente en los diseños de los programas de comunicación, fortaleciendo así procesos locales que promuevan reales cambios de actitud y comportamiento en salud. (Mosquera 2003,b. p 3 -6). A continuación haremos un breve resumen de los modelos y estrategias que Mario Mosquera describe como útiles para la comunicación en salud:

- Difusión de Innovaciones: Las innovaciones son ideas, prácticas u objetos percibidos como nuevos para quien va dirigido. La difusión de estas son comunicadas, teniendo en cuenta los canales de comunicación que son usados para lograr exitosamente dicha difusión, entre los cuales se encuentran los líderes de la comunidad. Rogers define este modelo como: "Proceso mediante el cual una innovación es comunicada en el tiempo y difundida por determinados canales entre los miembros de un sistema social" (Urrea, 2003). Esta difusión propone cuatro elementos que conforman el proceso de innovación: la innovación misma, los canales de comunicación empleados para la difusión, el tiempo de la difusión de la innovación y el sistema social donde se difunde la innovación. Finalmente la adopción de una innovación dependerá de los atributos que se perciben de la misma, el tipo de decisión sobre la innovación, los canales de comunicación utilizados y la naturaleza de los sistemas sociales

- Modelo de comunicación macrointencional: Parte de una convocatoria hecha por un productor social, orientada a líderes sociales determinados mediante redes de comunicación directa, apoyada en medios masivos y orientada a producir cambios en las áreas de actuación de los líderes, en función de un propósito colectivo. En este modelo, los líderes tienen un rol muy importante ya que son personas quienes por su rol social y su campo de actuación, tienen la capacidad de adecuar mensajes según las circunstancias o propuestas, con credibilidad y legitimidad (Mosquera, 2003, pág. 6).

- Modelo de comunicación para el cambio social: en este aspecto la comunicación es el resultado de la participación de la comunidad en todo el proceso de implementación de proyectos para el mejoramiento de la salud, teniendo en cuenta la importancia de la comunicación horizontal en la adopción y sostenibilidad de cambios reales. 
Se considera que en la medida en que la comunidad participe más activamente, habrá más apropiación y resultarán mejores cambios (Mosquera, 2003, pág. 7). Es fundamental evidenciar el importante papel que juega la comunidad en la definición tanto de sus problemas como de sus soluciones, lo cual genera empoderamiento y apropiación, llevando a los cambios reales, para la superación de los problemas.

- Eduentretenimiento: Estrategia basada en la concepción de que el comportamiento humano puede estar influenciado por modelos que se forman cuando la gente se identifica con alguien a quien admira y quiere imitar. En el eduentretenimiento, se usa este comportamiento para promover mensajes y valores localmente identificables, a través de personajes que se convierten en modelos a seguir. La información utilizada y transmitida debe ser atractiva, fácil de entender y capaz de incluir en los comportamientos (Mosquera, 2003). En este mismo sentido del eduentretenimiento, el comunicador danés Thomas Tufte lo presenta como un modelo de educación integrada que involucra principalmente la radio, la televisión, los musicales, el teatro y los talk shows, definido como el proceso de diseñar e implementar una forma mediada de comunicación con el potencial de entretener y educar a las personas, con el objetivo de mejorar y facilitar las diferentes etapas del cambio social.

A través de los años, en países como México, Sudáfrica y algunos países de Asia, se reportan estrategias de eduentretenimiento como el uso de novelas, series o textos que entretenían pero tenían como fin último la educación preventiva, como por ejemplo: prevención del VIH, poder de las mujeres, importancia de la educación, entre otros, destacando también la experiencia en el campo de instituciones internacionales como UNICEF (Tufte, 2015, pág. 26).

Se reconoce en diferentes niveles el potencial educativo de las telenovelas y los seriados para brindar información ya que son medios que llaman mucho la atención, son vistos de manera masiva y pueden generar cambios sociales importantes en especial cuando se combinan con estrategias multimetódicas como editoriales en prensa, cartillas, concursos, juegos, convocatorias que hacen participe a la comunidad, pasando de ser solo objetos a sujetos activos en el conocimiento y el cambio.

Sin embargo, es cuestionable el costo de esta estrategia para cualquier país que pretenda implementarla para los temas de salud, donde normalmente los costos son limitados y mucho más para los temas de promoción y comunicación y en especial debido al poder 
de los canales privados de televisión, en los cuales la transmisión de programas educativos tendría un costo bastante alto (Tufte, 2015, pág. 26).

- Mercadeo Social: Se basa en la primicia de que toda acción está basada en el intercambio y orienta hacia la investigación sobre los intereses que llevan a que las personas escojan dicho producto. En el proceso es necesario investigar los valores, conocimientos y expectativas de la comunidad cuando se busca influenciar en los comportamientos de salud. Este modelo se basa específicamente en los siguientes aspectos: producto, precio, lugar y la promoción (Mosquera, 2003).

Yaromir Molina realizó una revisión del significado de este tipo de marketing para varios autores y estableció como mercadeo social "Una rama del mercadeo que se ocupa de la relación de intercambio con beneficio en el campo de las ideas, centrada en el trasfondo de dicha relación con el ánimo de encontrar y facilitar, para todos los actores, un modo mejor de estar en el mundo; ello implica fortalecer el tejido social y el cambio de actitudes para mejorar la calidad de vida de todos” (Molina, 2001, pág. 75).

Es decir, el mercadeo social no se enfoca en la satisfacción de necesidades individuales de un cliente ya que su objeto es la satisfacción de necesidades de la sociedad en su conjunto y el producto del proceso no es la adquisición de un bien sino la adopción de nuevas ideas, actitudes o valores.

- Periodismo cívico: reconoce un modelo de democracia relacionado con la participación ciudadana, se basa en un concepto periodístico de doble vía en el que los ciudadanos tienen incidencia en el contenido de la información. Este modelo replantea las funciones en la construcción de lo público, usando los medios de comunicación como escenario de debate de la comunidad que hace la función de editores o periodistas.

- Estrategias basadas en tecnologías en internet: Es sabido el gran auge que el internet ha tenido al correr del tiempo, inclusive para temas de salud, en parte debido al tiempo corto que se tiene de consulta con el médico, en comparación con el tiempo indefinido que se puede tener en internet para conocer sobre estos temas. De igual manera se usa para conocer sobre cómo prevenir enfermedades y para el intercambio de experiencias en salud. Los expertos opinan que el papel de las TIC ha contribuido a la expansión de servicios de diagnóstico y tratamiento, especialmente en zonas alejadas, así como para prevenir enfermedades e infecciones. 
- IEC: La estrategia de información, educación y comunicación está dirigida a orientar acciones de la comunicación encaminadas a la prevención de la enfermedad y la promoción de la salud, fortaleciendo la capacidad de los individuos a incidir directamente en su desarrollo, orientando procesos locales que promuevan cambios en conocimientos, actitudes y prácticas de la población. En la IEC el proceso de comunicación se basa no solo en el diagnóstico sino en el potencial institucional y social existente, lo cual permite evidenciar mecanismos y canales de comunicación adecuados para desarrollar estrategias de comunicación. Esta estrategia fue promovida en la década de los setenta por planificadores de salud como una respuesta al modelo de atención primaria en salud, ya que partían de la necesidad de acompañar las acciones de la comunidad con actividades de información y educación para lograr un cambio de comportamiento favorable en el público objetivo de los proyectos.

Específicamente para la promoción de la alimentación saludable, la Organización de las Naciones Unidas para la Alimentación y la Agricultura - FAO, define la estrategia IEC como: "Conjunto de acciones que promueven estilos de vida saludables a través de buenas prácticas, conductas y hábitos alimentarios saludables en todas las dimensiones de la seguridad alimentaria y nutricional: disponibilidad, acceso, consumo, aprovechamiento biológico y calidad e inocuidad" (FAO, 2012, pág. 37).

Sin embargo para que una intervención a nivel de la alimentación sea adecuada, "la estrategia IEC debe seguir una línea que busque: 1.Modificar comportamientos alimentarios de las personas y las sociedades para lo cual se deben completar como mínimo las fases de motivación, acción y seguimiento, así como considerar los distintos tipos de aprendizaje, es decir, los conocimientos, habilidades, actitudes, prácticas y hábitos; 2. Promover la participación activa de la audiencia objetivo, que implica socializar, reflexionar o generar respuestas o alternativas de solución a las temáticas propuestas; y 3. Reconocer que un cambio de comportamiento implica incluir factores internos y externos que influyen en las decisiones que toman las personas en el día a día. Lo anterior implica que para el diseño de una estrategia IEC para promover la alimentación saludable, se cuente con los siguientes criterios básicos: Diagnóstico, enfoque participativo, cambios de conducta y comportamientos, metodologías efectivas, herramientas pedagógicas, sustentable, intersectorial y que genere empoderamiento". (Organización de las Naciones Unidas para la alimentación y la agricultura, 2015, pág. 37) 
-Movilización social: esta estrategia no se basa en los individuos, se concentra en la unión de comunidades para que se movilice y apoye en el marco de un tema. Convoca voluntades por un tema en común y puede ser de tipo política, gubernamental, comunitaria, de beneficiarios o corporativa. (Mosquera, 2003). Por ejemplo, a nivel del Ministerio de Salud y Protección Social, en el año 2012 con el objeto de plantear el Plan Decenal de Salud Pública, se conceptuó la movilización social como un proceso donde se involucró como aliados activos a instituciones sociales importantes, como poder de convocatoria e influencia en los grupos de personas con que trabajan. Este tipo de movilización buscó que los diferentes grupos de interés se apropiaran de la formulación de dicho plan de salud y su éxito fue gracias a la participación donde las personas podían expresar lo que pensaban durante todo el proceso, sintiéndose corresponsables de la formulación de esta herramienta de política en salud (MinSalud, 2012, págs. 11,12)

Luego de esta revisión de estrategias de comunicación utilizadas para la promoción de la salud de la población, hay algunos elementos que pueden servir para elaborar la estrategia de comunicación para las gestantes, como por ejemplo, el enfoque de la IEC que permite fortalecer capacidades en las personas para promover cambios a nivel de los conocimientos, actitudes y prácticas a la vez que guía a la comunidad a través de educación y la información. Sin embargo, la estrategia que se quiere proponer va más allá de la información y la educación. Esta iniciativa busca vincular en el proceso a las gestantes, a las personas significativas para las gestantes e involucrar a las diferentes entidades que dentro de sus competencias deben acompañar a la gestante a lo largo de este periodo. Se hace entonces, una revisión técnica de la comunicación estratégica, la cual brinda elementos para hacer un plan que integra acciones conjuntas y no solo el envío de mensajes.

\subsubsection{Comunicación estratégica}

En el texto, los desafíos de la comunicación en un mundo fluido, la filósofa, docente e investigadora argentina Sandra Massoni, considera que la comunicación estratégica es un modelo en el cual "no hay una lección única, modelos universales o formulas aplicables" (pág. 42). Llama al trabajo en equipo aprovechando las capacidades de cada uno para lograr mejores resultados, así como a la identificación de actores claves 
relevantes para la solución de problemáticas que aborda la estrategia de comunicación, la cual es entendida como un momento relacionante de la dinámica social y por tanto como un espacio estratégico para pensar sus límites y objeciones (Massoni, 2011, pág. 42).

Por lo anterior y pensando en el papel del comunicador como participe en la promoción de la alimentación saludables de las mujeres gestantes, este tipo de modelo investigativo, es idóneo para contribuir al cumplimiento de los objetivos propuestos en esta investigación, ya que parte de que no hay una "lección única, no hay modelos universales, no hay formas aplicables a todos los casos" (pág. 42), lo cual permite aprender de las situaciones que se encuentran, de las realidades, de las adversidades y además no se centra en los mensajes y la información sino en las interacciones porque un aspecto central de la estrategia es el reconocimiento de los actores relevantes para la resolución de la problemática que aborda la estrategia. Adicional a este reconocimiento, establece sus dinámicas sociales, analiza sus obstáculos y contradicciones, es decir, analiza el contexto real y particular de cada situación. La autora invita a "salir del corset de los mensajes para abordar el espesor de la comunicación en tanto fenómeno que está haciéndose y rehaciéndose todo el tiempo" (pág. 43). Esto significa que en esta investigación se retoma: 1. Las mujeres gestantes no son objetos sino sujetos, las cuales no deben pretender ser cambiadas, sino aceptadas, según sus diferencias, para trabajar juntos por el bienestar y la salud de ellas y sus bebés.

2. Se requiere de los actores claves tanto para la construcción de la estrategia como para su desarrollo, para lo cual se necesita conocer aquellos aspectos donde estos actores quieren y pueden colaborar. Es importante que estos sujetos se sientan satisfechos al participar en el proceso de transformación porque están participando en un proyecto donde sienten que le aportan algo al mundo. Deben estar motivados por los cambios culturales que pueden ayudar a producir

3. Se debe centrar en lo situacional, teniendo en cuenta esto puede cambiar, moverse, interponer obstáculos, es decir que no son situaciones estáticas sino dinámicas.

4. La finalidad de la estrategia no es encontrar una solución única y definitiva, porque las realidades son cambiantes por lo tanto se pueden dar opciones que contribuyan al mejoramiento del estado nutricional de las mujeres, pero siempre habrá diferencias acorde a las realidades de las comunidades, por lo cual las propuestas deben ser flexibles y dinámicas. 
5. Además se deben identificar las oportunidades y las fortalezas de las personas y actores, para que en el mundo cambiante, se puedan adaptar situaciones y obtener transformaciones que contribuyan al desarrollo.

6. Massoni (2011), explica que el diseño de la estrategia de comunicación "rebasa a los paradigmas ya que tampoco pretende una única visión o una perspectiva excluyente, no pone énfasis en la representación o en la organización, sino en un abordaje multiparadigmático de las situaciones de la comunicación” (pág. 46).

En conclusión, esta propuesta de comunicación no pretende dar soluciones a las gestantes, porque no hay soluciones absolutas, lo que se ofrece es posibilidad de encontrar alternativas en conjunto.

\subsection{Metodología}

Para dar cumplimiento a los objetivos propuestos, se utilizó el enfoque mixto ya que se requería recolectar, analizar y vincular datos cualitativos y cuantitativos que permitieran mayor comprensión e interpretación de los resultados obtenidos.

Por un lado, se realizó de una investigación hermenéutica interpretativa dirigida a abordar temas y captar el sentido de lo que expresa una mujer gestante en relación a su alimentación y utilización mediática. Consistía en interpretar y revelar el sentido del actuar alrededor del consumo de alimentos y formas de información, haciendo una descripción y comprensión de sus hábitos. El análisis de este tipo de estudio se enmarca en el paradigma interpretativo comprensivo.

Por el otro lado, se realizó una investigación cuantitativa donde se realizó recolección y análisis de datos del consumo de alimentos y del consumo medios de comunicación por parte de las mujeres gestantes, utilizando herramientas metodológicos descritos más adelante.

Así mismo, fue una investigación descriptiva, de corte cualitativa porque recogió información basada en la observación de comportamientos naturales, discursos y respuestas abiertas para su posterior interpretación de significados. Esta investigación analizó información dada por las mujeres gestantes y estableció su relación con el significado para ellas. Este tipo de investigación no descubre cómo se alimentan las gestantes ni cómo se informan sobre alimentación saludable, se encarga de dar 
información sobre la razón de sus comportamientos, contribuyendo al conocimiento y a la propuesta de abordajes, mediante el análisis y la interpretación de los datos y la información.

Para el caso en particular, la investigación cualitativa buscó:

- Establecer medios de comunicación ordinarios y cotidianos de las gestantes beneficiarias del proyecto.

- Comprender los hábitos alimentarios de las gestantes, en su contexto.

- Conocer y describir la realidad alimentaria y del uso de medios de las gestantes, para luego construir e interpretar esta información para su propio beneficio.

- Generar propuestas de comunicación, a partir de los datos obtenidos y analizados, para contribuir al mejoramiento del estado nutricional de las gestantes y sus hijos. (Hernández, Fernández y Baptista 2005)

El estudio es descriptivo, porque permite precisar y caracterizar como se alimentan y como se comunican e informan las gestantes en un contexto particular, como evento de estudio. Este tipo de metodología permitirá prefigurar y mostrar aspectos claves de los estilos de alimentación de las mujeres pertenecientes a un programa de la Secretaría Distrital de Integración social de Bogotá, a la vez que describirá cuáles son sus prácticas comunicativas, información clave para luego determinar que particularidades de la alimentación se deben reforzar y por medio de qué estrategia comunicativa para generar cambios reales que repercutan en la salud y nutrición del binomio madre - hijo (Lévano 2007).

Acorde a estos aspectos metodológicos la recolección de la información para se realizó en tres fases:

- Fase 1: Caracterización de las prácticas de alimentación de las gestantes

- Fase 2: Caracterización de los consumos mediáticos de las gestantes

- Fase 3: Validación de la información mediante grupos focales

\section{Muestra}

Dado que este estudio se encuentra enmarcado en la investigación del Instituto Nacional de Salud, denominado "Efecto de las prácticas alimentarias de mujeres gestantes y sus hijas e hijos hasta los 24 meses de edad sobre el estado nutricional, en una población 
atendida por la Secretaría Distrital de Integración Social de la Alcaldía mayor de Bogotá”, la muestra corresponde a la misma utilizada en el estudio marco, la cual fue seleccionada de la siguiente manera:

- El universo de referencia para la presente investigación se estima que esta en alrededor de 2,000 mujeres (trimestre 3 de gestación), esto por las cifras entregadas por el Distrito. Se propone una muestra aleatoria de 200 de mujeres beneficiarias del Servicio de Atención Integral a la Primera Infancia en el Ámbito Familiar de la Secretaría de Integración Social de la ciudad de Bogotá y que durante el periodo de recolección de la información (2016), estaban gestando.

- La muestra se recolectó bajo un diseño de muestreo probabilístico, estratificado de conglomerados. Todas las mujeres tenían una probabilidad de selección superior a cero, se implementó el algoritmo de selección de manera independiente en cada uno los estratos, cada localidad se consideró como un estrato y cada punto de atención como un conglomerado.

- La muestra se distribuyó de manera proporcional al número de mujeres que se estaban atendiendo en cada localidad al momento de la recolección de la información, esto permitió que las mujeres tuvieran una probabilidad de selección igual. De existir tasas altas de no respuesta, superiores a las esperadas o que pudieran ser diferentes por localidad, se analizaron y se realizó un ajuste en los factores de expansión a nivel de localidad y/o mes de gestación para evitar sesgos en las estimaciones.

- Criterios de inclusión: Mujeres gestantes en el tercer trimestre de gestación que aceptaran participar voluntariamente de la investigación y mujeres beneficiarias del Servicio de Atención Integral a la Primera Infancia en el Ámbito Familiar de la Secretaría de Integración Social de la ciudad de Bogotá

Acorde con lo anterior, la muestra utilizada para cada una de las fases fue:

Fase 1: Caracterización de las prácticas de alimentación de las gestantes: Se contó con una muestra de 464 gestantes, las cuales estaban en su tercer trimestre de la gestación y pertenecían a todas las localidades del distrito.

Fase 2: Caracterización de los consumos mediáticos de las gestantes: Se contó con una muestra de 202 mujeres pertenecientes a todas las localidades de Bogotá y que 
correspondían al grupo de las gestantes que habían sido entrevistadas durante su último trimestre de gestación para caracterizar sus prácticas alimentarias.

Fase 3: Validación de la información mediante grupos focales: A estos grupos fueron invitadas mujeres que habían sido parte de la fase 1 y 2 del presente estudio, pertenecían a 2 localidades del distrito y se solicitó que acudieran acompañadas por alguien significativo para ellas.

\section{Instrumentos de recolección de información}

Los instrumentos utilizados durante la investigación fueron diferentes en cada una de las fases y según los objetivos de cada una de ellas, así:

Fase 1. Caracterización de las prácticas de alimentación de las gestantes: en esta fase recolectamos información por medio de entrevistas semiestructuradas y luego se procesó la información por medio del Software Atlas Ti. (Anexo 1. Entrevista Caracterización del consumo de alimentos). Para el análisis de consumo de alimentos se aplicó un formulario de frecuencia (FFC) de consumo que representa un método directo de recordatorio, retrospectivo, semicuantitativo de estimación de la ingesta alimentaria de un individuo, al que se le presenta un formato estructurado que contiene una lista de alimentos y se le pregunta la frecuencia habitual de ingesta de dichos alimentos durante un periodo de tiempo determinado. El FFC estima información global de la ingesta en un periodo amplio de tiempo, Tiene el potencial de distinguir de forma acertada entre los individuos que consumen con alta frecuencia ese alimento de los que lo consumen rara vez o nunca.

Fase 2. Caracterización de los consumos mediáticos de las gestantes: Utilizamos entrevistas semi estructuradas como método para recolectar la información, la cual era diligenciada de casa en casa. Los datos recogidos fueron sistematizados, analizados y finalmente cruzados y graficados según las necesidades de la investigación. (Anexo 2. Entrevista Caracterización del consumo de medios).

Fase 3: Validación de la información mediante grupos focales: Para el desarrollo de los grupos focales realizamos una guía y una presentación mediante las cuales, una 
antropóloga del INS, iba validando la información resultante de las 2 fases anteriores e indagando sobre las prácticas culturales asociadas al consumo de alimentos y al consumo de medios. De igual manera validamos gustos y preferencias frente a contenidos y formatos para presentar la información en diferentes medios de comunicación (Anexo 3: Guía para el desarrollo del grupo focal y presentación) 


\section{Capítulo II}

\section{Características sociales y alimentarias de las mujeres gestantes}

\subsection{Características sociales}

Las mujeres gestantes incluidas en la muestra, pertenecientes a las 20 localidades del distrito, presentan las siguientes características sociales:

\section{Edad}

Las gestantes participantes en la investigación estaban distribuidas por grupos de edad de la siguiente manera: 2\% menores de 15 años, 24\% 15 a 18 años, $67 \% 19$ a 34 años y 7\% mayores de 35 años. Así, e

El promedio de edad de las gestantes es 23.5 años con una desviación estándar de 6.4.

Ilustración 1. Edad de las gestantes

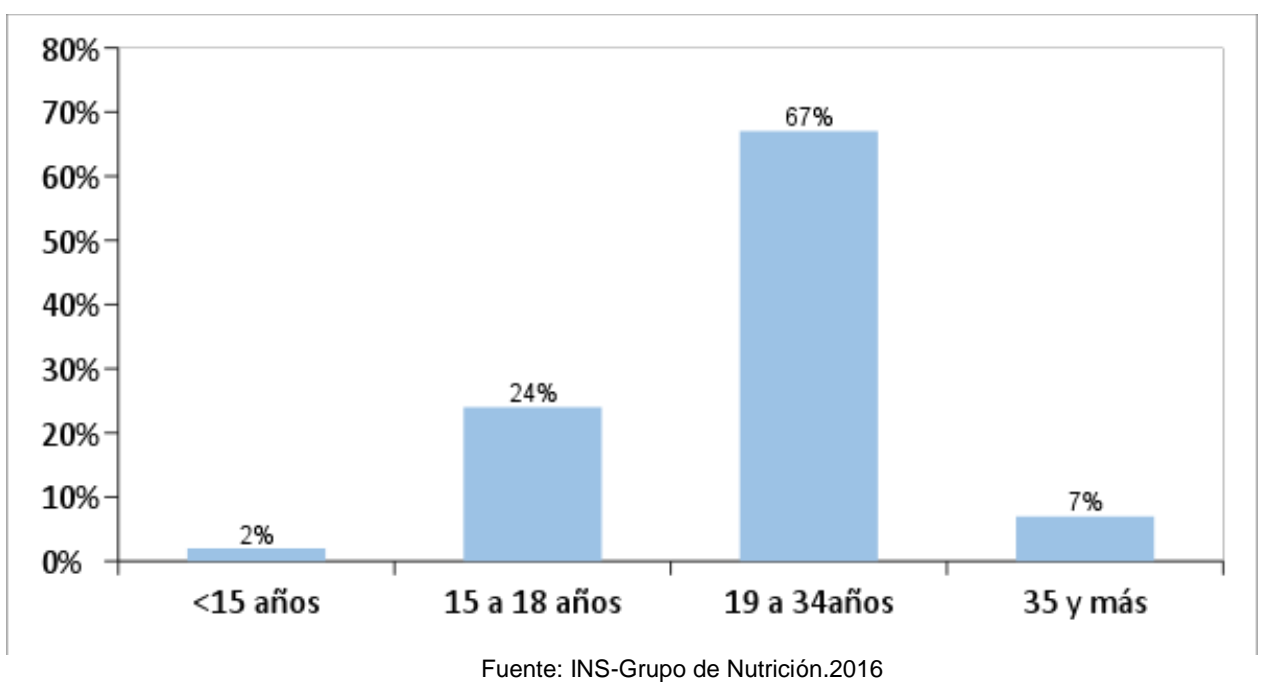

Esta grafica permite evidenciar que la mayoría de las mujeres gestantes de la muestra se encuentran en el rango de edad de 19 a 34 años, consideradas como adultas, pero es importante resaltar el porcentaje de mujeres adolescentes gestantes, $24 \%$, las cuales están consideradas como población de especial protección a nivel de salud. 


\section{Etnia}

Del total de las mujeres gestantes encuestadas el $93.1 \%$ no se reconoce como integrante de ningún grupo étnico; el $7.9 \%$ restante se reconoce como afrocolombianas o indígenas, con prevalencias del $4.4 \%$ y $2.2 \%$ respectivamente.

\section{Ubicación Geográfica}

El 100\% de las gestantes encuestadas, residen en el área urbana de la ciudad de Bogotá.

\section{Conformación de los hogares}

Con relación a esta variable se determinó que en promedio los hogares de las mujeres encuestadas están conformados por 5.5 personas, presentándose mayor prevalencia de hogares conformados por 3 personas $(31.3 \%)$, seguida de hogares conformados por 2, 4 y 5 personas $(23.7 \%, 20.5 \%$ y $12.7 \%$ respectivamente).

Los hogares conformados por una o más de 6 personas presentan prevalencias muy bajas, inferiores al 10\%. En Colombia los hogares están conformados en promedio por 3.9 personas, valor que se encuentra dentro del rango de mayor prevalencia en ésta investigación.

Ilustración 2. Número de personas que conforman el hogar

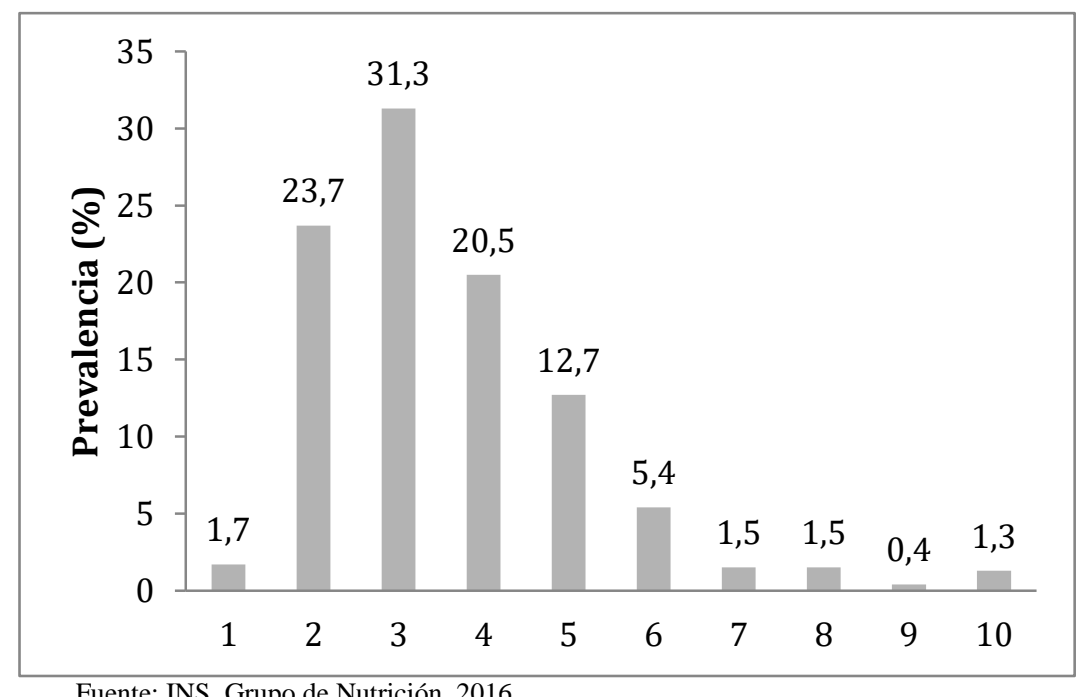

El $42.9 \%$ de las gestantes considera que el jefe del hogar es su esposo o cónyuge, $17.7 \%$ es la madre de la gestante, $16 \%$ la gestante, $11.8 \%$ el padre de la gestante y el $11.6 \%$ restante hace referencia al suegro, abuelo, hermano, otros parientes y/o amigos o no parientes.

Del total de las mujeres encuestadas el 79.1\% refirió que su pareja sentimental actual es el padre del bebé que espera, el 20.9\% restante reporta que el padre del bebé no es su 
pareja actual, sin embargo hay que aclarar que el $76.2 \%$ de estas mujeres no tenía pareja sentimental al momento de la encuesta.

En cuanto al estado civil, el 53.9\% de las gestantes es casada o está en unión libre, el $45.2 \%$ es soltera, $0.4 \%$ son divorciadas y $0.4 \%$ son viudas. De las mujeres casadas el $65.9 \%$ tienen más de 18 años y de las solteras el $95.6 \%$ son menores de 18 años.

\section{Ilustración 3. Estado civil}

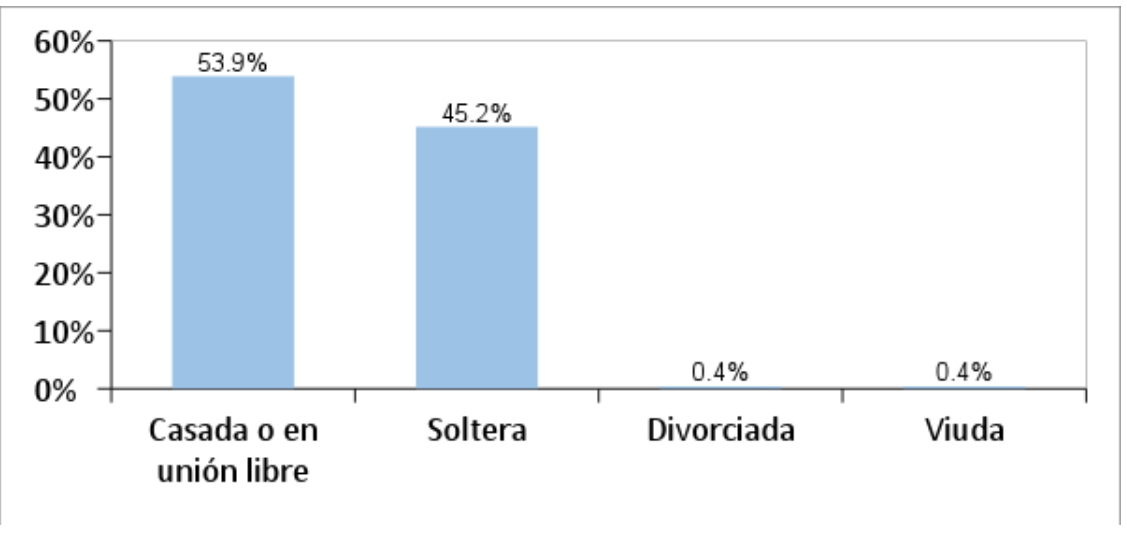

Fuente: INS-Grupo de Nutrición.2016

El nivel educativo de la población puede ser considerado como uno de los factores de riesgo de embarazos, especialmente en adolescentes ya que el entorno educativo y padres con mejor nivel educativo educan sobre salud sexual, métodos anticonceptivos y equidad de género (Fatima, Luordes, \& Leticia, 2017) . En la población participante el $35.1 \%$ tienen nivel de educación media completa, seguido de básica secundaria incompleta (21\%), estudios superiores técnicos (16.2\%), básica secundaria completa (10.6\%), media incompleta (9.1\%), primaria completa (4.3\%), estudios superiores profesionales $(2.2 \%)$, primaria incompleta (1.3\%) y sólo el $0.3 \%$ no tiene ningún estudio. La mitad de las gestantes menores de 18 años cuentan con estudios de básica secundaria incompleta y el $40.6 \%$ de las gestantes mayores de 18 años terminaron su educación media.

Ilustración 4. Nivel educativo 


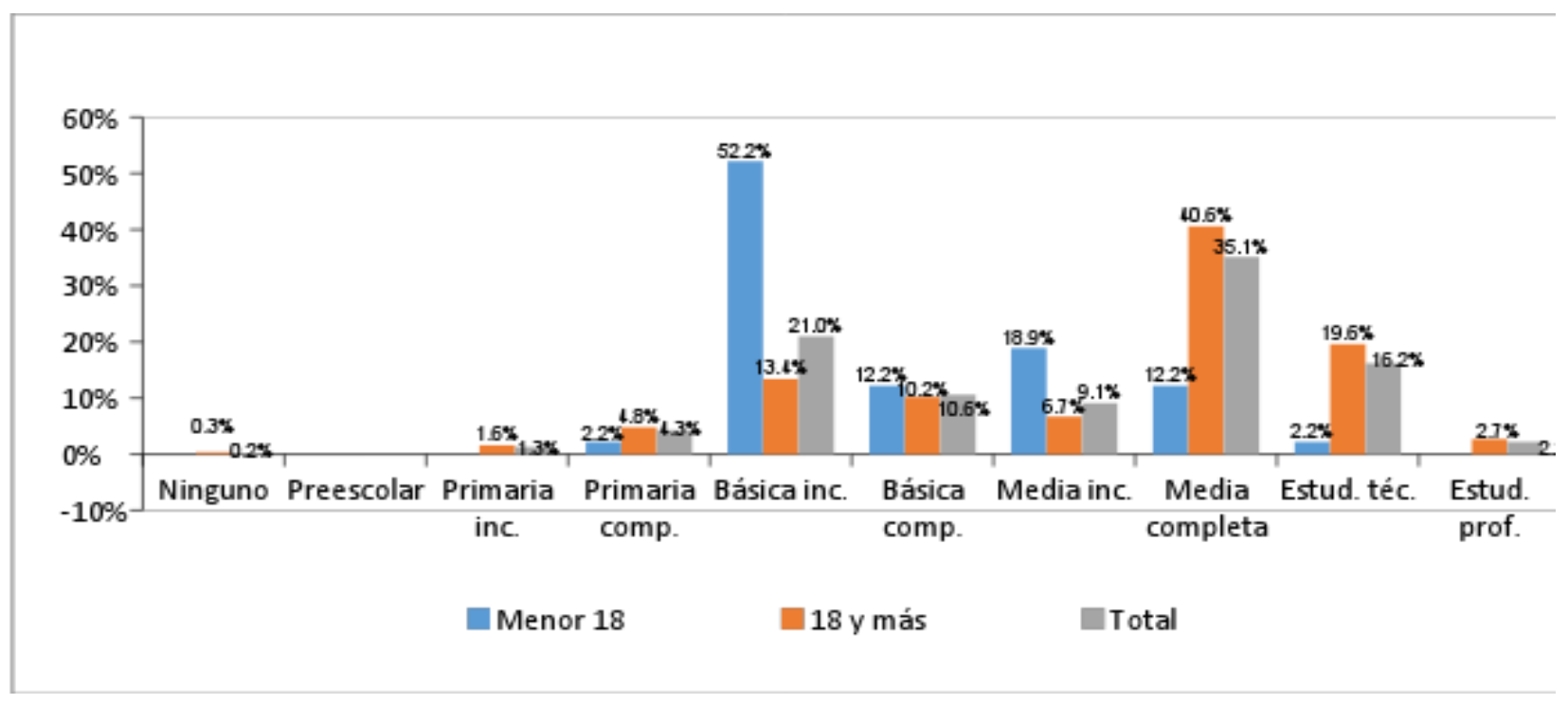

Fuente: INS-Grupo de Nutrición.2016

En relación al Sistema General de Seguridad Social en Salud- SGSSS, el $48.1 \%$ se encuentra afiliada al régimen contributivo, el $42.9 \%$ al régimen subsidiado, $8.4 \%$ es pobre no asegurado y sólo el $0.6 \%$ no se encuentra afiliado al sistema.

Ilustración 5. Tipo de afiliación al SGSSS

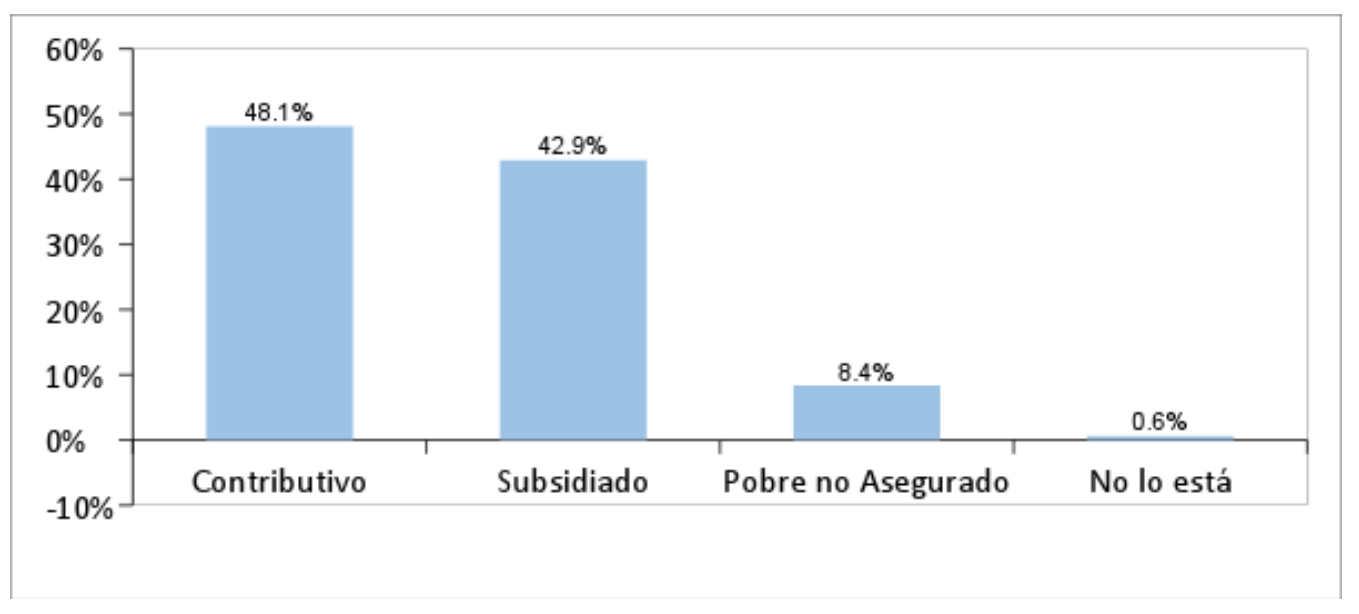

Fuente: INS-Grupo de Nutrición.2016

La actividad principal que realizaban las gestantes en el momento de la encuesta era realizar oficios en el hogar (64\%), seguido de trabajar (18\%), estudiar (14.9\%), buscando trabajo (6\%) y sin actividad el $2.7 \%$. El $48.9 \%$ de las menores de 18 años dedicaban parte de su tiempo a estudiar y el $41.1 \%$ en oficios en el hogar. En cuanto a las mayores de 18 años el $70 \%$ se dedica a oficios en el hogar y el $21 \%$ se encuentra trabajando. 
Ilustración 6. Actividad económica de las gestantes

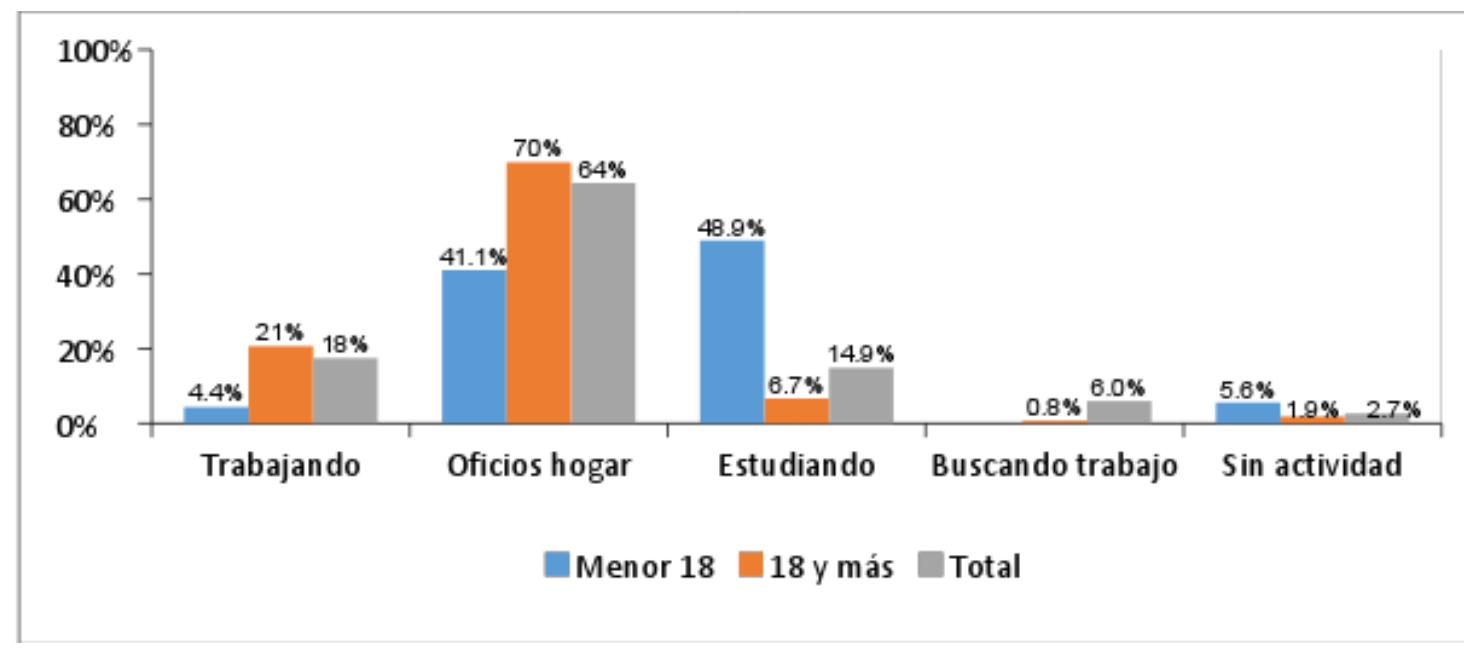

Fuente: INS-Grupo de Nutrición.2016

\section{Vivienda}

En cuanto al estrato de las viviendas donde residen las gestantes, se encontró que el estrato dos presenta la mayor prevalencia de residencia entre las encuestadas con un $65.3 \%$, seguido por el estrato 1 y 3 . Con relación a los estratos de vivienda extremos ( 0 y 5$)$, son los que presentan las prevalencias más bajas cercanas al $0 \%$. Lo anterior es congruente con uno de los criterios de inclusión al programa de ámbito familiar de la SDIS, que se refiere a incluir a las mujeres gestantes y niños menores de 2 años que pertenezcan a estratos 1,2 y 3 .

Ilustración 7. Estrato de la vivienda

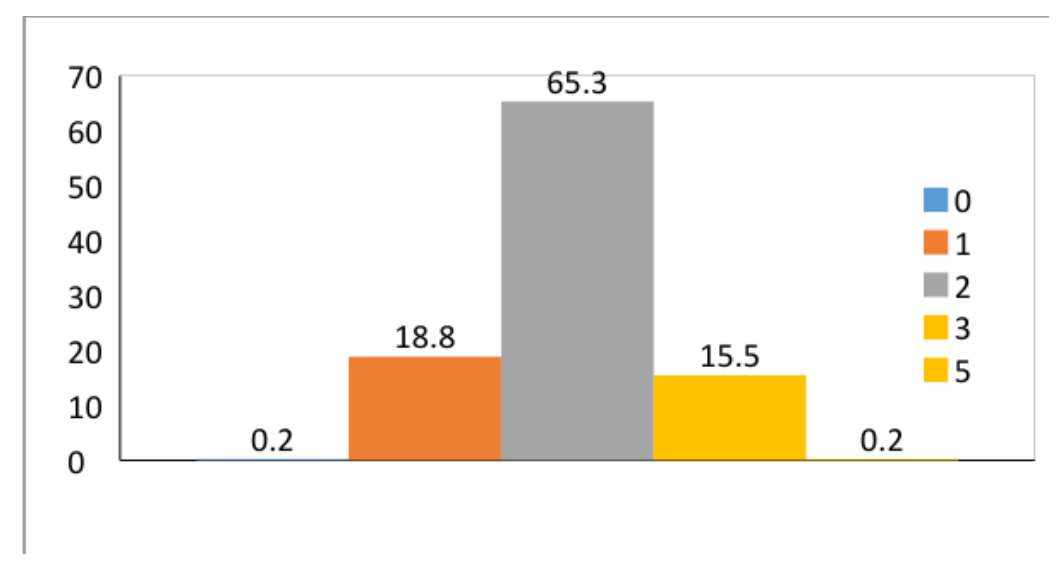

El $73.3 \%$ de las gestantes reside en vivienda arrendada, mientras que el $15.1 \%$ comparte vivienda familiar, el $11.2 \%$ posee vivienda propia y sólo el $0.4 \%$ reside en otros lugares diferentes como invasión, en la calle, etc. 


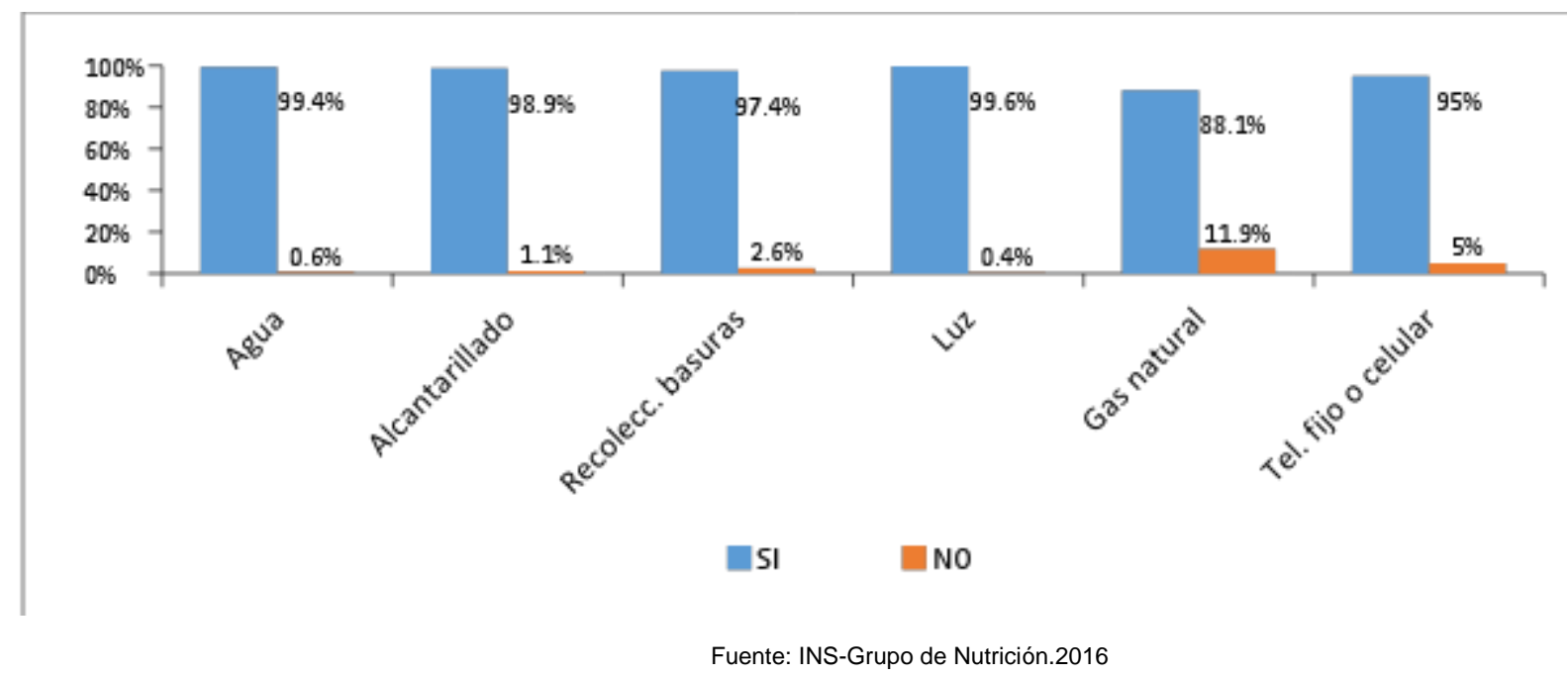

De acuerdo con el gráfico anterior, más del 95\% de la población encuestada cuenta los servicios públicos de agua, alcantarillado, recolección de basuras, luz y teléfono fijo o celular y sólo el $88.1 \%$ cuenta con gas natural.

Por otra parte, cerca de la mitad de la población cuenta con 2 habitaciones en la vivienda para dormir, $32.3 \%$ tienen sólo una habitación, $16.4 \%$ tres habitaciones y $4.8 \%$ entre 4 y 5 habitaciones.

\section{Ingresos y gastos}

En el $56.7 \%$ de los hogares de las gestantes sólo 1 persona tiene ingresos para los gastos del hogar, en el $33.6 \%$ de los casos son dos personas y en el $9.7 \%$ restante entre tres y cinco personas.

El promedio de ingresos mensuales que se aportan a los hogares es de \$713.570. Si el salario mínimo es de \$781.242, se evidencia que el ingreso de la mayoría de estas familias no alcanza ni siquiera a ser un mínimo.

En cuanto a los gastos del hogar, según la siguiente gráfica, más del 94\% de los hogares tuvo gastos en alimentos, artículos para el aseo personal y de la casa y servicios públicos, $81 \%$ en transporte, $75.4 \%$ en alquiler de vivienda y $57.3 \%$ en comidas fuera de la casa, por el contrario, no tuvieron gastos por encima del $70 \%$ en salud y medicamentos, educación y pensiones, combustible, préstamos de vivienda, loterías, chance, bebidas alcohólicas y tabaco, así como en servicios personales. Lo anterior significa que la 
mayoría de los recursos lo gastan cada mes en comida, servicios y aseo personal y del hogar y menos en gastos considerados como no primarios: recreación, prevención pensional o juegos.

Ilustración 9. Gastos del hogar

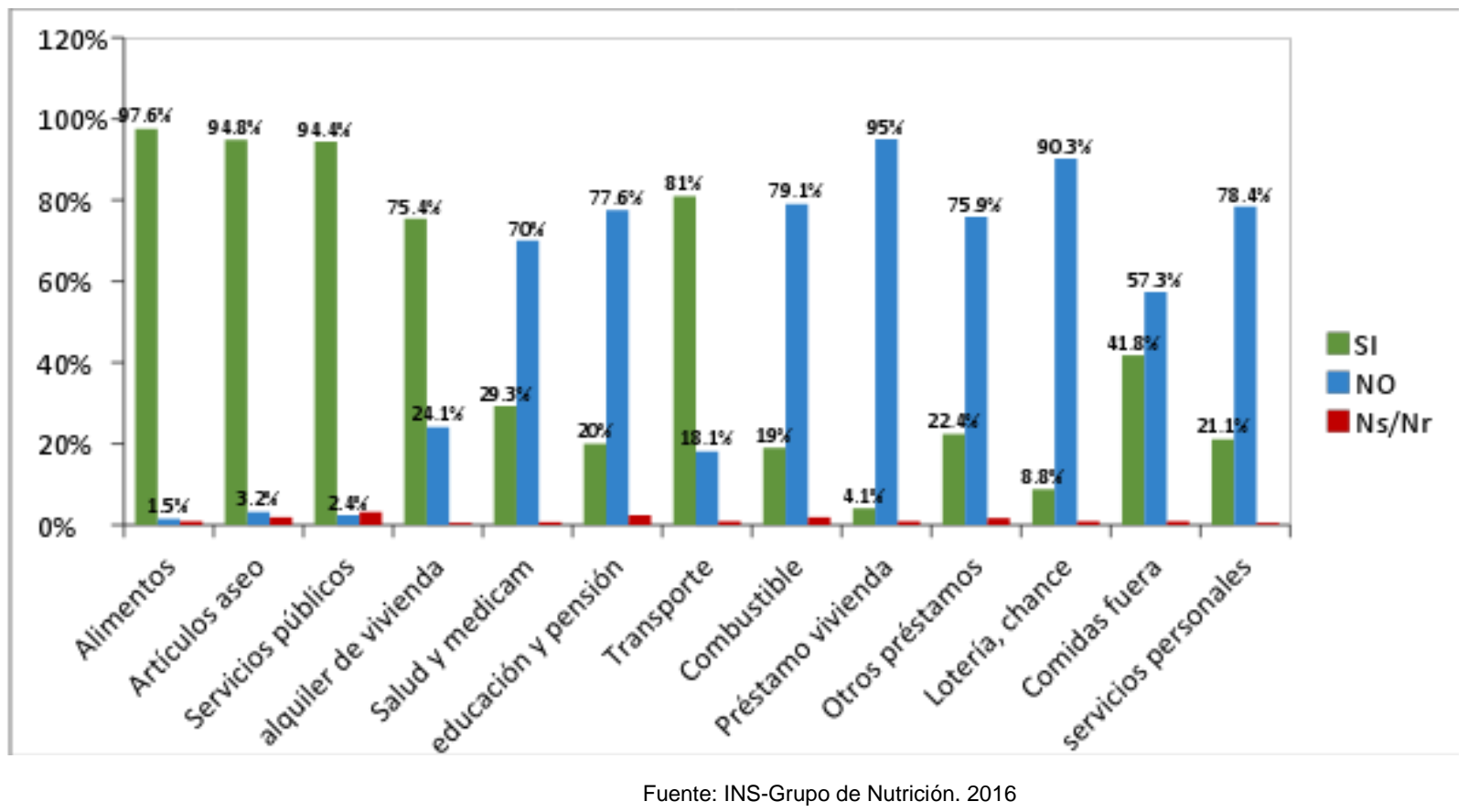

\section{Participación en apoyos alimentarios}

Teniendo en cuenta la siguiente gráfica menos del 10\% de los hogares participa en alguno de los programas de apoyo alimentario referenciados en la encuesta, en donde el $9.9 \%$ de los hogares participa en el programa Familias en acción, seguido por un $2.4 \%$ y $2.2 \%$ de los programas Bono Mi vital y FAMI del ICBF respectivamente, por otra parte, el $83.4 \%$ de los hogares no participa en ningún programa de apoyo alimentario. 
Ilustración 10. Participación en apoyos alimentarios

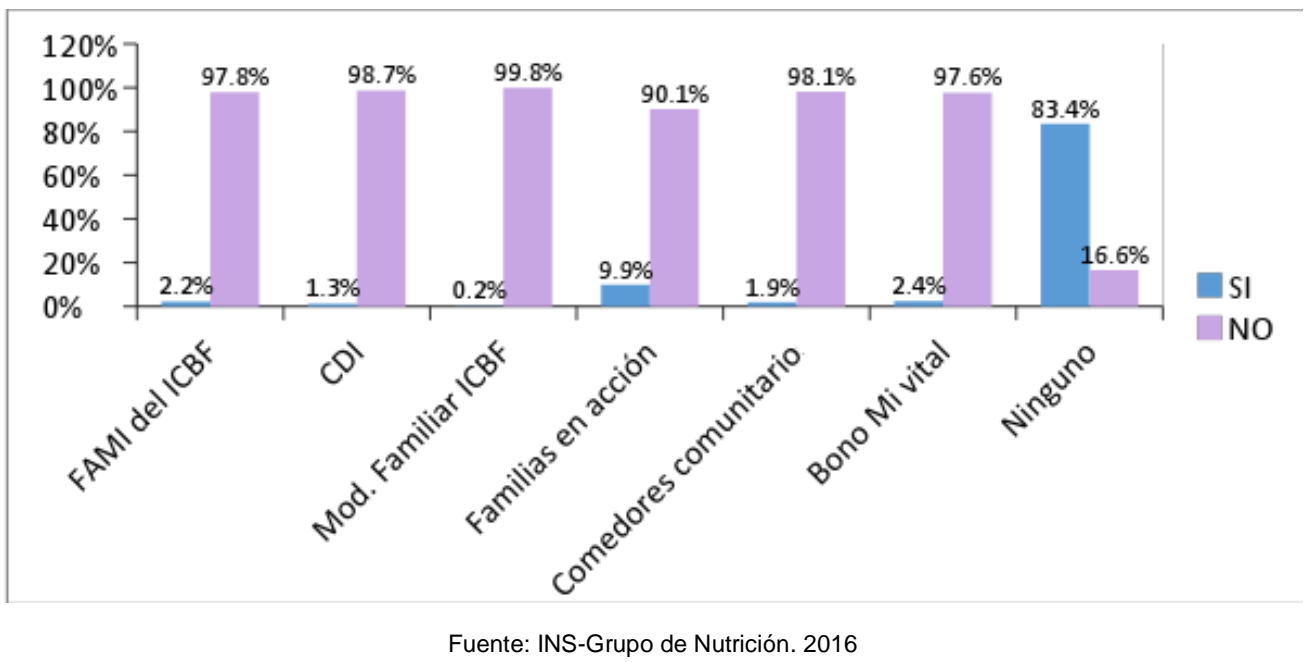

Vale la pena aclarar que los hogares que participan de los apoyos alimentarios reciben algunos beneficios como alimentos (en el caso de los programas del ICBF, comedores comunitarios y Bono Mi vital) y dinero en el Programa Familias en acción y han estado recibiendo éstos beneficios entre 6 meses a 1 año.

En relación al Programa de Ámbito Familiar de la Secretaría Distrital de Integración Social, al cual todas las participantes pertenecen, el $75.6 \%$ participa desde hace 1 a 6 meses, el 20.9\% hace menos de un mes, 2.6\% desde hace 6 a 12 meses y sólo el $0.9 \%$ lleva más de un año en este programa. Al finalizar la Primera medición de la investigación (Noviembre de 2014) el 72.5\% de las madres gestantes ya han recibido el bono canjeable por alimentos y las madres restantes (27.5\%) no ha recibido aún éste beneficio, lo mismo sucede con las actividades educativas que hacen parte del componente pedagógico de éste Programa, el 63.4\% recibió la visita de la maestra técnica y/o profesional, quienes realizan las actividades educativas en domicilio o de la dupla pedagógica, el profesional psicosocial o el nutricionista, quienes desarrollan los encuentros pedagógicos grupales y al $36.6 \%$ no se le ha impartido ningún tipo de orientación.

Las gestantes que han participado del encuentro pedagógico en domicilio y/o grupal han recibido orientación en los siguientes temas: alimentación y nutrición (51.1\%), orientación familiar (49.8\%), salud (37.4), salud sexual y reproductiva (29.5\%), higiene (28.2\%) y las madres que no han recibido orientación en algún tema corresponden al $34.4 \%$. 


\subsection{Caracterización de las prácticas alimentarias}

La importancia de la nutrición a lo largo de la vida no puede negarse bajo ningún concepto. No obstante, la significación de la nutrición en etapas especificas del crecimiento, el desarrollo y el envejecimiento está siendo tomada cada vez más en consideración (Krause A, 1995).

El "origen fetal" tiene mayores efectos a lo largo de la vida de lo que se creía en principio. El establecimiento de hábitos alimentarios adecuados durante la infancia disminuye la posibilidad de desarrollar una conducta alimentaria inapropiada con posterioridad. Aunque la influencia de una nutrición adecuada sobre la morbilidad y la mortalidad no se suele conocer hasta la edad adulta, las prácticas dietéticas orientadas a prevenir enfermedades degenerativas que se desarrollan en etapas posteriores han de instaurarse desde la infancia (Niljand, 2008).

Uno de los aspectos de mayor importancia durante la etapa de gestación es la necesidad de una ingestión adecuada de energía y nutrientes, los cuales se obtienen mediante el consumo de alimentos variados. Por esto, la calidad y cantidad de la dieta se consideran puntos decisivos para mantener un adecuado estado nutricional de la madre y el desarrollo adecuado del hijo (R. Wildman, 2000) . La alimentación inadecuada puede ocasionar malnutrición ya sea por déficit o por exceso, y convertirse en una de las situaciones más comunes de alto riesgo para la madre y su hijo durante el embarazo.

En este capítulo se describen los resultados del componente de consumo y prácticas alimentarias de las mujeres en periodo de gestación, en el marco del estudio longitudinal "Efecto de las prácticas alimentarias de mujeres gestantes y sus hijas e hijos hasta los 24 meses de edad sobre el estado nutricional, en una población atendida por la Secretaría Distrital de Integración Social de la Alcaldía Mayor de Bogotá", en su primera fase de medición, realizado por el Grupo de Nutrición del Instituto Nacional de Salud.

El análisis estadístico comprendió la determinación de frecuencias simples o análisis univariados de consumo derivados de las 10 categorías de frecuencia, para cada uno de los alimentos. Los grupos de edad para los análisis simples fueron menores de 19 años, entre 19 y 35 y mayores de 35 años.

El grupo de menores de 19 años se estableció a partir de la definición de la OMS para la edad de adolescencia que comprende desde los 10 a 19 años de edad y que en 
comparación con otras mujeres, las jóvenes adolescentes corren mayor riesgo de complicaciones y muerte a consecuencia del embarazo.

Seguidamente, se realizaron agrupaciones de las prácticas de consumo de lácteos, fuentes de proteína, cereales, leguminosas, frutas y verduras, que se analizaron por grupos de edad (menores de 18 años y adultas) y de manera complementaria con otras variables de interés del estudio como las antropométricas. Se calculó el error estándar, coeficientes de variación e intervalos de confianza al 95\%.

Finalmente, la información recolectada en los formularios, fue analizada en conjunto con los resultados obtenidos en los grupos focales, con el fin de validar la información y conocer las razones de las gestantes para consumir o no cierto tipo de alimentos.

\section{Muestra para la caracterización de la alimentación}

Para el análisis de frecuencia de consumo se contó con una muestra de 464 gestantes distribuidas de la siguiente manera:

Tabla 2. Población de gestantes evaluadas en el componente de consumo

\begin{tabular}{|l|c|c|}
\hline \multicolumn{1}{|c|}{ Edad } & No. & $\%$ \\
\hline$<15 a$ ños & 11 & 2,4 \\
\hline 15a18 años & 110 & 23,7 \\
\hline 19a34años & 309 & 66,6 \\
\hline 35ymás & 34 & 7,3 \\
\hline Total Fuente: INS-Grupo de Nutrición-2016 \\
\hline \multicolumn{2}{|c|}{100,0} \\
\hline
\end{tabular}

\section{Consumo de fuentes de calcio y vitamina D}

La leche y sus derivados son la primera opción como fuente de calcio para satisfacer las principales necesidades de este nutriente en la mujer gestante. Según la ENSIN 2010 (Ministero de Salud, 2010) es uno de los alimentos más consumidos por los colombianos, y la ingesta de estos alimentos en las gestantes cobra gran importancia debido a su alto aporte de nutrientes especialmente de calcio de alta biodisponibilidad, importante ya que durante la gestación es el momento en el cual se deposita la mayor cantidad de calcio en el esqueleto en formación porque se acumulan aproximadamente $30 \mathrm{~g}$ de calcio, casi 
todos ellos en el esqueleto fetal ( $25 \mathrm{~g})$. El resto se almacena en el esqueleto materno, quedando como reserva para las demandas de calcio durante la lactancia.

Este grupo de alimentos se analizó a partir de consumo de leche entera, deslactosada, baja en grasa y en polvo y los derivados lácteos queso, kumis y yogurt. En relación al consumo de leche se evidenció que el $26.3 \%$ de las gestantes consumía leche 2 veces al día, el $25.4 \%$ la consumía 1 vez al día y solo el $15.7 \%$ la consumía 3 veces o más veces al día; el consumo diario total (1 a 3 o más veces al día) de leche se dio en el $67.4 \%$ de esta población, siendo superior al consumo nacional de leche para este grupo poblacional (57.4\%). De otra parte, el $25.4 \%$ de las gestantes consume leche de manera semanal y hay un $2.4 \%$ de gestantes que no consumen leche. No hubo diferencias por grupos de edad para el consumo de leche.

Lo anterior evidencia un frecuente consumo diario de leche, tanto por hábitos alimentarios como por preferencias en relación al sabor o los gustos. Ante esto las gestantes en los grupos focales refirieron:

"Los alimentos que se consumen actualmente están altamente influenciados por lo que se comía antes en el hogar, por ejemplo en mi casa siempre tomamos leche" (G.F.B. ${ }^{1}$ ).

"Por el sabor prefiero consumir leche que carne" (G.F.S $\left.{ }^{2}\right)$

Sin embargo, hay un porcentaje importante de mujeres que consumen estos alimentos de manera semanal, al parecer debido al alto precio de estos alimentos:

“Los lácteos son costosos” (G.F.B).

"Cuando no hay dinero, prefiero comprar carne y no leche" (G.L.S).

Es importante recordar que la población gestantes de la muestra pertenece principalmente al estrato 2, muchas dependen económicamente de una persona que trabaja en el hogar, invierten en promedio $\$ 200.000$ para el mercado del mes, lo cual implica que si quisiéramos recomendar un consumo de 2 vasos de leche al día por cada mujer gestante, requeriríamos aproximadamente de $\$ 90.000$ para poder pagar este requerimiento, lo cual equivale a $45 \%$ del ingreso familiar en leche para la gestante. Lo anterior evidencia que económicamente es inviable para estas mujeres cubrir el requerimiento diario de leche dado su alto costo.

\footnotetext{
${ }^{1}$ Grupo Focal, Localidad de Bosa, 15 de Agosto de 2016.

${ }^{2}$ Grupo Focal, Localidad de Suba, 16 de Agosto de 2016
} 
Ilustración 11. Distribución de la frecuencia de consumo de leche en las gestantes

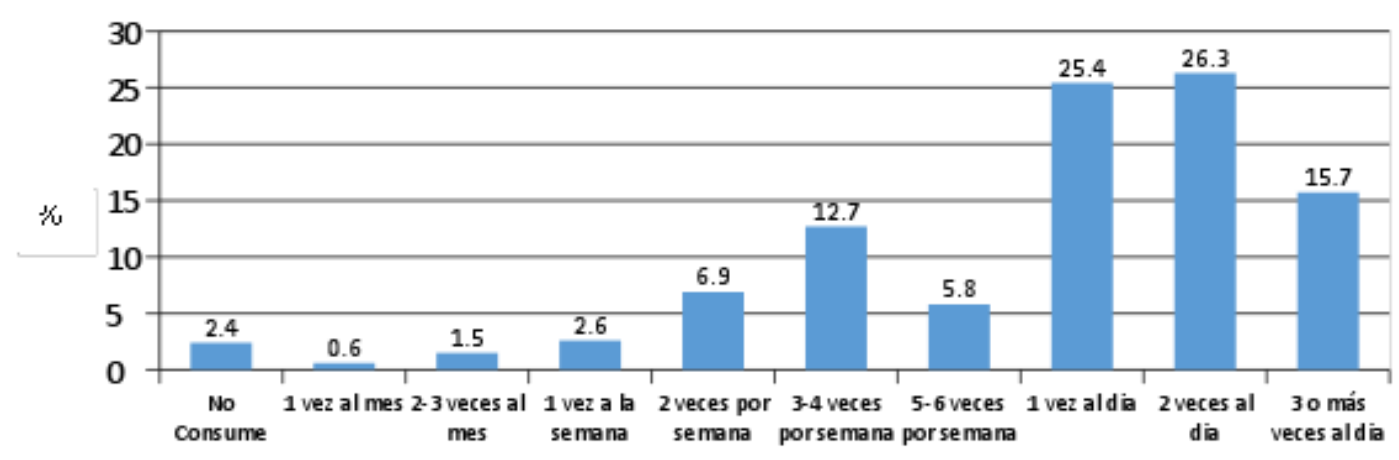

Fuente: INS-Grupo de Nutrición-2016

El consumo de derivados lácteos fue más frecuente de manera semanal, el 20\% de las gestantes consume estos alimentos de 3 a 4 veces por semana. El 15.5\% consume estos alimentos 1 vez al día. El consumo diario total (1 a 3 o más veces día) fue de $26.3 \%$, prevalencia superior en relación al consumo a nivel nacional (22.9\%) de estos alimentos reportado por la ENSIN 2010 para este grupo poblacional. Por último es importante resaltar que un $12.3 \%$ de las gestantes no consumió derivados lácteos en el último mes.

Este tipo de comportamientos, según lo expresado en los grupos focales, está mediado por el costo de los derivados lácteos y por las preferencias especiales de las mujeres durante la gestación:

“Consumía pocos lácteos debido a su alto costo" (G.F.B.).

"Me daban antojos de queso durante el embarazo" (G.L.S).

Ilustración 12. Distribución de la frecuencia de consumo de derivados lácteos en las gestantes

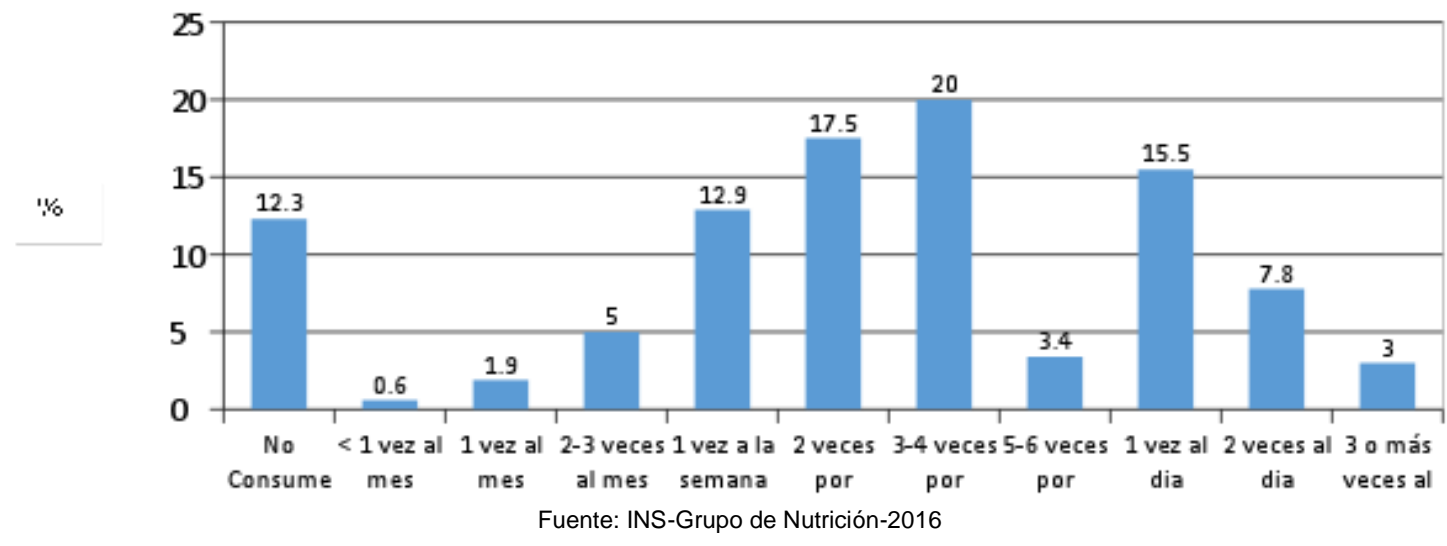


Al igual que en el caso de la leche, los derivados lácteos son costosos y el presupuesto mensual destinado a la alimentación no permite cubrir los requerimientos diarios de estos alimentos.

\section{Consumo de fuentes de proteína y hierro}

Durante el embarazo se registran necesidades adicionales de proteínas para sostener la síntesis de tejidos maternos y fetales, aunque la magnitud del incremento resulta incierta. Las necesidades de proteínas aumentan a lo largo del embarazo y son máximas durante el tercer trimestre.

De otra parte, el significativo incremento del aporte sanguíneo materno durante el embarazo aumenta en gran medida la demanda de hierro. Una embarazada ha de consumir un aporte adicional de 700 a $800 \mathrm{mg}$ de hierro a lo largo de la gestación, 500 mg para la hematopoyesis y de 250 a $300 \mathrm{mg}$ para los tejidos fetales y placentarios. La mayor parte del aumento tiene lugar después de la semana 20 de gestación, cuando las demandas maternales y fetales son mayores (Krause A, 1995)).

\section{Consumo de Huevo}

El huevo aporta proteínas de alto valor biológico y es fuente importante de ácidos grasos poliinsaturados (DHA) durante la gestación. Los resultados muestran, un consumo diario de este alimento en el $47 \%$ de las mujeres, de las cuales el $37.9 \%$ lo consume 1 vez al día. El $48.2 \%$ consume este alimento de manera semanal. No hubo diferencias estadísticamente significativas por grupos de edad ( $p>0.005)$.

Varias mujeres opinan que el huevo es consumido de manera frecuente tanto por el valor, es accequible, como por el sabor y el hábito diario del consumo.

"Siempre como huevo, me gusta mucho y lo como de varias formas. No lo rechace durante el embarazo" (G.L.S).

"Todos los días como huevo porque lo compro en el mercado semanal y alcanza para todos" (G.L.S).

"Prefiero comer huevo frito que carne, además es más barato" (G.F.B.).

Acorde al promedio del presupuesto mensual de los hogares encuestados, el precio de este alimento permite su consumo diario, ya que una mujer gestante podría consumir todos los días huevo, aportando una cantidad importante de proteína y solo gastaría en 
promedio $\$ 7.500$ mensuales para comer un huevo diario. Lo anterior equivale a un $3.7 \%$ del ingreso mensual.

Tabla 3. Frecuencia de consumo de huevo

\begin{tabular}{|l|c|c|c|c|c|c|c|c|c|c|}
\hline \multirow{2}{*}{ Frecuencia } & $<15$ años & \multicolumn{2}{|c|}{ 15a18 años } & \multicolumn{3}{c|}{ 19a34años } & \multicolumn{3}{c|}{ 35ymás } & \multicolumn{2}{c|}{ Total } \\
\cline { 2 - 13 } & $\mathrm{N}$ & $\%$ & $\mathrm{~N}$ & $\%$ & $\mathrm{~N}$ & $\%$ & $\mathrm{~N}$ & $\%$ & $\mathrm{~N}$ & $\%$ \\
\hline No consume huevo & 0 & 0 & 4 & 3,6 & 13 & 4,2 & 0 & 0 & 17 & 3,7 \\
\hline $\begin{array}{l}\text { Mensualmente } \\
\text { consume huevo }\end{array}$ & 1 & 9,1 & 1 & 0,9 & 2 & 0,6 & 1 & 2,9 & 5 & 1,1 \\
\hline $\begin{array}{l}\text { Semanalmente } \\
\text { consume huevo }\end{array}$ & 5 & 45,5 & 56 & 50,9 & 147 & 47,6 & 16 & 47 & 224 & 48,2 \\
\hline $\begin{array}{l}\text { Diariamente } \\
\text { consume huevo }\end{array}$ & 5 & 45,5 & 49 & 44,5 & 147 & 47,6 & 17 & 50 & 218 & 47 \\
\hline
\end{tabular}

\section{Consumo de Carnes rojas, pollo o gallina y pescados}

Como se observa en la gráfica 14, la carne y el pollo son los alimentos de este grupo que se consumen con mayor preferencia. Sin embargo, se presenta un bajo consumo de estos alimentos, ya que solo el $6.8 \%$ y el $2.6 \%$ de las gestantes consume carne de res o pollo de manera diaria. No hubo diferencias estadísticamente significativas por grupos de edad $(\mathrm{p}>0.005)$

De otra parte, el $51.1 \%$ y el $50.6 \%$ de las gestantes no consumen pescados o mariscos ni atún o sardinas y para este grupo la frecuencia mayor de consumo se presentó de manera semanal para el atún o sardinas (30.6\%). No hubo diferencias estadísticamente significativas por grupos de edad para el consumo de pescado $(p>0.005)$

Ilustración 13. Consumo de fuentes de proteína en las gestantes por tipo de frecuencia de consumo

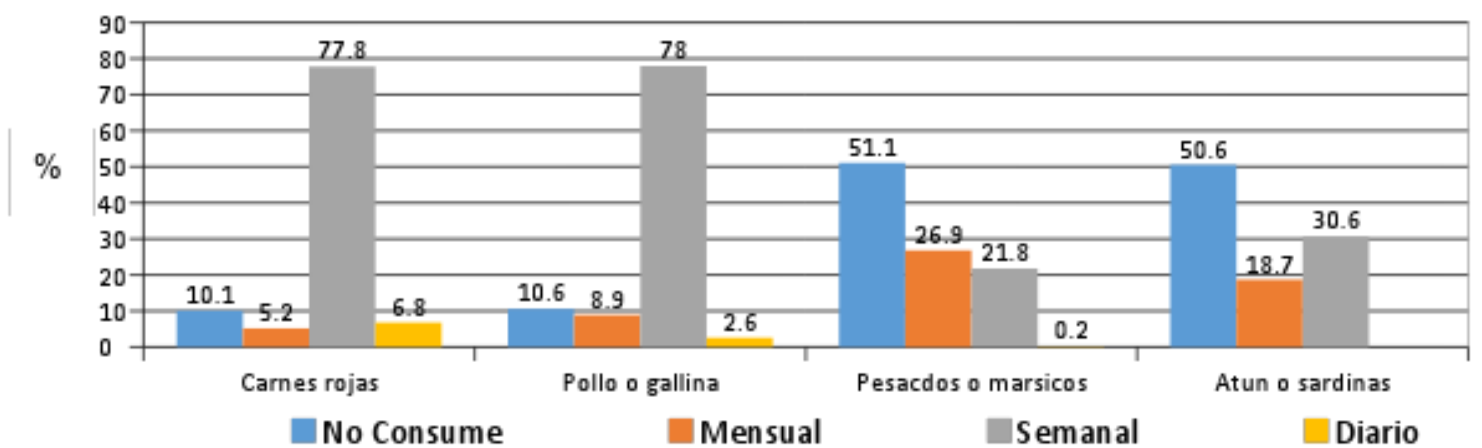

Fuente: INS-Grupo de Nutrición-2016 
Tabla 4. Consumo de fuentes de proteína en las gestantes

\begin{tabular}{|l|c|c|c|c|c|c|c|c|}
\hline \multirow{2}{*}{ Frecuencia } & \multicolumn{2}{|c|}{ Carnes rojas } & \multicolumn{2}{c|}{ Pollo o gallina } & \multicolumn{2}{c|}{ Pescados o mariscos } & \multicolumn{2}{c|}{ Atún o sardinas } \\
\cline { 2 - 10 } & No. & $\%$ & No. & $\%$ & No. & $\%$ & No. & $\%$ \\
\hline $\begin{array}{l}\text { No Consume } \\
\text { proteínas }\end{array}$ & 47 & 10,1 & 49 & 10,6 & 237 & 51,1 & 235 & 50,6 \\
\hline $\begin{array}{l}\text { Mensualmente } \\
\text { consume proteínas }\end{array}$ & 24 & 5,2 & 41 & 8,9 & 125 & 26,9 & 87 & 18,7 \\
\hline $\begin{array}{l}\text { Semanalmente } \\
\text { consume proteína }\end{array}$ & 361 & 77,8 & 362 & 78 & 101 & 21,8 & 142 & 30,6 \\
\hline $\begin{array}{l}\text { Diariamente } \\
\text { consume proteínas }\end{array}$ & 32 & 6,8 & 12 & 2,6 & 1 & 0,2 & 0 & 0 \\
\hline
\end{tabular}

Fuente: INS-Grupo de Nutrición-2016

Acorde a la información recolectada en los grupos focales, el consumo de alimentos fuente de proteína animal, como huevos, carne roja, pollo o pescado, está altamente relacionado con el alto costo de estos alimentos, seguido de los hábitos alimentarios y los gustos particulares durante la gestación, así:

1. Grupo focal en la localidad de Bosa, 15 de Agosto de 2017:

“También se inició consumo de cabeza de pescado que es buena para las gestantes."

"Los lácteos son costosos, igual que las carnes, las frutas y las verduras".

"Por sabor prefiero consumir lácteos que carnes".

"Consumí poca carne de cerdo, influyen mucho los alimentos que a uno le den ganas de comer".

2. Grupo focal en la localidad de Suba, 16 de Agosto de 2017:

"Cuando no hay plata prefiero comprar carne que leche"

"Durante el embarazo rechace la carne los primeros meses".

“Consumía carne solamente, no quería comer pollo".

"Prefería comer pescado"

"No podía consumir carne porque embarazada lo rechazaba"

"No consumía huevo porque estando en embarazo lo rechazaba"

"Tenía bajo consumo de proteínas y lácteos debido a su alto costo"

Es evidente como el costo de este grupo de alimentos afecta su consumo: si queremos que un gestante consuma 2 veces al día una porción de carne o pollo, tendrían que gastar en promedio el $57 \%$ del presupuesto mensual en estos alimentos, lo cual no es viable cuando el ingreso es tan bajo. 
Por otra parte es importante recordar el lugar de procedencia de las personas encuestadas, quienes en su mayoría son del centro del país donde el consumo de pescado y comida de mar es muy bajo, por lo cual no es un hábito incluir dentro de la canasta básica pescados ni mariscos.

Lo anterior evidencia que el consumo de estos alimentos está mediado tanto por el costo como por el hábito alimentario.

\section{Consumo de vísceras de res y de pollo o morcilla}

En general, se presenta un bajo consumo de estos alimentos ya que el $75.6 \%$ y el $62.1 \%$ de las gestantes no los consumen con regularidad. El $9.4 \%$ y el $17.2 \%$ de las gestantes consumen morcilla o vísceras de res y menudencias de pollo de manera semanal. No hubo diferencias por grupos de edad $(\mathrm{p}>0.005)$

Tabla 5. Consumo de vísceras por las gestantes

\begin{tabular}{|l|c|c|c|c|}
\hline \multirow{2}{*}{ Frecuencia } & \multicolumn{2}{|c|}{ Morcilla o vísceras de res } & \multicolumn{2}{|r|}{ Menudencias de pollo } \\
\cline { 2 - 5 } & No. & $\%$ & No. & $\%$ \\
\hline No Consume & 351 & 75,6 & 288 & 62,1 \\
\hline Mensual & 68 & 14,7 & 93 & 20 \\
\hline Semanal & 44 & 9,4 & 80 & 17,2 \\
\hline Diario & 1 & 0,2 & 3 & 0,6 \\
\hline \multicolumn{3}{|c|}{ Fuente: INS-Grupo de Nutrición-2016 }
\end{tabular}

Las mujeres refirieron bajo consumo debido principalmente a que no es un alimento que se encuentre de sus hábitos alimentarios:

"No me gustan mucho las vísceras porque no es mi costumbre" (G.F.B.).

"Casi no consumo vísceras por que no las sé preparar, en mi casa no se consumían mucho" (G.L.S).

Sin embargo, las mujeres y sus acompañantes refirieron conocer sobre la importancia del consumo de visceras para la buena salud de ellas y sus hijos, en su mayoría razones relacionadas con mitos sobre estos alimentos:

“Son recomendadas para el cerebro". (G.L.S).

"Aumenté de consumo de vísceras y mano de res porque tienen las vitaminas de los pies, es un agüero". (G.L.S). 
"Durante el embarazo debía comer más vísceras y mano de res" (G.F.B.).

"Recomiendan el hígado crudo con jugo de mora, tomárselo rápido. Yo tomé varias veces." (G.F.B.).

Para un grupo menor de gestantes, las visceras son un alimento opcional para reemplazar la carne, cuando por gustos o hábitos, ésta no se consume:

"Cuando comía vísceras era sobretodo el hígado, por costumbre o recomendaciones" (G.F.B.).

"Consumo alto de hígado o piedra (mollejas de pollo), por lo que no me gustaba la carne entonces lo remplazaba con vísceras" (G.L.S).

"Uno come vísceras porque es un hábito consumirlo" (G.F.B.).

\section{Consumo de leguminosas secas}

El consumo de leguminosas secas (frijol, lenteja, garbanzo, arveja verde seca) se dio principalmente de manera semanal, el 30\% de las gestantes consumió granos secos de 3 a 4 veces por semana, el $19 \% 2$ veces por semana y el $18.8 \% 1$ vez por semana. El consumo total semanal es de $67.8 \%$, valor similar al reportado para estos alimentos en población gestante por la ENSIN 2010.

Ilustración 14. Consumo de leguminosas secas en las gestantes

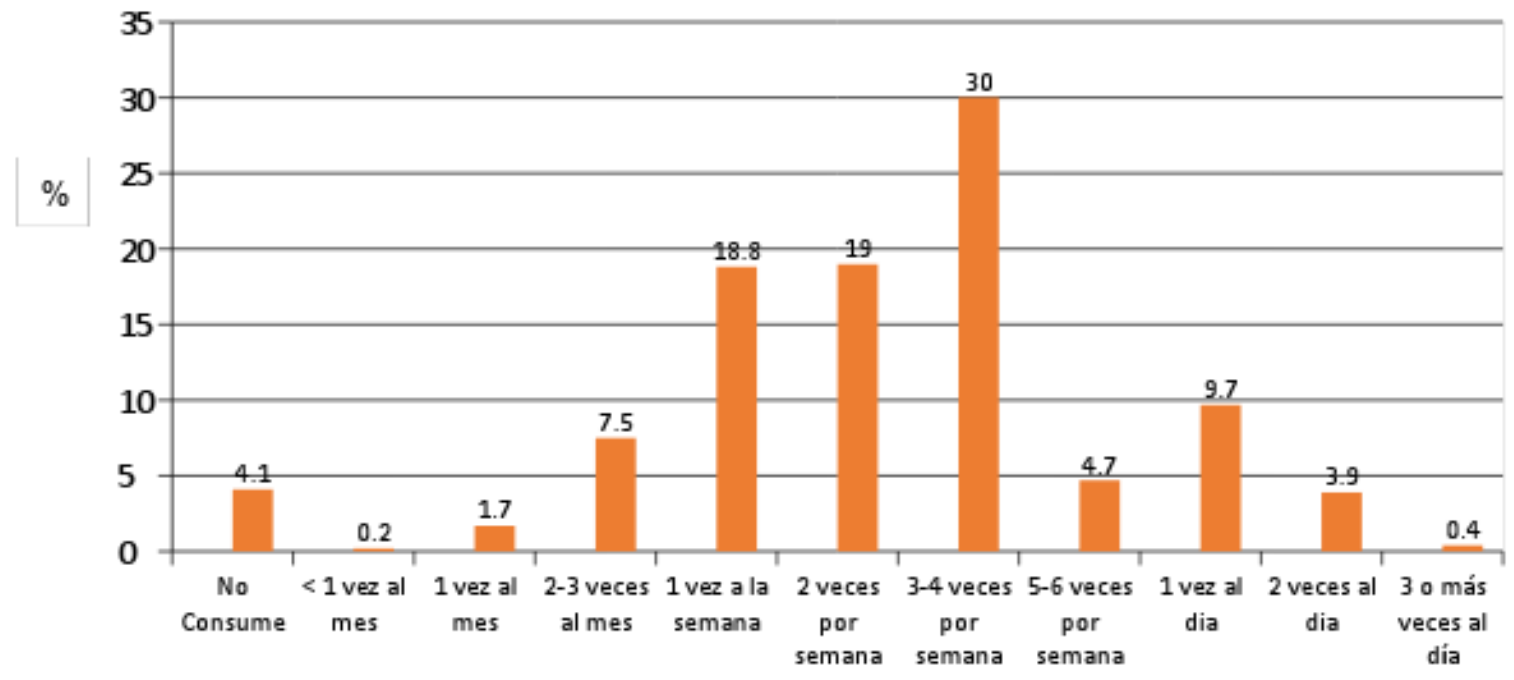

Fuente: INS-Grupo de Nutrición-2016

Aunque las leguminosas no son un alimento de consumo diario, su consumo semanal está dado por los hábitos alimentarios de las gestantes, ya que son parte de la canasta familiar, sin embargo cuando su consumo disminuye, está relacionado con los problemas 
digestivos que aparecen después del consumo de algunos de ellos, como lo refiere una de las mujeres asistentes al grupo focal de la localidad de Bosa:

"Deje de comer granos por el colon inflamado, no por recomendación médica sino por mí misma" (G.F.B.).

Este grupo de alimentos es una opción viable para incrementar el aporte proteico que requieren las mujeres gestantes, ya que para su consumo 3 veces a la semana, se requiere en promedio invertir el $2 \%$ del presupuesto mensual que se invierte en alimentos.

\section{Alimentos fuente de carbohidratos}

Para analizar el consumo de fuentes de carbohidratos en las gestantes se indagó por el consumo de arroz o pasta, pan o productos de panadería, arepas o galletas y papa, plátano o yuca. Estos alimentos son ampliamente consumidos por la población en general y representan la mayor fuente de energía proveniente de la alimentación. Las gestantes del estudio consumieron arroz y pasta de manera diaria en un $84.6 \%$, el consumo de productos de panadería fue de $72.1 \%$ de manera diaria $(20.3 \% 2$ veces al día y $7.8 \% 3$ o más veces al día) y el consumo de papa, yuca y plátano se dio de manera diaria en el $43.8 \%$ de las gestantes, el consumo diario de estos últimos fue mayor en las gestantes mayores de 35 años.

El consumo de estos alimentos es alto y está estrechamente relacionado con los hábitos alimentarios de la región de donde se provenga, así una persona de la costa, consumirá mayor cantidad de plátano, una persona de la región oriental consumirá mayor cantidad de yuca y una persona de la región central consumirá más papa, como se evidencia en el siguiente ejemplo:

"Consume uno los alimentos de la región donde se crio, a mí me gusta la papa porque soy de Boyacá" (G.F.B.).

"No pueden faltar las sopas, el mute con mucha papa picada, como lo comíamos en Chiquinquirá. (G.F.B.).

Ilustración 15. Consumo de fuentes de carbohidratos por grupos de edad 


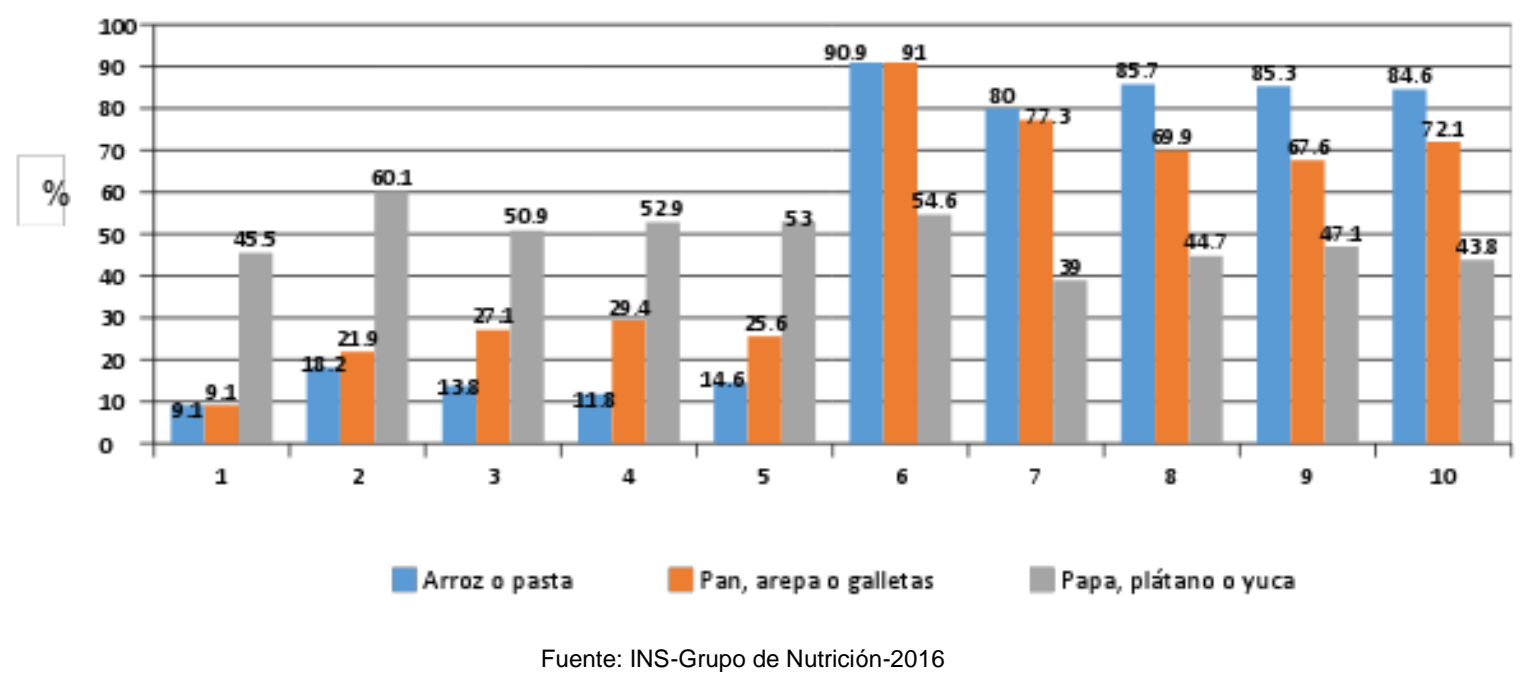

De otra parte, el consumo de azúcar, miel y panela como fuente de energía proveniente de los carbohidratos se dio en las gestantes con una frecuencia alta de consumo diario $(76.1 \%)$.

Ilustración 16. Consumo de azúcar, miel y panela.

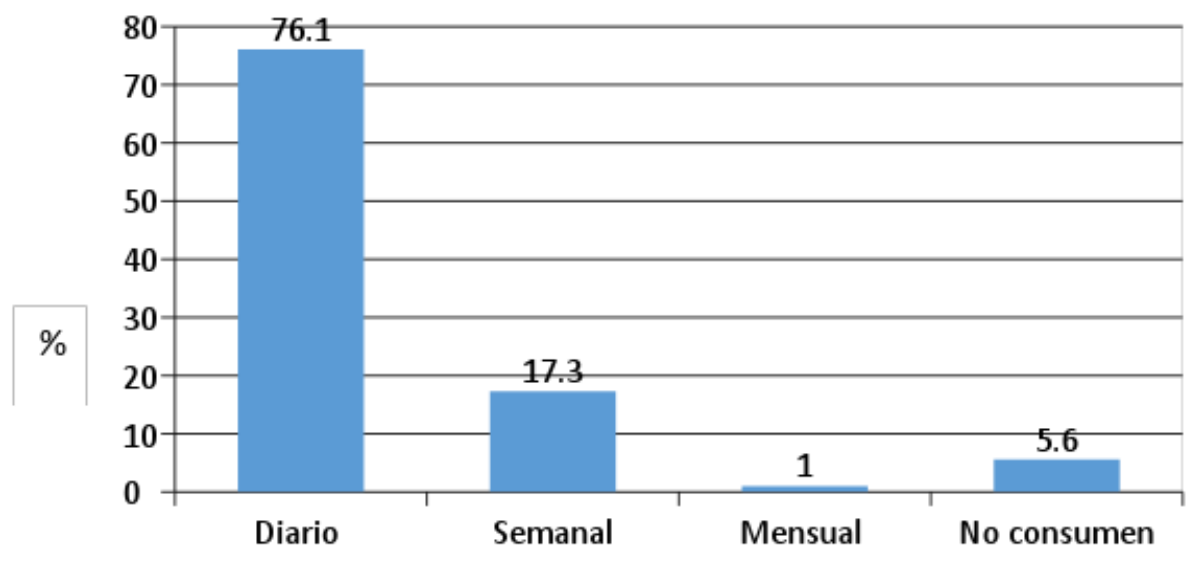

Fuente: INS-Grupo de Nutrición-2016

El consumo de gaseosas o refrescos que también representan una fuente importante de energía aportada principalmente por el azúcar se presentó de manera semanal en el 39\% de las gestantes, de manera mensual en el $13.1 \%$ y el $10.1 \%$ las consumen de manera diaria.

En los grupos focales algunas mujeres afirmaron que la compra de productos como la miel o el azúcar son parte de la canasta familiar y su compra es prioritaria y rutinaria con el presupuesto mensual, argumentando también que el precio es un motivo de su compra: "Cuando se hace mercado, la prioridad es el azúcar, el arroz, la panela y de últimas lo más costoso: las verduras y las frutas" (G.F.B.). 
Otra de las razones por las cuales el consumo de azúcar, la panela y la miel es diario en la mayoría de las mujeres, es porque en el país es habitual consumir las bebidas endulzadas con alguno de estos productos:

“Se requiere siempre para las bebidas, la aromática y el agua de panela.” (G.F.B.).

Ilustración 17. Frecuencia de consumo de gaseosas o refrescos por las gestantes

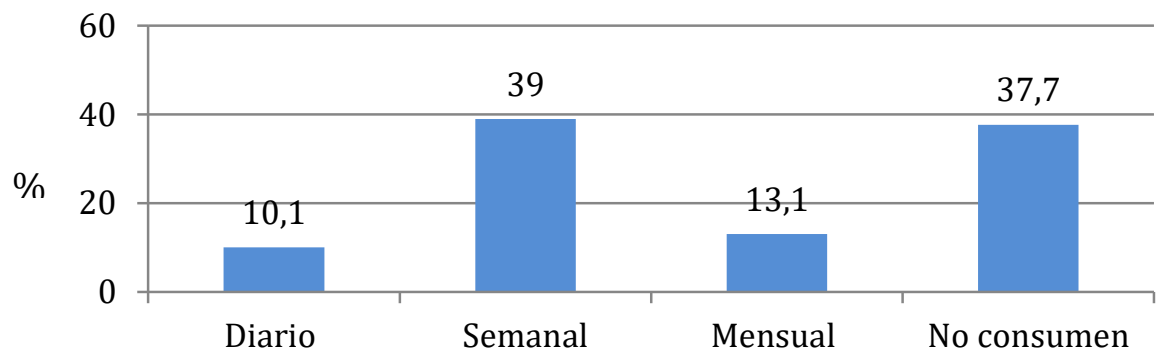

Fuente: INS-Grupo de Nutrición-2016

Finalmente para este grupo de alimentos se indagó por el consumo de dulces, golosinas y postres, presentándose un alto consumo de estos de manera diaria (25.2\%) pero más alto aún de manera semanal (38.8\%).

Ilustración 18. Consumo de dulces y golosinas en las gestantes

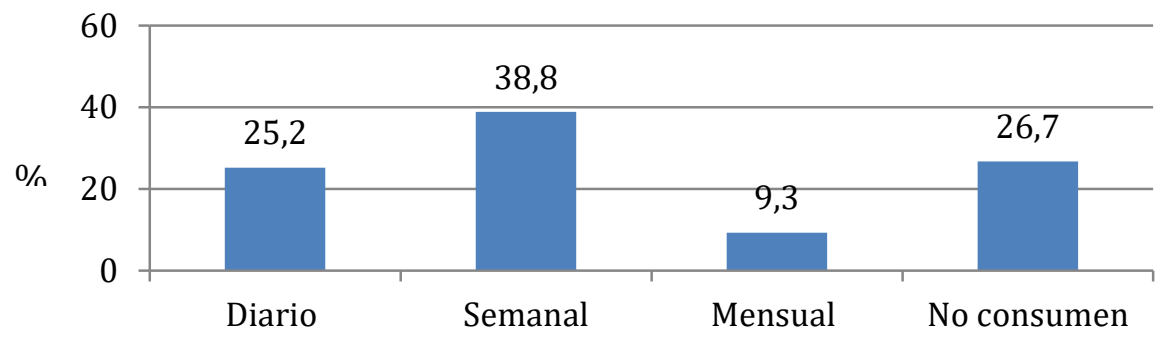

Fuente: INS-Grupo de Nutrición-2016

A pesar de los resultados anteriores que evidencian un alto consumo de alimentos energéticos como los dulces, el azúcar, la panela, las gaseosas y la miel, varias gestantes manifestaron su interés en relación a reducir su consumo durante la gestación, especialmente por problemas de salud:

"Bajé el consumo de gaseosas por los problemas de azúcar" (G.L.S).

"Tomo jugos sin dulce y bajo consumo de azúcar después de los exámenes del azúcar que salieron altos" (G.F.B.). 


\section{Alimentos fuente de vitaminas, minerales y fibra}

Todas las vitaminas son necesarias para un desenlace idóneo del embarazo. En algunos casos, la provisión de las vitaminas específicas puede cubrirse con la dieta, mientras que en otros es necesario aportar suplementos. Se ha constatado que el aporte complementario multivitamínico periconcepcional reduce el riesgo de alteraciones cardiacas en los lactantes si se inicia en los primeros momentos de la gestación. La mayoría de las recomendaciones sobre vitaminas y minerales indican aumentos en torno al $15 \%$ con respecto a los valores no gestacionales (Krause A, 1995).

En cuanto al consumo de fibra es necesario fomentar el consumo diario de pan y cereales integrales, verduras de hoja verde y amarilla, y frutas frescas y desecadas, con el fin de aportar minerales, vitaminas y fibra adicionales. En este estudio, este importante grupo está representado por las frutas y las verduras, se indagó acerca del consumo de frutas en su forma entera y en jugos y se tuvo en cuenta el consumo de verduras cocidas y crudas. $\mathrm{Al}$ analizar el consumo de verduras se observa una baja prevalencia de consumo de estas de manera diaria ( $10.8 \%$ para verduras cocidas y $18.3 \%$ para crudas), aun teniendo en cuenta el consumo de verduras cocidas y crudas de manera conjunta. En promedio, solo el $4 \%$ de las gestantes consumían verduras dos veces al día, que es la cantidad diaria recomendada de porciones de estos alimentos para la población en general (GABA Colombia 2014). De otra parte, hay un porcentaje importante de mujeres gestantes que no consumen verduras crudas (21.8\%), representadas comúnmente por las ensaladas y un $14,7 \%$ no consumen verduras cocidas.

Al revisar el consumo de verduras de manera agrupada (cocidas y crudas), el $40.1 \%$ de las gestantes las consume de manera diaria (de 1 a 3 o más veces por día), el 50\% las consume de manera semanal, el $3.7 \%$ las consume con intervalos mensuales y un $6.3 \%$ no las consumen de manera habitual.

La razón de este tipo de comportamientos alimentarios, está estrechamente relacionado a dos factores principales: los hábitos alimentarios y el costo de las verduras. Varias de las gestantes que asistieron a los grupos focales argumentan que las verduras son muy costosas, por lo cual, no son diariamente consumidas:

"Los lácteos son costosos, igual que las carnes, las frutas y las verduras" (G.F.B.).

"Las verduras que consumimos actualmente están altamente influenciados por lo que yo comía antes en el hogar." 
Sin embargo, y aunque, el consumo de las verduras es bajo, se podría presumir que el consumo era más bajo antes de la gestación, ya que varias participantes aseguran haber incrementado el consumo de verduras durante el embarazo debido a su preocupación por brindar los nutrientes necesarios para el bebé, así:

"En mi embarazo aumenté el consumo de frutas y verduras, estas últimas especialmente por el hierro." (G.F.B.).

En este testimonio, se puede evidenciar el incremento del consumo de verduras durante la gestación, sin importar que las razones por las cuales lo hagan sean erróneas como que las verduras son fuente de hierro. Otros ejemplos son:

“Antes comía menos frutas verduras y ahora, con el embarazo, consumo más” (G.L.S).

"Durante el embarazo se aumentó el consumo de frutas y verduras porque es bueno para el bebé” (G.F.B.).

Estos ejemplos muestran como, aunque el consumo de verduras no es un patrón habitual, este comportamiento puede variar cuando la salud del bebé cuando se sabe que algunos alimentos como las verduras son necesarias para el crecimiento y desarrollo adecuados, lo cual refuerza algunos hallazgos de investigaciones que aseguran que la única etapa en la cual se pueden hacer cambios alimentarios reales es durante la gestación, dado el interés por la salud del bebé.

Por otra parte, las gestantes también manifestaron su interés por la manipulación e inocuidad de los alimentos, diciendo que durante esta etapa estaban más atentas a la forma de lavar y guardar los alimentos:

"Ahora con el embarazo hice cambios y mayores cuidados con el lavado, higiene y conservación de alimentos" (G.L.S). 
Ilustración 19. Consumo de verduras cocidas y crudas en las gestantes por subcategoría de frecuencia

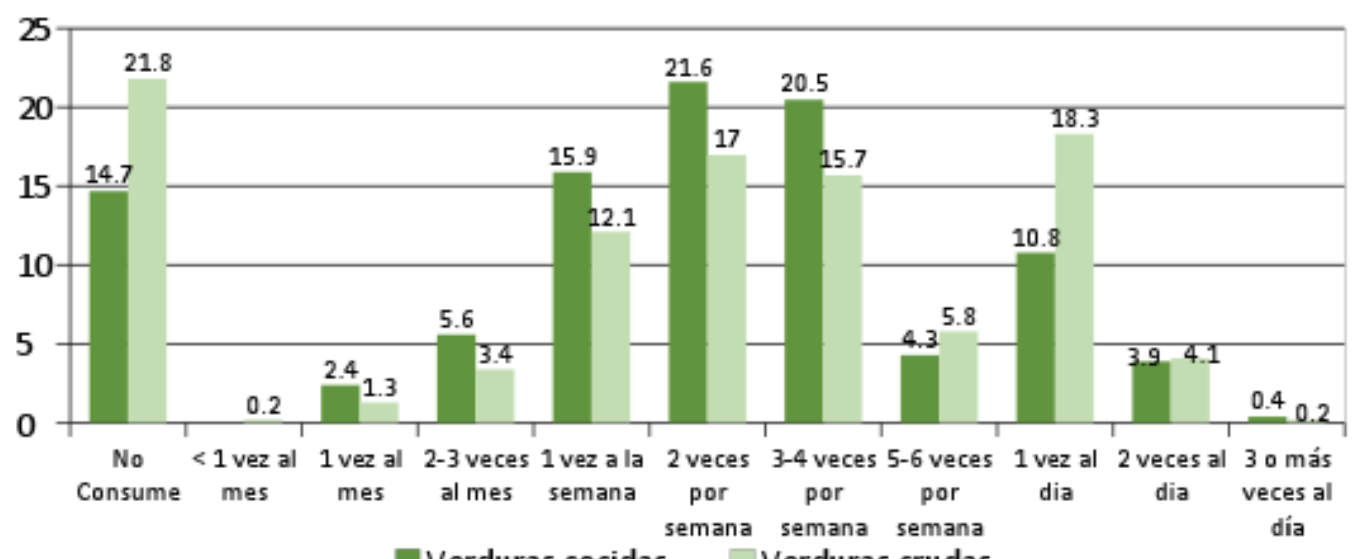

Fuente: INS-Grupo de Nutrición-2016

En cuanto al consumo de frutas, solo el $12.7 \%$ consume frutas enteras 3 o más veces al día (la recomendación de consumo de frutas para la población en general es de 3 porciones al día). En general se observa un bajo consumo de frutas, el $23.1 \%$ de las gestantes consume frutas enteras solo 1 vez al día, y el 22,2\% las consume 2 veces al día. De otra parte, el consumo de frutas en jugo fue más frecuente de manera diario, el $29.7 \%$ los consume 2 veces al día.

Ilustración 20. Consumo de frutas enteras y en jugo por subcategorías de frecuencia.

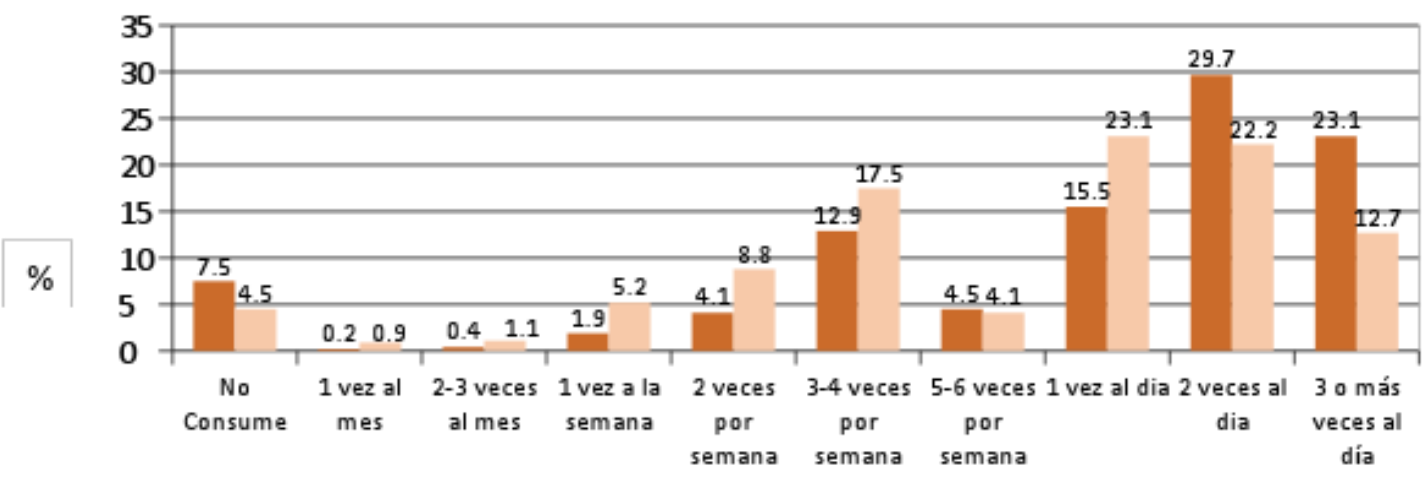

Frutas en jugo $\square$ Frutas enteras

Fuente: INS-Grupo de Nutrición-2016

$\mathrm{Al}$ análisis agrupado se encontró un consumo diario de frutas por el 87.9\%, sin embargo este es en su mayoría por el consumo de jugos de fruta que no representan una fuente importante de nutrientes. Un $10 \%$ consume frutas de manera semanal y un $1.1 \%$ con intervalos de tiempo mensual. 
Tabla 6. Descripción del análisis agrupado de consumo de frutas y verduras en gestantes

\begin{tabular}{|c|c|c|c|c|c|c|c|c|c|c|c|c|}
\hline \multirow{2}{*}{ Alimentos } & \multicolumn{3}{|c|}{ Diario } & \multicolumn{3}{|c|}{ Semanal } & \multicolumn{3}{|c|}{ Mensual } & \multicolumn{3}{|c|}{ No consume } \\
\hline & $\mathbf{n}$ & $\%$ & IC & $n$ & $\%$ & IC & $\mathbf{n}$ & $\%$ & IC & $\mathbf{n}$ & $\%$ & IC \\
\hline Frutas & 408 & 87,9 & {$[84.6,90.6]$} & 47 & 10,1 & {$[7.7,13.2]$} & 5 & 1,1 & {$[0.4,2.6]$} & 4 & 0,9 & {$[0.3,2.3]$} \\
\hline Verduras & 186 & 40,1 & {$[35.7,44.6]$} & 232 & 50 & {$[45.4,54.6]$} & 17 & 3,7 & {$[2.3,5.8]$} & 29 & 6,3 & {$[4.4,8.9]$} \\
\hline
\end{tabular}

Para revisar el consumo de algunas fuentes de fibra adicionales, se indagó por el consumo de alimentos integrales (avena, productos de panadería integrales), encontrándose un bajo consumo de los mismos, solo el $11 \%$ consume estos alimentos de manera diaria $(8.6 \% 1$ vez al día). Un alto porcentaje de las gestantes no consume alimentos integrales.

Ilustración 21. Consumo de alimentos integrales

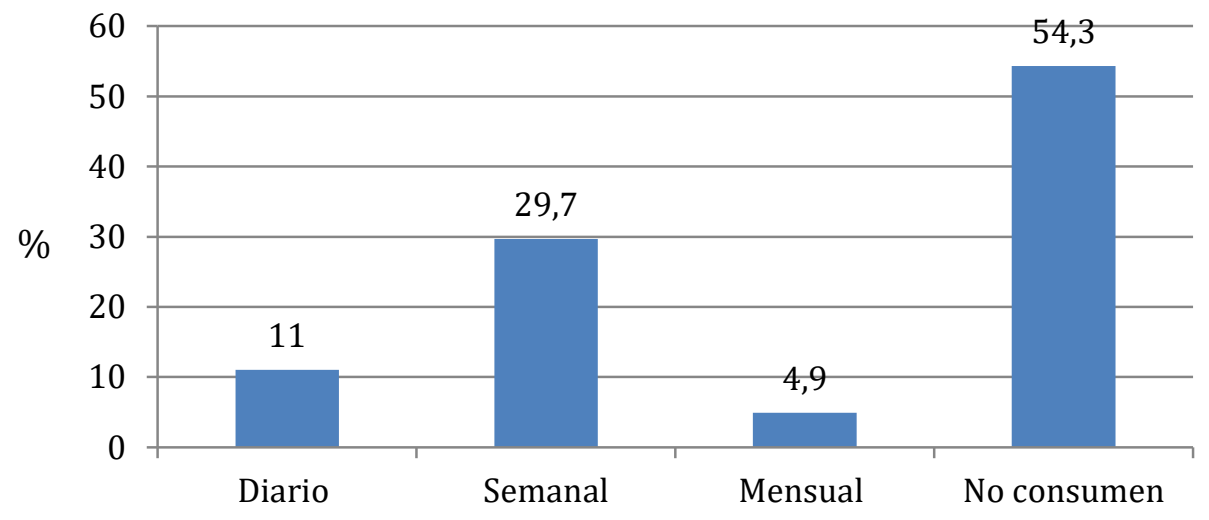

Fuente: INS-Grupo de Nutrición-2016

Los grupos focales evidenciaron que el consumo de frutas es bajo, especialmente por los hábitos de las familias, en los cuales no es común tener las frutas en su menú diario:

"En mi familia no tenemos el hábito de consumir frutas" (G.L.S).

De igual manera argumentan razones de precio y del alto uso de químicos en la producción de frutas para no consumir las porciones recomendadas por los profesionales:

"Las frutas y verduras son ricas pero costosas, no es una costumbre en el hogar" (G.L.S).

"Las frutas ya no son tan naturales como antes, tiene muchos químicos" (G.F.B.).

\section{Consumo de alimentos fuente de grasas}


El consumo de fuentes de grasas para este estudio se definió a partir de la frecuencia de consumo de embutidos; margarina, mantequilla, crema de leche; alimentos fritos, comidas rápidas y snacks y representan un grupo de alimentos que pueden llegar a ser un factor de riesgo para enfermedad cardiovascular, sobrepeso y obesidad si no se consumen con moderación tanto en la gestación como a nivel general.

\section{Embutidos}

Estos alimentos en su mayoría, representan más una fuente de grasa que de proteínas. El consumo de embutidos o carnes procesadas fue bajo, el $42.2 \%$ de las gestantes no los consumen de manera regular. Su prevalencia más alta de consumo se da de manera semanal por el $33.8 \%$ de las gestantes $(14.2 \% 1$ vez a la semana, $10.8 \% 2$ veces por semana, $7.3 \%$ 3-4 veces por semana y el $1.5 \%$ los consume 5 a 6 veces por semana). No hubo diferencias estadísticamente significativas por grupos de edad ( $>0.005)$

Margarina, mantequilla, crema de leche

Estos alimentos se deben consumir con moderación durante la gestación ya que pueden representar un riesgo para la salud cardiovascular por su alto contenido de grasas saturadas. El consumo de estos alimentos fue más frecuente de manera semanal (17.1\%) y un $6.5 \%$ de las gestantes reportaron no consumirlos de manera habitual.

Ilustración 22. Consumo de alimentos fuentes de grasas.

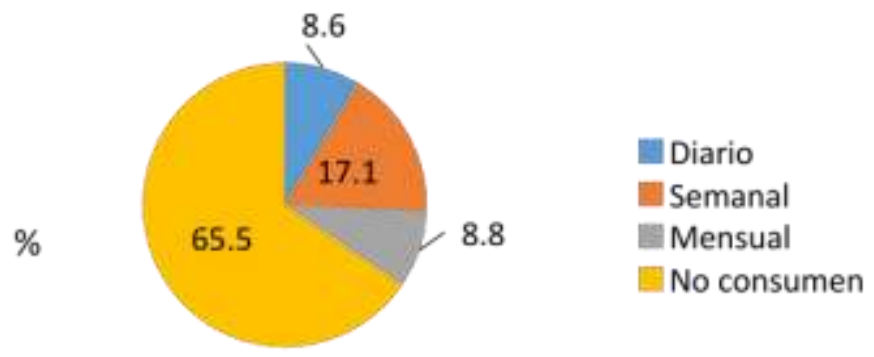

Fuente: INS-Grupo de Nutrición-2016

Los alimentos fritos fueron ampliamente consumidos por las gestantes, aunque se presentó con mayor proporción de manera semanal, el $44.6 \%$ los consume más de 2 veces por semana y el $19.3 \%$ los consume de manera diaria. Solo el $13.6 \%$ de las gestantes reportaron no consumir alimentos fritos. 


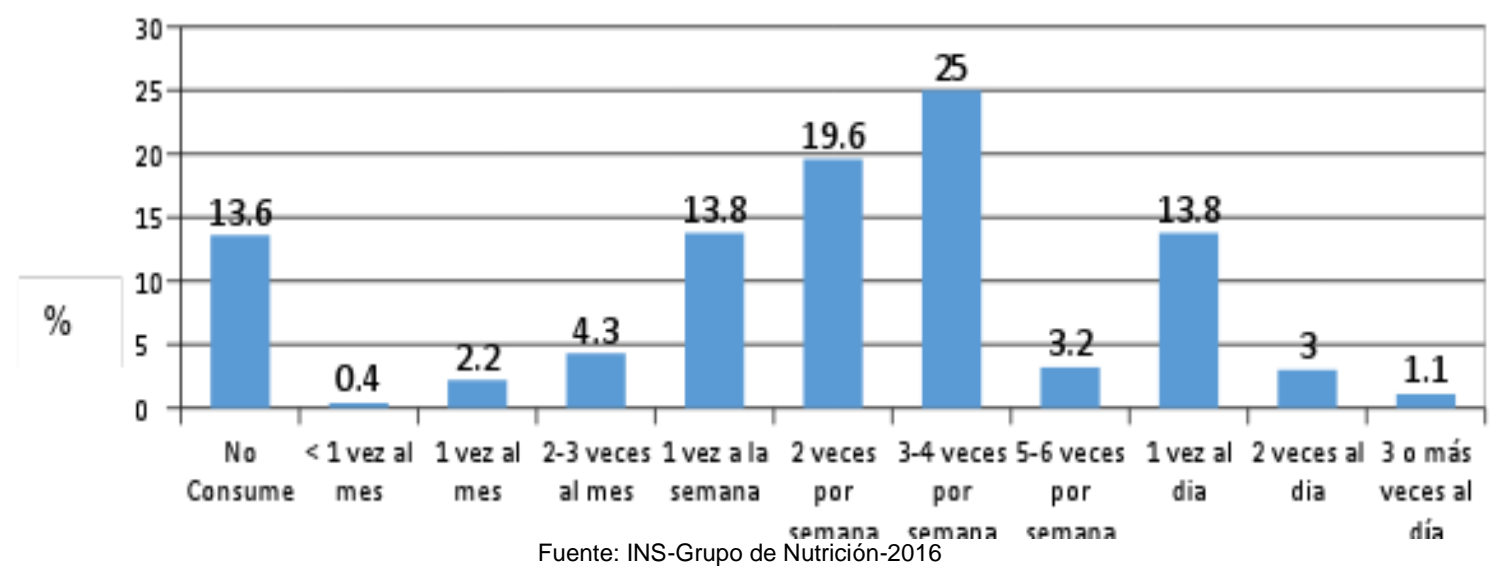

Otra fuente de grasas saturadas y trans son las comidas rápidas tipo hamburguesas, fritos (empanadas, pasteles de papa, etc.). En esta población se presentó un bajo consumo de estos alimentos ya que el $48.5 \%$ de las mujeres reportaron no consumirlas y su frecuencia mayor de consumo se dio de manera mensual (2.86\%) y semanal (22.2\%), sin embargo se debe hacer énfasis en el control sobre el consumo de estos alimentos sobre todo para el manejo del peso durante la gestación y prevención de enfermedades cardiovasculares.

Ilustración 24. Consumo de comidas rápidas en la población de estudio

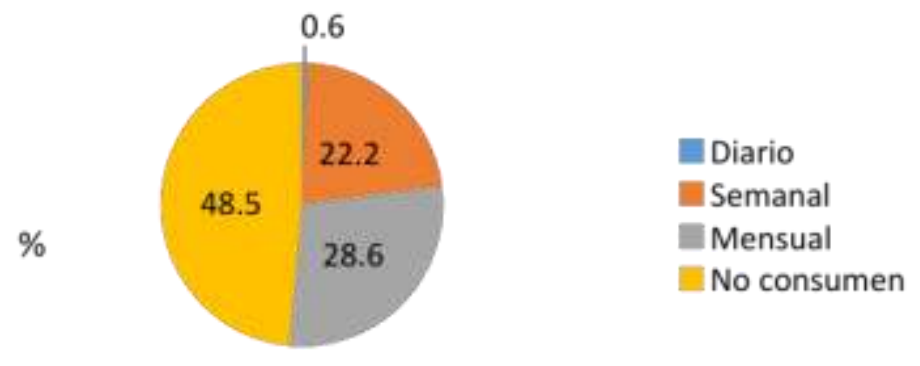

Fuente: INS-Grupo de Nutrición-2016

Finalmente, los snacks o productos de paquetes, representan de la misma manera una fuente de grasas saturadas y trans y aunque la mitad de las gestantes no los consumen de manera frecuente, otro porcentaje importante de las gestantes consumen estos productos de manera habitual con intervalos de tiempo semanal (26.6\%) y mensual (19.2\%). 


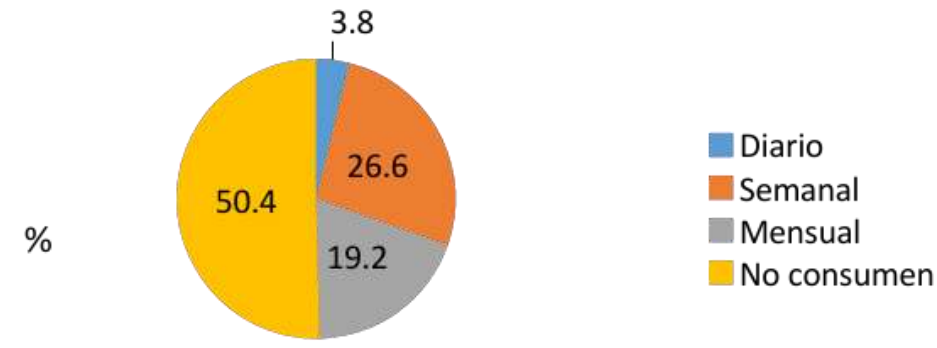

Fuente: INS-Grupo de Nutrición-2016

Con relación a las opiniones dadas de las mujeres gestantes en los grupos focales, algunas de ellas dijeron que durante la gestación realizaron los siguientes cambios:

"Bajamos el consumo de comidas rápidas porque no son buenas, por las grasas que contienen y porque hacen que uno aumente mucho de peso" (G.L.S).

"A mí me recomendaron cambiar mi forma de comer, como por ejemplo con el tema de bajarle a las grasas. (G.F.B.).

"También influye los hábitos alimentarios, acorde a como se comía en la familia, pero se hacen cambios como la disminución de alimentos fritos y carnes con gordo. (G.F.B.).

"Recomendaron consumir en el embarazo cabeza de pescado, por la grasa que contiene" (G.L.S).

Ninguna de las mujeres participantes opinaron haber incrementado el consumo de alimentos fritos o grasosos, por el contrario varias afirmaron su intención de reducir el consumo de estos alimentos o cambiar su fuente debido a que son conscientes de lo perjudicial que es su alto consumo. Estas opiniones son útiles para soportar la importancia de invertir esfuerzos durante la gestación para la promoción de la reducción de alimentos fuente de grasa, dado que es una etapa de la vida donde se pueden hacer cambios en los patrones alimentarios, los cuales probablemente permanezcan durante el resto de la vida.

\section{Tiempos de comidas}

La recomendación de tiempos de comidas para la población colombiana en general es de 5 al día y aplica igual para las gestantes, que son tres principales: desayuno, almuerzo y comida o cena, y dos meriendas pequeñas una en la mañana y otra en la tarde. El estudio mostró que el $38.1 \%$ de las gestantes cumple con la recomendación de las 5 comidas 
diarias, el 40.7\% solo consume los tres tiempos principales diariamente y solo el 13.2 consume menos de 3 tiempos de comidas. No se presentaron diferencias estadísticamente significativas por grupos de edad $(\mathrm{p}>0.005)$.

Tabla 7. Tiempos de comidas vs recomendación

\begin{tabular}{|l|c|c|c|c|c|c|}
\hline \multirow{2}{*}{ Tiempos de comidas } & \multicolumn{9}{|c|}{ DIARIO } \\
\cline { 2 - 8 } & \multicolumn{2}{|c|}{$<18$ años } & \multicolumn{2}{c|}{$>18$ años } & \multicolumn{2}{c|}{ Total } \\
\cline { 2 - 8 } & $\mathrm{n}$ & $\%$ & $\mathrm{n}$ & $\%$ & $\mathrm{n}$ & $\%$ \\
\hline $\begin{array}{l}\text { Gestantes que consumen 5 tiempos de comidas a } \\
\text { diario }\end{array}$ & 37 & 8,009 & 139 & 30,09 & 176 & 38,1 \\
\hline $\begin{array}{l}\text { Gestantes que consumen solo los tres tiempos } \\
\text { principales a diario }\end{array}$ & 39 & 8,442 & 151 & 32,68 & 188 & 40,7 \\
\hline $\begin{array}{l}\text { Gestantes que consumen menos de 3 tiempos de } \\
\text { comidas }\end{array}$ & 8 & 1,732 & 53 & 11,47 & 61 & 13,2 \\
\hline \multicolumn{1}{|c|}{ Fuente: INS-Grupo de Nutrición-2016 }
\end{tabular}

Al analizar por tiempo de comida de manera diaria, se encontró que el $87.7 \%$ de las gestantes consume desayuno a diario, es decir que un $12.3 \%$ de las mujeres dejan de desayunar o varios días a la semana. Solo la mitad de las madres consumen medias nueves y onces de manera diaria y hay un $30 \%$ de las gestantes que consume algo después de la comida o cena.

Las mujeres gestantes participantes en los grupos focales confirmaron que consumen principalmente desayuno y almuerzo y aunque la frecuencia de la alimentación ha aumentado durante la gestación, es porque sienten más hambre entre comidas pero no porque tengan horarios específicos para consumir onces y medias nueves:

"Lo que más como es el almuerzo y el desayuno". (G.L.S).

"A veces como algo entre comidas pero no onces o medias nueves como tal" (G.F.B.).

"Uno come cuando le da hambre es decir a cada rato" (G.L.S).

El consumo de comida es menos frecuente que el desayuno y el almuerzo, al igual que el refrigerio nocturno, recomendado para antes de dormir, es menos frecuente que las onces y medias nueves:

"No es muy habitual consumir refrigerio antes de acostarse, a veces a media noche se levantaba uno a comer algo, tomar leche o algo pequeño". (G.L.S).

"Con el embarazo se cambió el tema de los horarios de comida, yo trataba de comer en horarios establecidos" (G.F.B.). 
"En cantidades, se incrementó el consumo de alimentos en cantidad porque da mucha ansiedad de comer, al igual que en la lactancia, las cantidades eras grandes porque da mucha hambre" (G.L.S).

Finalmente, aunque la frecuencia de la alimentación aumenta durante la gestación, las mujeres no cumplen la recomendación médica de consumir de 5 a 6 tiempos de comida, al parecer, solo se rigen por la sensación de hambre o las ganas de comer algo.

Tabla 8. Consumo diario por tiempo de comida

\begin{tabular}{|c|c|c|c|c|c|c|c|c|c|}
\hline \multirow{3}{*}{$\begin{array}{c}\text { Tiempos de } \\
\text { comidas } \\
\text { prevalencias } \\
\text { simples }\end{array}$} & \multicolumn{9}{|c|}{ DIARIO (1 vez día) } \\
\hline & \multicolumn{3}{|c|}{$<18$ años } & \multicolumn{3}{|c|}{$>18$ años } & \multicolumn{3}{|c|}{ Total } \\
\hline & $\mathrm{n}$ & $\%$ & IC & $\mathrm{n}$ & $\%$ & IC & $\mathrm{n}$ & $\%$ & IC \\
\hline Desayuno & 77 & 85,6 & {$[76.7,91.4]$} & 330 & 88,2 & {$[84.5,91.1]$} & 407 & 87,7 & {$[84.4,90.4]$} \\
\hline Nueves & 51 & 56,7 & {$[46.3,66.5]$} & 201 & 53,7 & {$[48.7,58.8]$} & 252 & 54,3 & {$[49.7,58.8]$} \\
\hline Almuerzo & 81 & 90 & {$[81.8,94.7]$} & 338 & 90,4 & {$[86.9,93.0]$} & 419 & 90,3 & {$[87.2,92.7]$} \\
\hline Onces & 56 & 62,2 & {$[51.8,71.6]$} & 197 & 52,7 & {$[47.6,57.7]$} & 253 & 54,5 & {$[50.0,59.0]$} \\
\hline Comida o cena & 80 & 88,9 & {$[80.5,93.9]$} & 307 & 82,1 & {$[77.8,85.7]$} & 387 & 83,4 & {$[79.7,86.5]$} \\
\hline $\begin{array}{l}\text { Algo después de la } \\
\text { comida }\end{array}$ & 31 & 34,4 & {$[25.4,44.8]$} & 108 & 28,9 & {$[24.5,33.7]$} & 139 & 30 & {$[25.9,34.3]$} \\
\hline
\end{tabular}

\section{Preferencias alimentarias de las gestantes}

Las gestantes manifestaron mayores preferencias por el consumo de frutas enteras (58.6\%) y en jugo (58.6\%). Se observó poca preferencia por las verduras crudas $(28.2 \%)$ y cocidas (38.8\%). Las comidas rápidas fueron las menos apetecidas por las gestantes. Se presentó una diferencia estadísticamente significativa para el consumo de alimentos de paquete o snacks que fue mayor en las menores de 18 años $(\mathrm{P}=0.001)$. Dato importante para reforzar la educación nutricional para este aspecto en gestantes adolescentes.

Tabla 9. Preferencias alimentarias de las gestantes

\begin{tabular}{|c|c|c|c|c|c|c|c|c|c|c|}
\hline \multirow{3}{*}{ Alimentos } & \multicolumn{9}{|c|}{ PREFERENCIAS POR GRUPO DE EDAD } & \multirow{3}{*}{ Valor $\mathbf{P}$} \\
\hline & \multicolumn{3}{|c|}{$<18$ años } & \multicolumn{3}{|c|}{$>18$ años } & \multicolumn{3}{|c|}{ Total } & \\
\hline & $\mathbf{n}$ & $\%$ & IC & $\mathbf{n}$ & $\%$ & IC & $\mathbf{n}$ & $\%$ & IC & \\
\hline Frutas en jugo & 49 & 54,4 & {$[44.1,64.4]$} & 59,6 & 223 & {$[54.6,64.5]$} & 272 & 58,6 & {$[54.1,63.0]$} & 0,375 \\
\hline Frutas enteras & 72 & 80 & {$[70.4,87.0]$} & 75,9 & 284 & {$[71.3,80.0]$} & 356 & 76,7 & {$[72.6,80.4]$} & 0,394 \\
\hline Verduras cocidas & 24 & 26,7 & {$[18.5,36.8]$} & 41,7 & 156 & {$[36.8,46.8]$} & 180 & 38,8 & {$[34.4,43.3]$} & 0,005 \\
\hline Verduras crudas & 19 & 21,1 & {$[13.9,30.8]$} & 29,9 & 112 & {$[25.5,34.8]$} & 131 & 28,2 & {$[24.3,32.5]$} & 0,073 \\
\hline Comidas rápidas & 14 & 15,6 & {$[9.4,24.6]$} & 10,7 & 40 & {$[7.9,14.3]$} & 54 & 11,6 & {$[9.0,14.9]$} & 0,242 \\
\hline $\begin{array}{l}\text { Alimentos de } \\
\text { paquete }\end{array}$ & 24 & 26,7 & {$[18.5,36.8]$} & 10,7 & 40 & {$[7.9,14.3]$} & 64 & 13,8 & {$[10.9,17.3]$} & 0,001 \\
\hline Gaseosas refrescos & 18 & 20 & {$[13.0,29.6]$} & 19,3 & 72 & {$[15.6,23.6]$} & 90 & 19,4 & {$[16.0,23.3]$} & 0,873 \\
\hline Otros & 13 & 14,4 & {$[8.6,23.3]$} & 16,8 & 63 & {$[13.4,21.0]$} & 76 & 16,4 & {$[13.3,20.0]$} & 0,567 \\
\hline
\end{tabular}


La siguiente tabla presenta la lista de todos los alimentos indagados con las prevalencias más altas de consumo que presentaron, así como su porcentaje de no consumo.

Tabla 10. Resumen de frecuencia de consumo por alimento

\begin{tabular}{|c|c|c|c|}
\hline Alimento & Frecuencia & $\begin{array}{l}\text { \% Mayor } \\
\text { Frecuencia }\end{array}$ & $\begin{array}{l}\% \text { No } \\
\text { consumen }\end{array}$ \\
\hline Leche & $102 \mathrm{v} / \mathrm{d}$ & $\begin{array}{c}57,1 \\
(26,3 \% 2 \mathrm{v} / \mathrm{d}-25,4 \% \\
1 \mathrm{v} / \mathrm{d})\end{array}$ & 2,4 \\
\hline Queso, kumis, yogur & $2 \mathrm{v} / \mathrm{s}$ & 17,5 & 12,3 \\
\hline Huevos & $1 \mathrm{v} / \mathrm{d}$ & 37,9 & 3,7 \\
\hline Carnes rojas & $3-4 v / s$ & 33,4 & 10,1 \\
\hline Pollo o gallina & $3-4 v / s$ & 30,4 & 10,6 \\
\hline Atún o sardinas & $1 \mathrm{v} / \mathrm{s}$ & 20,9 & 50,6 \\
\hline Pescados o mariscos & $1 \mathrm{v} / \mathrm{s}$ & 14,9 & 51,1 \\
\hline $\begin{array}{l}\text { Embutidos } \\
\text { (salchichas, chorizo, jamón) }\end{array}$ & $1 \mathrm{v} / \mathrm{s}$ & 14,2 & 44,2 \\
\hline Morcilla o vísceras de res & $1 \mathrm{v} / \mathrm{m}$ & 8,2 & 75,6 \\
\hline Menudencias de pollo & $1 \mathrm{v} / \mathrm{m}$ & 9,7 & 62,1 \\
\hline $\begin{array}{l}\text { Granos secos } \\
\text { (fríjol, lenteja, arveja, garbanzos) }\end{array}$ & $3-4 v / s$ & 30 & 4,1 \\
\hline Arroz o pasta & $2 \mathrm{v} / \mathrm{d}$ & 52,2 & 0,4 \\
\hline Pan, arepa o galletas & $1 \mathrm{v} / \mathrm{d}$ & 44 & 1,9 \\
\hline Papa, plátano, yuca & $1 \mathrm{v} / \mathrm{d}$ & 27,6 & 1,9 \\
\hline $\begin{array}{l}\text { Verduras cocidas } \\
\text { (pepinos, zanahorias, ahuyama, arveja verde, } \\
\text { habichuela, remolacha) }\end{array}$ & $2 v / s$ & 21,6 & 14,7 \\
\hline $\begin{array}{l}\text { Verduras crudas } \\
\text { (Cebolla, tomate, espinaca, } \\
\text { zanahoria, lechuga, repollo) }\end{array}$ & $1 \mathrm{v} / \mathrm{d}$ & 18,3 & 21,8 \\
\hline Frutas en jugo & $2 v / d$ & 29,7 & 7,5 \\
\hline Frutas enteras & $1 \mathrm{v} / \mathrm{d}$ & 23,1 & 4,5 \\
\hline $\begin{array}{l}\text { Comidas rápidas } \\
\text { (empanadas, hamburguesas, } \\
\text { perros calientes, pizza, arepas...) }\end{array}$ & $1 \mathrm{v} / \mathrm{s}$ & 14,4 & 48,5 \\
\hline Mantequilla, crema de leche, manteca de cerdo & $1 \mathrm{v} / \mathrm{d}$ & 6,9 & 65,5 \\
\hline Café o té & $1 \mathrm{v} / \mathrm{d}$ & 14,4 & 33,8 \\
\hline Panela, azúcar, miel & $2 \mathrm{v} / \mathrm{d}$ & 33,2 & 5,6 \\
\hline Gaseosas o refrescos & $1 \mathrm{v} / \mathrm{s}$ & 14,9 & 37,7 \\
\hline $\begin{array}{l}\text { Alimentos de paquete } \\
\text { (papas, chitos, chicharrones, plátano...) }\end{array}$ & $1 \mathrm{v} / \mathrm{s}$ & 14 & 50,4 \\
\hline Bienestarina & $2 \mathrm{v} / \mathrm{s}$ & 5,8 & 75,2 \\
\hline Alimentos fritos & $3-4 v / s$ & 25 & 13,6 \\
\hline Golosinas o dulces & $1 \mathrm{v} / \mathrm{d}$ & 78 & 26,7 \\
\hline $\begin{array}{l}\text { Alimentos bajos en calorías o light (mayonesa, } \\
\text { chocolates, azúcar, postres, yogurt) }\end{array}$ & $2 v / s$ & 2,6 & 86,2 \\
\hline Alimentos integrales (galletas, avena, pan...) & $1 \mathrm{v} / \mathrm{s}$ & 11,6 & 54,3 \\
\hline
\end{tabular}




\begin{tabular}{|l|l|c|c|} 
Suplementos o complementos nutricionales & $1 \mathrm{v} / \mathrm{d}$ & 22,8 & 62,1 \\
\hline Alimentos en la calle & $1 \mathrm{v} / \mathrm{s}$ & 11,2 & 58 \\
\hline
\end{tabular}

De acuerdo a lo anterior, la alimentación de las gestantes del estudio se caracteriza por el alto consumo de alimentos fuente de carbohidratos y energía, en este sentido se observa un patrón de dieta en que predominan alimentos como arroz, pastas, tubérculos y plátanos así como productos de panadería que son consumidos a diario y en gran porcentaje varias veces al día, situación que no es diferente a la reportada por la ENSIN 2010 para este mismo grupo poblacional y para la población en general. El consumo de azúcar, panela y miel se presentó de manera diaria en 7 de cada 10 gestantes. Las razones encontradas para este patrón de consumo están dadas tanto por los hábitos alimentarios como por el costo de estos alimentos.

El consumo de lácteos, carnes, frutas y verduras es bajo en general, la mayoría de gestantes consumen estos alimentos con intervalos de tiempo semanal y fue más común en gestantes del estrato 3. Así mismo, el consumo de estos alimentos importantes durante la gestación fue mayor en las gestantes con mayor nivel educativo. Al parecer, el costo de estos alimentos conlleva a un bajo consumo, al igual que el hábito de consumo en el caso de las frutas y las verduras. Sin embargo, las mujeres manifestaron tanto el conocimiento de la importancia del consumo de estos alimentos como la intención y acción de incrementar su consumo para el beneficio de la salud de ellas y sus hijos.

Más de la mitad de las gestantes no consume de manera habitual fuentes importantes de grasas saturadas como embutidos, margarina o mantequilla, ni comidas rápidas, sin embargo 5 de dada 10 consumen alimentos fritos de manera habitual ya que los consumen más de 3 veces por semana. Acorde a lo manifestado por las mujeres, durante la gestación son más conscientes de la importancia de reducir el consumo de grasas y embutidos, especialmente dada su relación con el incremento de peso.

El huevo, importante por ser fuente de proteínas y ácidos grasos esenciales, fue un alimento ampliamente consumido por las gestantes ya que 4 de cada 10 lo consumen a diario y 4 de 10 semanalmente. El costo accesible y el hábito alimentario del consumo del huevo hacen que sea consumido de manera frecuente en los hogares encuestados. Se presentó un bajo consumo de vísceras en esta población ya que 8 de cada 10 mujeres 
gestantes no las consume de manera habitual. Estos alimentos no son parte del patrón alimentario de la población encuestada, por lo cual, aunque conocen los beneficios durante el embarazo, no hace parte de la alimentación usual.

3 de cada 10 gestantes consumen a diario 5 tiempos de comidas, 4 de cada 10 consumen los 3 tiempos principales y 1 de cada 10 consume menos de 3 tiempos. Los tiempos de comida consumidos con mayor frecuencia de manera diaria fueron el almuerzo y el desayuno y 1 de cada 10 gestantes no consume estos tiempos de manera diaria. Las medias nueves y onces son los tiempos de comida menos consumidos solo la mitad de las gestantes los realizan de manera diaria. Es evidente el aumento de la frecuencia de los alimentos, sin embargo, esto está dado por la ganas de comer entre comidas, más que por las recomendaciones médicas de comer de manera fraccionada.

Finalmente, se evidenció que el consumo de alimentos mejora durante la gestación, por la intención de cuidar su salud y la de su hijo, pero no siempre cumple con las recomendaciones dadas por los profesionales de la salud y prefieren guiarse por sus hábitos alimentarios, recomendaciones de sus familiares, costo de los alimentos y preferencias o ganas de comer ciertos alimentos particulares durante el embarazo. 


\section{Capítulo III}

\section{Consumo mediático de las gestantes}

El consumo mediático abarca el uso y los hábitos asociados a los diferentes medios de comunicación, esto es la televisión y el cine, así como medios impresos: los libros, revistas y periódicos y medios digitales o impresos, la radio y en general la interacción (Cifuentes \& Reyes, 2014)que se realiza con los nuevos medios como el internet, las aplicaciones y los juegos. (Cifuentes \& Reyes, 2014).

Con el objeto de conocer cuáles son los hábitos de consumo mediáticos de un grupo de gestantes de Bogotá de estrato 1 y 2, en noviembre de 2016 se realizaron entrevistas a 202 mujeres de las 20 localidades del Distrito Capital beneficiarias del Servicio de Atención Integral a la Primera Infancia en el Ámbito Familiar de la Secretaría de Integración Social de la ciudad de Bogotá.

Del total de las mujeres consultadas, el 2,4\% eran menores de 15 años, el $23.7 \%$ tenía entre 15 y 18 años 11 meses, el grupo más representativo fue el de 19 a 34 años 11 meses con $66.6 \%$ y el $7.3 \%$ de las gestantes eran mayores de 35 años.

Tabla 11. Población de gestantes participantes en la encuesta del consumo de medios

\begin{tabular}{|l|c|}
\hline \multicolumn{1}{|c|}{ Edad } & $\%$ \\
\hline$<15$ años & 2,4 \\
\hline 15 a 18 años & 23,7 \\
\hline 19 a 34años & $\mathbf{6 6 , 6}$ \\
\hline 35 y más & 7,3 \\
\hline Total & 100,0 \\
\hline \multicolumn{2}{|c|}{ Fuente: INS-Grupo de Nutrición-2016 } \\
\hline
\end{tabular}

A través de este instrumento se recolectó la información necesaria para comprender de qué manera las participantes narran y dan sentido a la experiencia de alimentar a sus hijas e hijos, así como de las prácticas de información más frecuentemente usadas. Una vez consolidada la información, se convocó a una muestra representativa de mujeres gestantes y sus acompañantes, de las localidades de Suba y Bosa, para validar los resultados obtenidos, lo que ayudó a ratificar las preferencias mediáticas de las participantes. En la 
misma sesión, se presentaron propuestas de formatos para ir definiendo otras alternativas para informar sobre prácticas alimentarias.

A continuación se describen los resultados obtenidos en estas evaluaciones, que aportan en la propuesta de la estrategia de comunicación que se planteará en el marco del estudio longitudinal "Efecto de las prácticas alimentarias de mujeres gestantes y sus hijas e hijos hasta los 24 meses de edad sobre el estado nutricional, en una población atendida por la Secretaría Distrital de Integración Social de la Alcaldía Mayor de Bogotá".

\subsection{Características del consumo de medios}

Para determinar las características del consumo de medios de las mujeres gestantes, se establecieron las siguientes variables: a) consumo de medios con relación a la edad de la gestante; b) preferencia de medios para recibir cualquier tipo de información; c) medio que utiliza para buscar u obtener información sobre alimentación saludable; d) medio que preferiría para recibir información sobre alimentación saludable; y e) interés en recibir información sobre alimentación saludable independiente del medio que se utilice.

Estos son los resultados arrojados en cada una de ellas:

a) Consumo de medios con relación a la edad de la gestante: se definieron dos categorías, las menores de 18 años y las mayores de 18 años. Para las primeras sus preferencias están en televisión con 45.7\%; WhatsApp 17.1\%; internet y Facebook 14.3\% y radio 8.6\%. Por su parte las mayores de 18 años respondieron que la televisión 46\%; internet $18 \%$, radio 11\%; WhatsApp 8\%; Facebook 7\%; prensa 4\%, medios comunitarios 3\%, revistas y twitter $1 \%$.

Esto nos muestra una preferencia global por la televisión, seguidas de las redes sociales a excepción de twitter, mientras poco interés en medios impresos.

Determinar que la televisión es el medio preferido para recibir información, seguido del uso de redes sociales es predecible y se ratifica con los resultados presentados en la Encuesta de Calidad de Vida del DANE, 2017, que destaca :"... En 2017, el 93,9\% de hogares manifestaron tener al menos un televisor ya sea convencional, LCD, plasma o LED. La TV por suscripción pasó de 69,9\% en el año 2016 a 73,4\% en 2017. El 44,3\% de los hogares manifestaron tener algún tipo de computador (computador de escritorio, portátil o tableta). La conexión a Internet pasó de 45,8\% en 2016 a 50,0\% en 2017”. 
En cuanto a Tecnologías de información y comunicación los resultados a nivel nacional señalan que “...del total de personas que manifestaron tener celular $(73,2 \%)$, el $71,2 \%$ tenía teléfono inteligente (Smartphone) para el total nacional, mientras que el 29,5\% reportó tener celular convencional."

Al hacer la validación de estos resultados con las mujeres gestantes asistentes a los grupos focales realizados en Soacha y Bosa, en adelante GFS y GFB, respectivamente, se obtuvieron comentarios como: "Televisión es el medio que más utilizo para recibir información" (GFB). "Para información en general yo prefiero ver televisión o usar internet" (GFB). "Yo uso mucho internet" (GFS).

También se pudo establecer que los canales de televisión más vistos fueron: Caracol, RCN y City TV que son privados, de los cuales los dos primeros tienen cobertura nacional, aunque los tres se pueden sintonizar en televisión por cable.

Ilustración 26. Consumo de medios con relación a la edad de la gestante

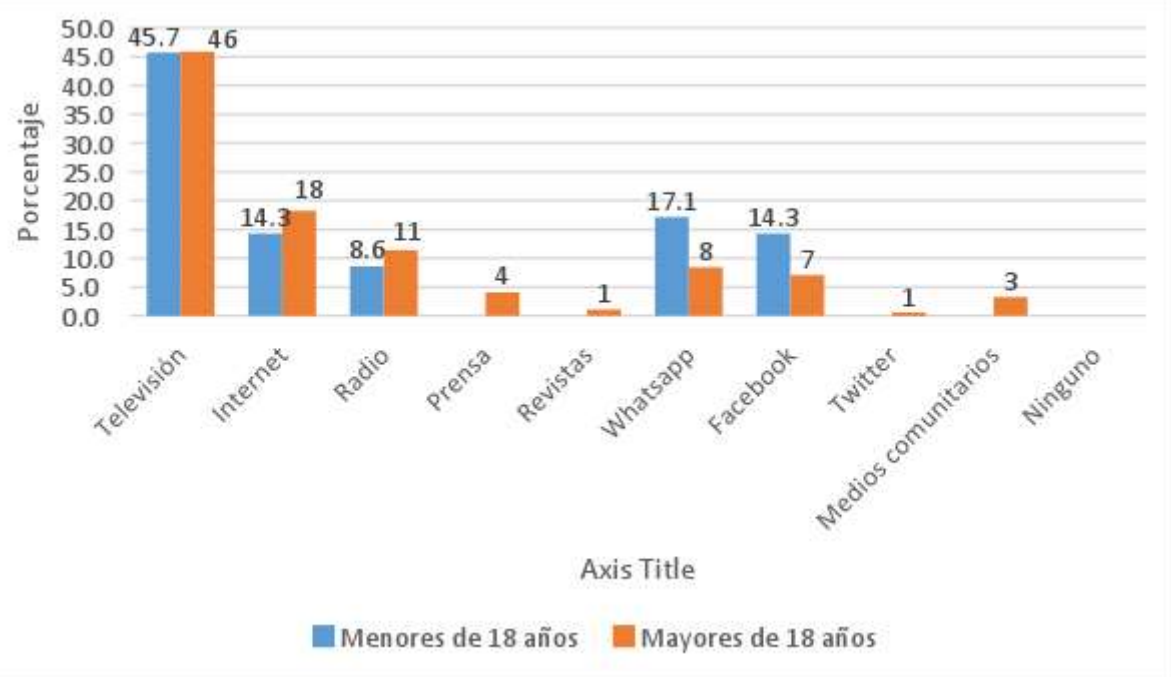

b) Preferencia de medios para recibir cualquier tipo de información: Con el ánimo de conocer las preferencias del consumo de medios de comunicación, se preguntó sobre cuál era el medio que más les gustaba para recibir información, resultando que al igual que en la pregunta anterior, la población del estudio prefiere, en su orden, la televisión, el internet y el WhatsApp para recibir información, mientras que la radio, la prensa y los medios comunitarios son los menos usados. Esto permite evidenciar la preferencia por lo visual, (imágenes, ilustraciones, gráficas, entre otras) sobre lo impreso, la radio o los medios que requieran interacción directa con las personas (canales comunitarios). 
Las participantes en los grupos focales, dijeron que aun presentan algunas restricciones de acceso para usar internet, por lo cual, el medio que está más alcance es la televisión y también manifiestan usar el radio para recibir información: "No todos tienen internet en sus celulares o en sus casas, por eso es más fácil prender el televisor" (GFB). "Yo no uso casi el internet y por televisión no nos informamos porque dan es novelas" (GFB). "Escucho radio y noticias en televisión" (GFS). "Radio y televisión para información en general" (GFS).

Ilustración 27. Preferencia de medios para recibir cualquier tipo de información

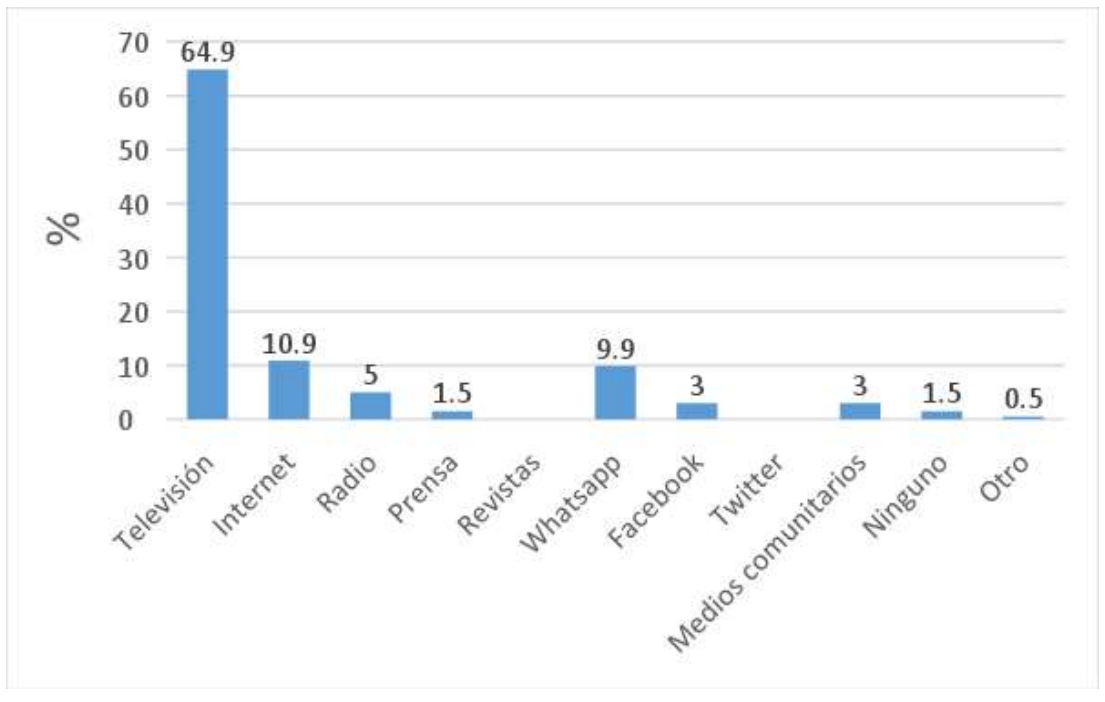

c) Medio que utiliza para buscar u obtener información sobre alimentación saludable: específicamente para obtener este tipo de información, las gestantes recurren a la televisión en un $40.6 \%$, a internet en un $28.7 \%$, a los medios comunitarios en un $8.9 \%$ y a Facebook 7.4\%. Se destaca en esta variable que el $26.7 \%$ de las consultadas no recurren a ningún medio de comunicación para informase o conocer sobre el tema y que redes sociales como WhatsApp no son protagonistas. Continúan siendo los medios menos usados los impresos (prensa, revistas), los medios comunitarios y twitter que no ha marcado en ninguna de las variables. 
Ilustración 28. Medio que utiliza para buscar u obtener información sobre alimentación saludable

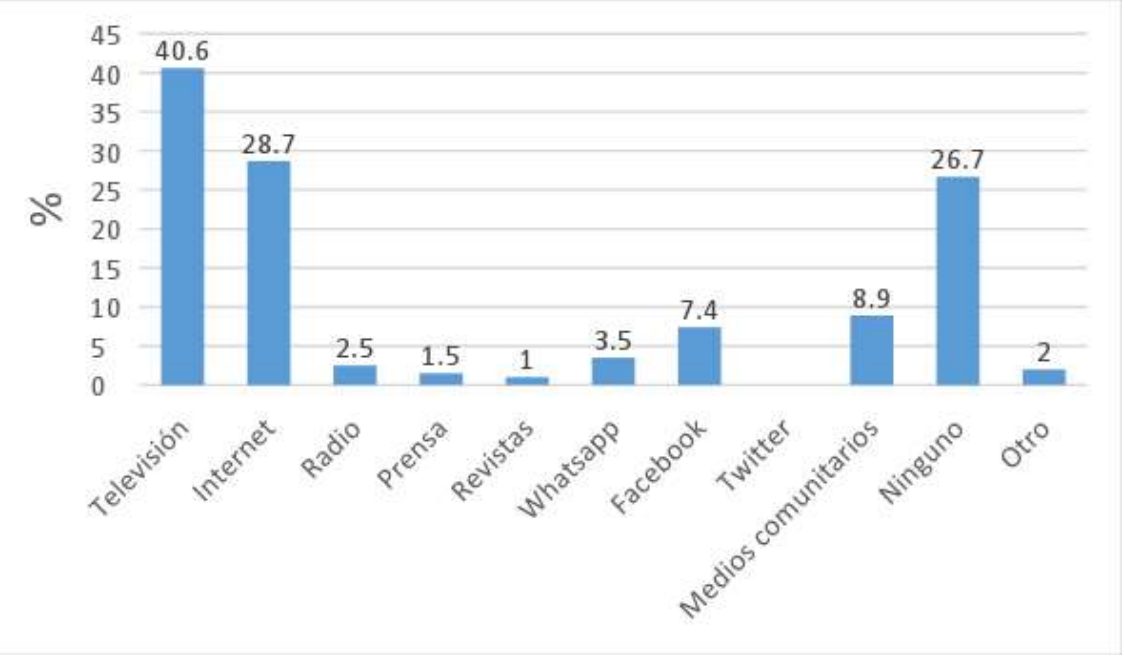

d) Medio que preferiría para recibir información sobre alimentación saludable: si bien la variable anterior hace referencia al medio que utilizan las gestantes para buscar información sobre alimentación saludable, para las investigadoras era importante conocer cuál sería el medio preferido de las gestantes para obtener esa información con el propósito de que en la implementación de la estrategia planteada en este documento, se pueda tener una mejor planeación en el uso de los medios para su divulgación.

Se encontró que la televisión (47\%) y el Internet (23.8\%) continúan siendo los medios más atractivos; sin embargo, se destaca la importancia que le dan a los medios comunitarios como un vehículo interesante para obtener información clave para su periodo de gestación (5.9\%), seguido del WhatsApp (5\%). Con relación a este último explicaron que desde el programa de la Secretaria de Integración Social les enviaban de manera frecuente mensajes cortos sobre el consumo de suplementos, el consumo de frutas, verduras, alimentos fuente de proteína y calcio.

Se resalta que un porcentaje importante de las mujeres (9.9\%) no manifiestan ningún tipo de preferencia frente a los medios de comunicación y la alimentación saludable ya que al parecer creen no necesitar información adicional sobre este tema.

Sin embargo, de acuerdo a lo manifestado en los grupos focales, se encontró mayor interés de las mujeres por buscar información sobre salud y nutrición en los diferentes medios:

“Al quedar embarazada consultaba mucha información por You Tube” (GFS).

"Internet es el medio más usado en mi casa ahora para buscar ese tipo de información, pero no es muy frecuente" (GFS) 


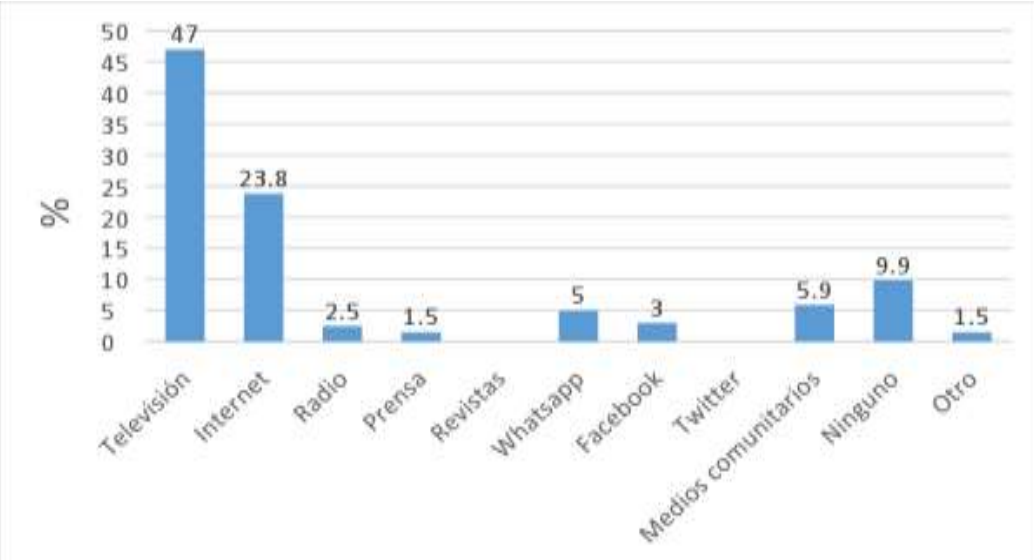

e) Interés en recibir información sobre alimentación saludable independiente del medio que se utilice: ante esta consulta, el $89.1 \%$, respondieron que les gustaría recibir información sobre este tema, el 6.9\% manifestaron no querer recibirla y el $4 \%$ no lo sabe o no responde.

Ilustración 30. Interés en recibir información sobre alimentación saludable independiente del medio.

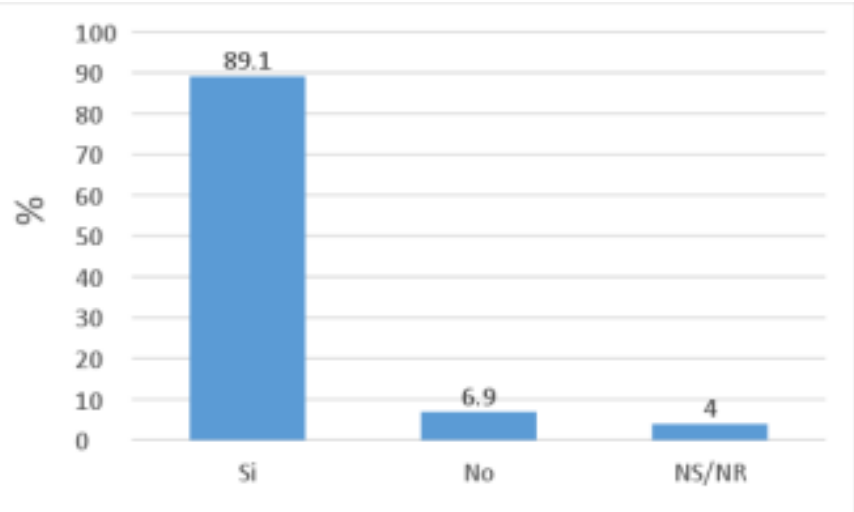

A manera de conclusión sobre las características del consumo de medios de las gestantes podemos decir que en el global, la televisión, internet y redes sociales son los más referenciados para recibir la información sobre alimentación saludable mientras que la radio, los medios impresos (periódicos y revistas), los medios comunitarios y el twitter son los de menor preferencia; aunque si se tiene en cuenta por grupo de edad, las gestantes mayores de 18 años prefieren en un $11 \%$ hacer uso de la radio para obtener información. Estos resultados reflejan las preferencias por medios visuales y se puede asociar por las características del grupo participante: socialmente es un grupo poblacional caracterizado por tener un nivel educativo medio y pertenecer en su mayoría a hogares compuestos 
(casadas o en unión libre) lo cual implica mayores responsabilidades y falta de tiempo para consultar por lo que prefieren una manera más rápida de obtener la información.

De igual forma, es necesario dejar claro que sí bien la televisión es el medio más utilizado, los costos que implica la producción y emisión de los mensajes resultaría muy oneroso para una entidad distrital que maneja un programa social ya que deberían tener presupuestos muy altos para dar una alta frecuencia al aire y entrar a pelear la pauta con los mensajes comerciales de productos que no resultan favorables para las gestantes como son las bebidas azucaradas, los refrescos en polvo, los sustitutos de leche materna, los complementos vitamínicos, entre otros y cuyas empresas productoras pueden mantener presupuestos muy altos.

Por lo anterior, para continuar con el objeto de la investigación y la propuesta de la estrategia de comunicación, se ha seleccionado a las redes sociales como el medio más viable de suministrar información.

\subsection{Consumo de internet $y$ redes sociales}

Para obtener la información sobre internet y redes sociales, se diseñó una encuesta con 11 preguntas las cuales fueron realizadas a un total de 171 mujeres lactantes y con niños menores de 2 años, habitantes de las 20 localidades de Bogotá y pertenecientes al mismo grupo beneficiarias del programa “Ámbito Familiar” que habían respondido la encuesta en el primer trabajo de campo. Los formatos fueron diligenciados casa a casa por el equipo de Nutrición del Instituto Nacional de Salud y por mi, durante 3 semanas del mes de mayo de 2017.

Así como en la primera etapa, también se hizo validación de la información recolectada en los grupos focales realizados en las localidades de Bosa y Soacha.

Con esta herramienta aplicada se esperaba determinar: las páginas más consultadas, las palabras claves usadas, el tiempo destinado a navegar en internet o a usar las redes sociales y la fuente principal diferente a los medios masivos cuando quiere saber algo sobre alimentos.

Por grupos etarios las gestantes participantes fueron:

Tabla 12. Población de gestantes participantes en encuesta de consumo de internet y redes sociales 


\begin{tabular}{|l|c|c|}
\hline \multicolumn{1}{|c|}{ Edad } & $\mathrm{n}$ & $\%$ \\
\hline$<15$ años & 0 & $0 \%$ \\
\hline 15 a 18 años & 10 & $5.8 \%$ \\
\hline 19 a 34años & 138 & $81 \%$ \\
\hline 35 y más & 23 & $13.2 \%$ \\
\hline Total & $\mathbf{1 7 1}$ & $\mathbf{1 0 0}$ \\
\hline
\end{tabular}

A continuación se entregan las preguntas del cuestionario y el consolidado de las respuestas.

1.- ¿Ha buscado información sobre alimentación saludable para usted o su bebé en YouTube?

De las mujeres encuestadas la mayoría (66.7\%) no utilizan el portal de internet YouTube para buscar información sobre alimentación saludable mientras que el 20.4 \% sí lo hace y un $13.0 \%$ no sabe o no responde

Acorde a la información dada por las mujeres y sus familias en los grupos focales, efectivamente la página de YouTube es más utilizada para ver videos de música para ellas y sus hijos: "Yo utilizo YouTube para ver videos de música y cuando el bebé está cansado le pongo también videos infantiles a él” (GFB).

Por otra parte, varias de las mujeres participantes expresaron utilizar este medio para ver videos de recetas y para aprender cómo cocinar algo: “Cuando quiero cocinar algo diferente, busco en YouTube cómo hacerlo, por ejemplo, para hacer ensaladas raras y ricas" (GFB). "Veo videos de recetas para preparar algo diferente cuando me canso de lo mismo de siempre, arroz, papa y carne" (GFS). "Me gusta buscar cómo hacer comidas para mi nena y para la familia, a uno se le acaban las ideas" (GFS). 
Ilustración 31. ¿Ha buscado información sobre alimentación saludable en You Tube?

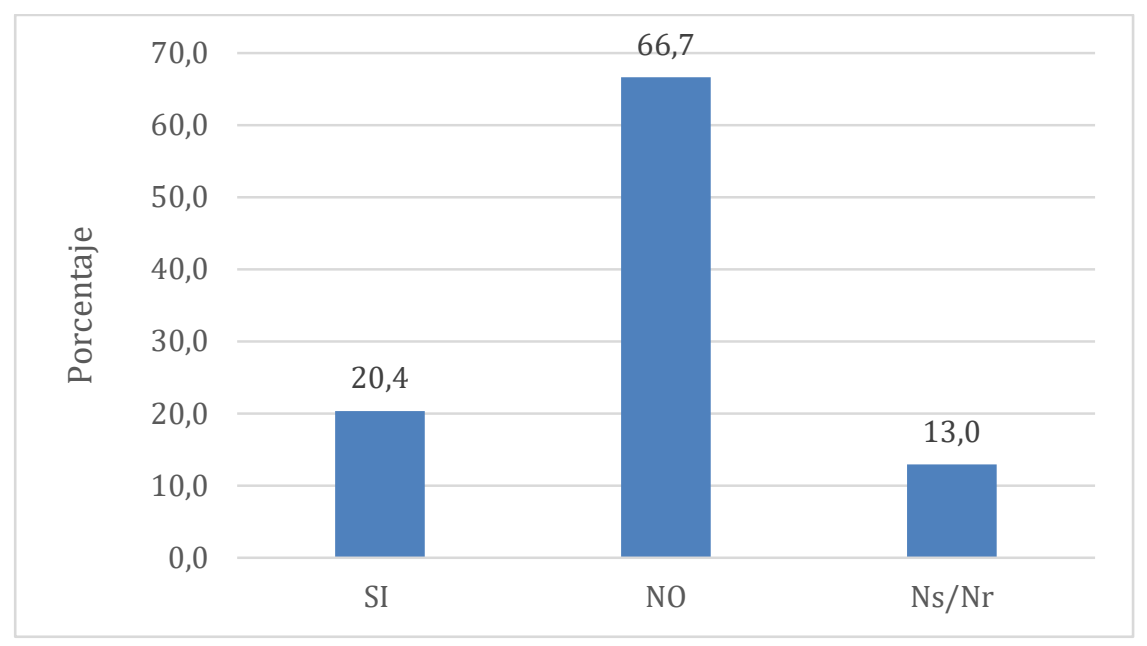

2- ¿Qué palabra utiliza para hacer la búsqueda relacionada con alimentación saludable?

El 39\% de las gestantes buscan información a través de la palabra alimentación; el 25\% por recetas; un $14 \%$ por alimento, otro $14 \%$ por alimentación y enfermedad y finalmente un $8 \%$ con palabras más técnicas como nutrición y crecimiento.

Adicionalmente informaron que en el buscador combinaban también palabras base como alimentación con complementarias como saludable o alimentación para "cierta" edad (alimentación de la gestante, alimentación del bebé). En cuanto a la palabra alimentos, se combina con alimentos sanos, saludables, alimentos según la edad, mientras que en el caso de las recetas, se indaga en combinación con las palabras frutas, verduras. En alimentación y enfermedad se relaciona con bajo peso, bajo apetito o que alimentos preparar en caso de enfermedad.

llustración 32. ¿Qué palabras usa para la búsqueda?

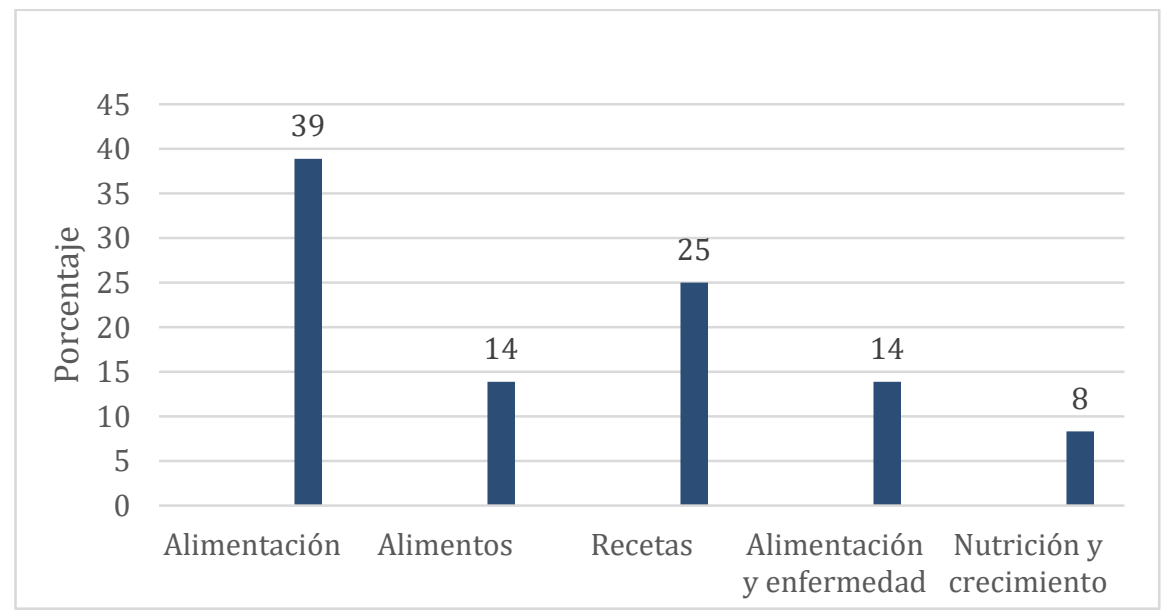


3. ¿Ha buscado información sobre alimentación saludable en Google?

De las mujeres entrevistadas, el 27\% usan Google para buscar información relacionada con alimentación saludable, el $60 \%$ no lo utiliza y un $13 \%$ no sabe o no responden.

Acorde a esta información, en los grupos focales las mujeres constataron el uso frecuente de Google como medio para buscar cualquier tipo de información: "Google se usa para consultar de todo: tareas, averiguar cosas, cómo hacer algo, música" (GFS). "Se busca cualquier inquietud: todo aparece". (GFS). "Lo uso para las tareas, para información y conocer información variada, significado de palabras e historia.” (GFB).

En relación a salud, los participantes en los grupos manifestaron usar este medio para: "Busco corroborar las recomendaciones médicas" (GFB). "Lo uso para saber si es verdad lo que le dice el médico" (GFS). "Para averiguar si lo que les recomendaron es bueno" (GFS)

Específicamente para el tema de alimentación saludable, algunos de los asistentes de los grupos focales opinaron usar Google para buscar la siguiente información: "En Google busco cada fruta y sus beneficios" (GFB). "Busco que alimentos dar a los niños acorde a la edad de ellos." (GFB). "Lo usé para saber cómo iniciar la complementaria." (GFS). "Qué hacer cuando están enfermos, cuidados y alimentos para ofrecer" (GFB). "Buscar recetas, como hacer ensaladas y cosas raras" (GFS).

Ilustración 33. ¿Busca información sobre alimentación en Google?

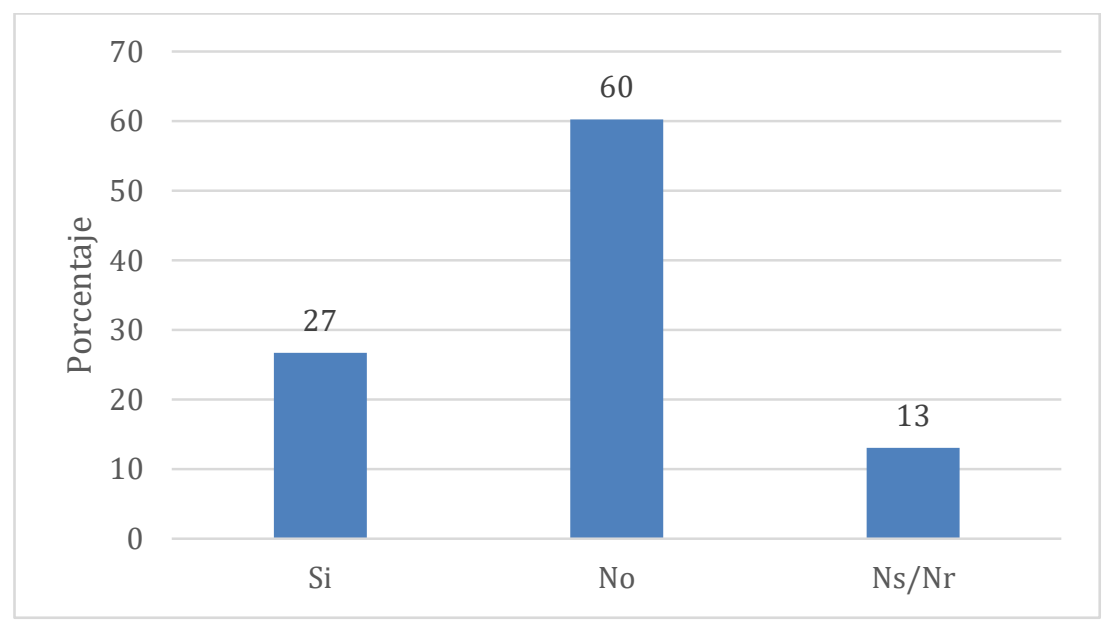


4. ¿Cuáles fueron las Palabras utilizadas para la búsqueda en Google?

Según la evaluación, la palabra recetas fue la más utilizada por las gestantes para realizar búsquedas en Google (38\%), combinadas en varios casos con: recetas con frutas, recetas según la edad, cómo preparar alimentos, recetas creativas, recetas divertidas, recetas de ensaladas y batidos de frutas.

Le siguen alimentos saludables con el $26 \%$, alimentación saludable con $21 \%$, nutrición y crecimiento $19 \%$ y alimentación y enfermedad con $5 \%$.

Con relación a los alimentos saludables, las palabras complementarias más utilizadas fueron: alimentos sanos, alimentos según la edad, alimentos que se pueden comer a cierta edad, mientras que para la palabra alimentación la combinación fue con la palabra sana y asociada con edad. En nutrición y crecimiento las consultas tuvieron que ver con vitaminas y defensas principalmente y por último las palabras alimentación y enfermedad estuvieron relacionadas con bajo peso y presencia de diarrea.

Ilustración 34. Palabras utilizadas para la búsqueda en Google

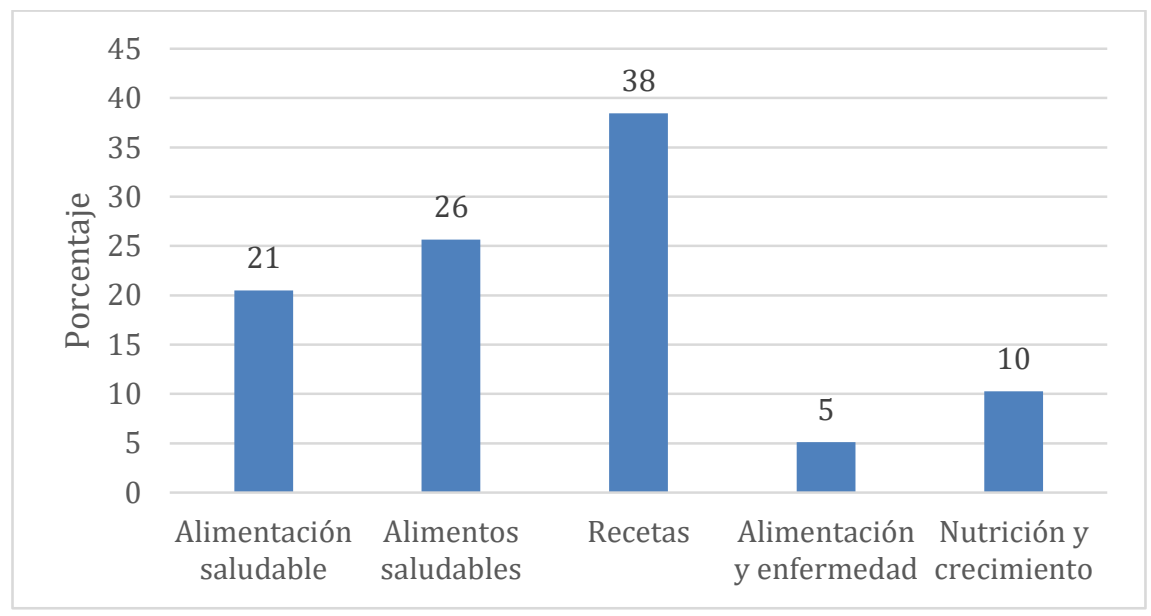

\section{5. ¿Tiene cuenta en Facebook?}

Los resultados demostraron que el 73\% de la población encuestada tienen Facebook, que el $14 \%$ no tiene y el restante $13 \%$ no sabe o no responde.

Esto significa que la mayoría de las mujeres de la muestra tienen esta red social, la cual, según los resultados del grupo focal, es utilizada principalmente para enterarse de noticias, chismes, ver diversos videos y recibir información variada: "Me gusta face para enterarme de las ultimas noticias y ver qué comenta la gente" (GFB). "Uno se entera de 
chismes y de lo que está pasando" (GFB). "Me gusta utilizar Facebook para ver videos de diferentes cosas" (GFS).

Ilustración 35. ¿Tiene cuenta de Facebook?

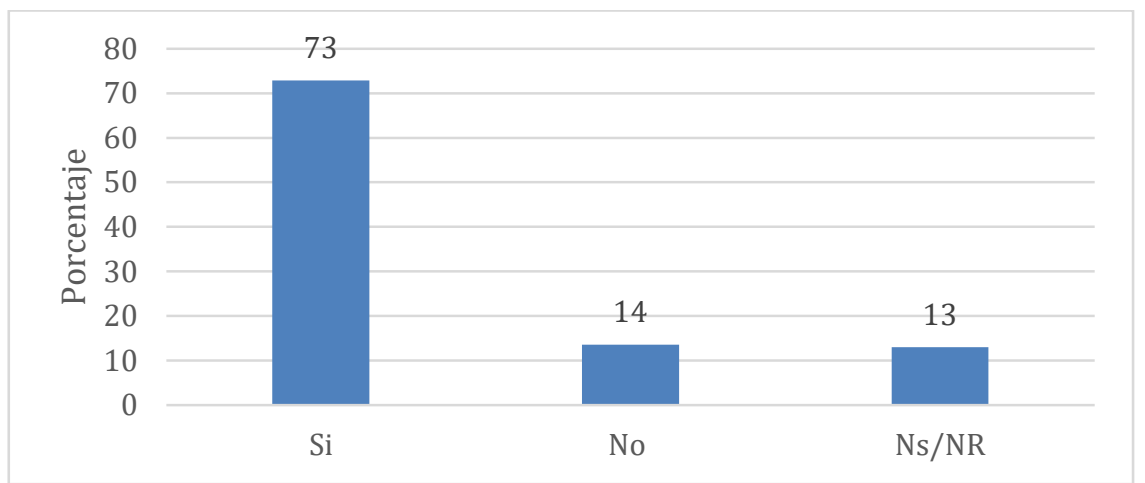

6. ¿Cuántas veces al día consulta Facebook?

Para el $86 \%$ de las consultadas revisan esta red social entre 1 y 5 veces al día, el $8 \%$ lo hace más de 10 veces diariamente y un $6 \%$ lo hace entre 6 y 10 veces. Lo anterior evidencia que el Facebook puede ser una red social adecuada para enviar mensajes a las gestantes sobre alimentación saludable.

Ilustración 36. ¿Cuántas veces al día utiliza Facebook?

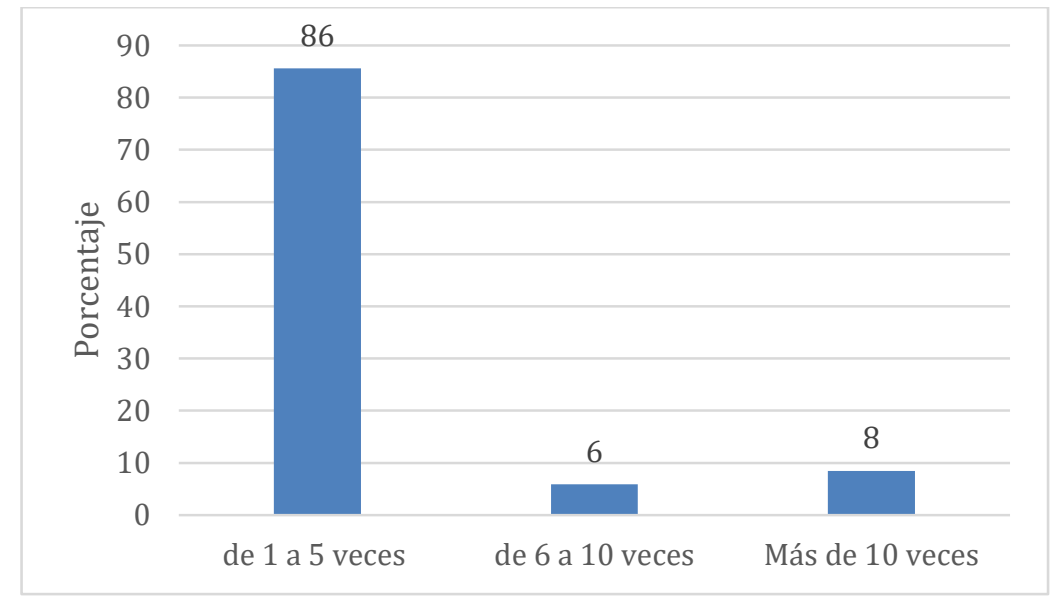

7. ¿Cuánto tiempo le dedica a Facebook al día?

El tiempo total que las entrevistadas dedican a mirar Facebook, está que la gran mayoría (80\%) lo hace de 1 a 30 minutos al día, el $10 \%$ lo hace más de una hora, mientras que el restante $10 \%$ está dividido entre quienes lo revisan de 31 a 45 minutos (5\%) y los que lo 
hacen de 46 a 60 minutos (5\%). Lo anterior evidencia que aunque es masivamente usado, el tiempo dedicado no es tan alto a diario.

Ilustración 37. ¿Cuánto tiempo al día le dedica al Facebook?

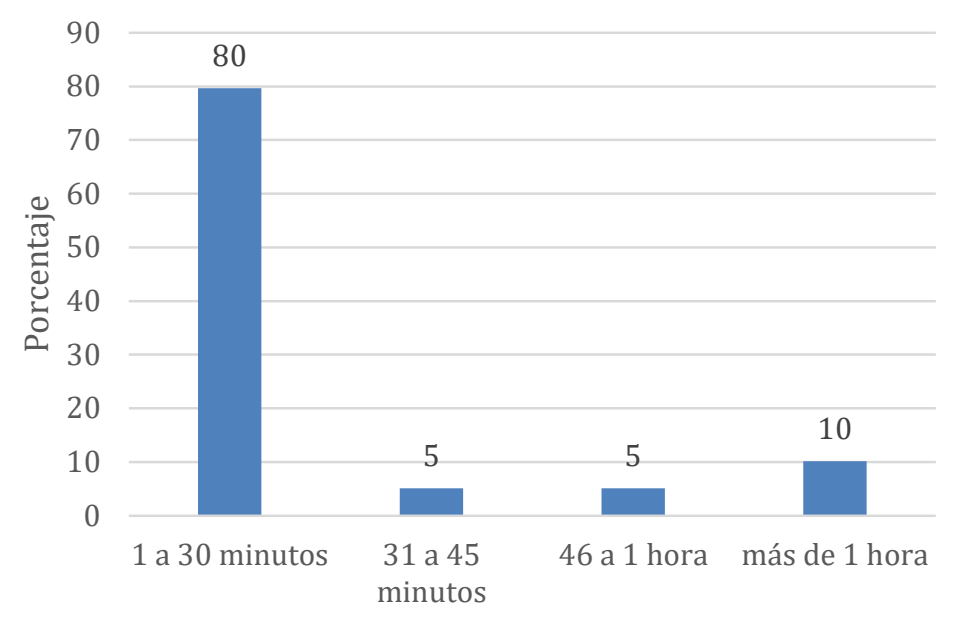

\section{8. ¿Tienen WhatsApp?}

Similar a los resultados obtenidos con relación a Facebook, el $70 \%$ de las mujeres tienen WhatsApp, el $19 \%$ refiere no tener y el $12 \%$ no sabe o no responde.

Ilustración 38. ¿Tienen WhatsApp?

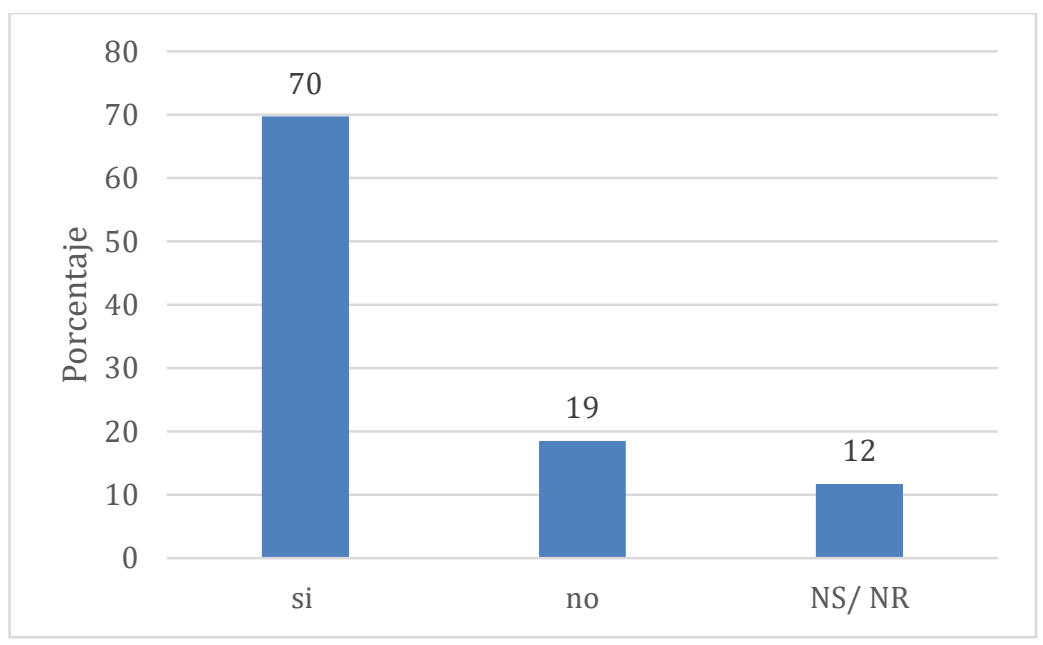

9.- ¿Usa WhatsApp para consultar sobre alimentación saludable?

Aunque el nivel de usuarios de esta aplicación a nivel general es alto, no es usado de forma amplia para consultar sobre alimentación saludable como lo señala el $81 \%$ de las gestantes consultadas contra un $19 \%$ que sí lo usa para ese fin. Estos resultados pueden ser entendibles si se tiene en cuenta que WhatsApp es una aplicación configurada para enviar y recibir mensajes en teléfonos móviles más que para la búsqueda de información. 
Esta información está acorde a lo manifestado en los grupos focales: "Me gusta WhatsApp para comunicarme con los compañeros del trabajo" (GFB). "Yo uso esa aplicación para comunicarme con todo el mundo" (GFS). "A mí me gusta para hablar con mi familia y no gastar minutos" (GFB).

Ilustración 39. ¿Usa WhatsApp para consultar sobre alimentación saludable?

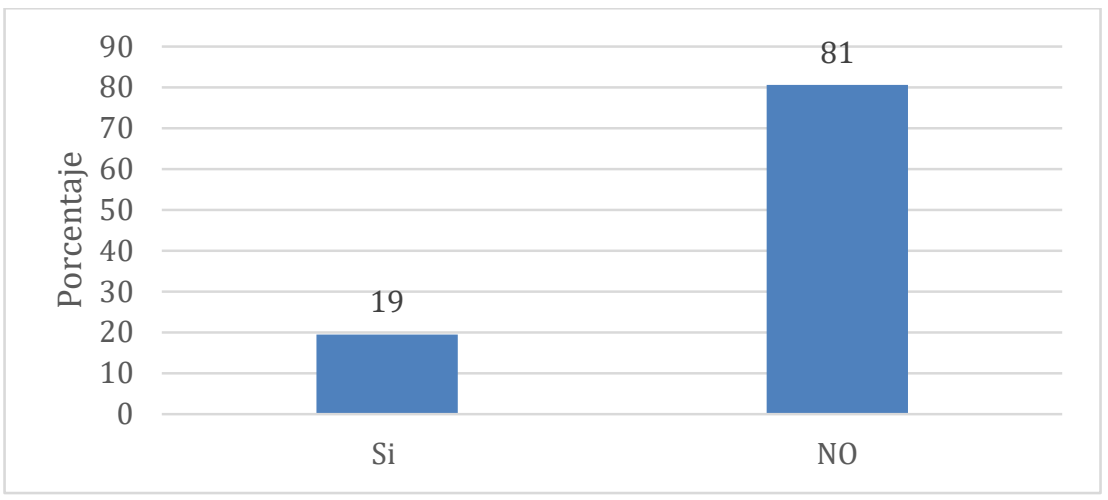

10. Temas consultados con sus contactos.

Es interesante que las mujeres que respondieron la encuesta afirman que cuando consultan algún tema relacionado con la alimentación saludable por WhatsApp, el tema de mayor interés es la alimentación con relación a la enfermedad, (44\%) y buscaban especialmente sobre: bajo peso, bajo apetito, qué alimentos dar en caso de enfermedad y sobre remedios caseros.

También consultaban a sus conocidos sobre recetas (28\%), sobre alimentos saludables (17\%), donde preguntaban por frutas y alimentos que se pueden ofrecer a cierta edad y finalmente, para las consultas relacionadas con alimentación (11\%), se encontró que la palabra que acompañaba era alimentación infantil.

Ilustración 40. ¿Qué temas consulta con sus contactos en WhatsApp? 


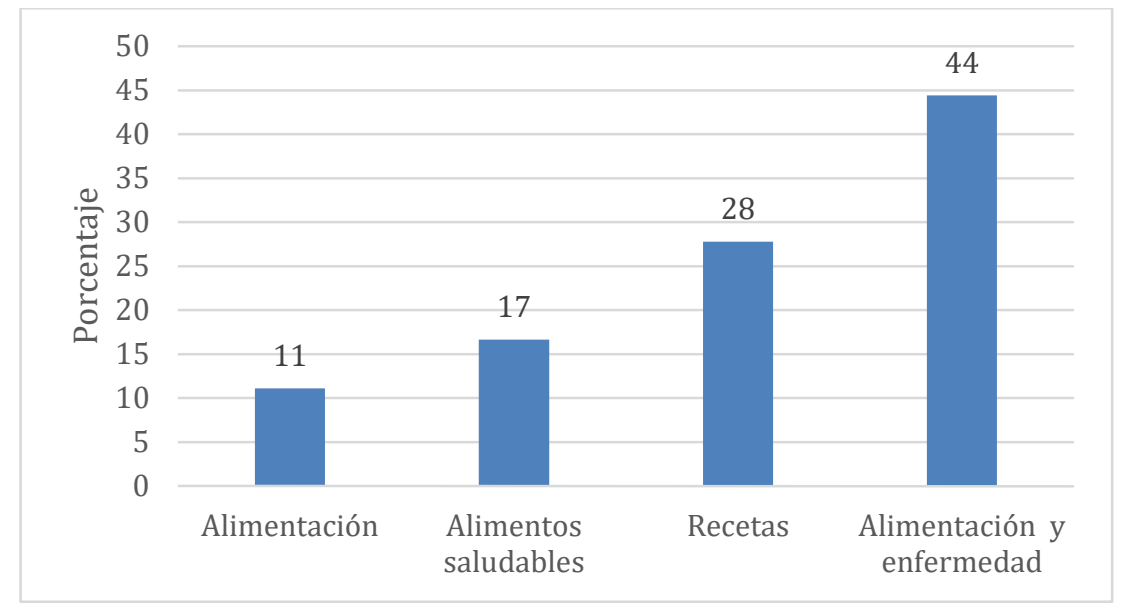

11. ¿Cuándo tiene dudas sobre alimentación saludable para usted o su bebé, a quién consulta?

En caso de dudas relacionadas con la alimentación saludable, las mujeres consultaban preferentemente a la mamá, (55\%) seguido del profesional de la salud (21\%), de una amiga (8\%), otra persona (hermana, tía, papá, profesora del ámbito, abuela y nutricionista) $(8 \%)$, de la suegra (7\%) y tan sólo en pequeño grupo (2\%) consulta al compañero. En caso de otros, la información fue muy variada como por ejemplo, consultaban a la vecina o al tendero. Esta respuesta está acorde a la encontrada en algunos estudios donde la referente en relación a la alimentación saludable es la mamá de la mujer.

Ilustración 41. ¿A quién consulta en caso de dudas relacionadas con alimentación?

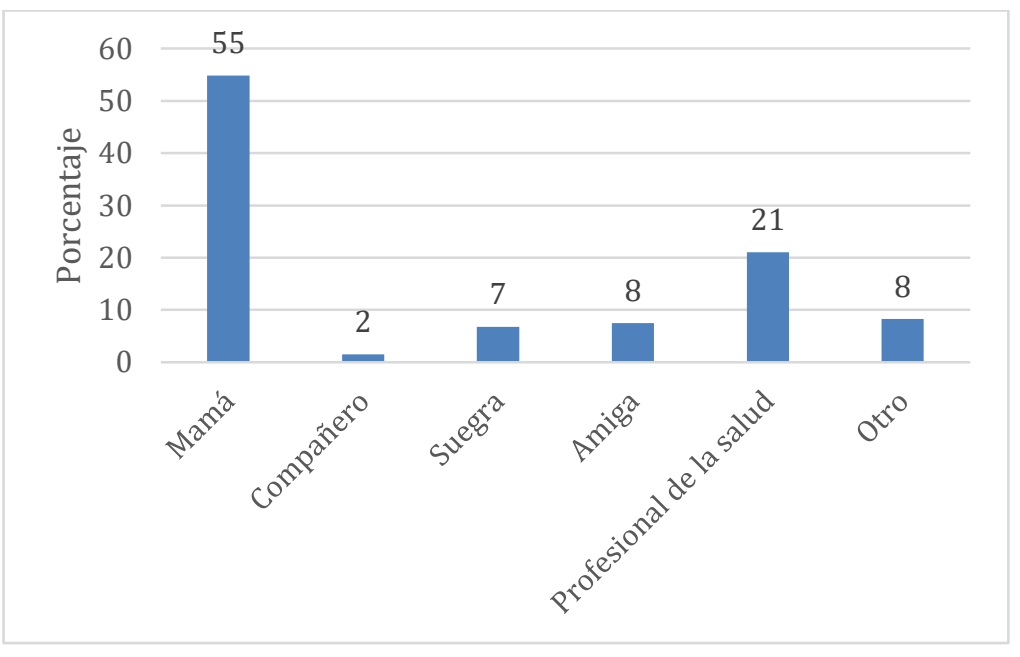

Este tema fue muy interesante indagarlo en los grupos focales, porque llama la atención que las mujeres gestantes de los dos grupos coinciden con la misma respuesta de que la persona que las guía en relación a la alimentación es la madre por encima del profesional de la salud: "Le hago caso a mi mamá y abuela, porque los profesionales dicen cosas a 
las que uno no está acostumbrado, entones uno le pregunta a la mamá y a la abuela y si ella lo aprueba uno lo hace” (GFB). "El doctor me decía coma pescado pero a mí no me gusta, le hacía caso en lo que me gustaba" (GFB). "Yo le hago caso a la experiencia de mi mamá y mi abuela" (GFS). "Le hago caso a mi mamá y a mi suegra” (GFB). "Mi abuela crio once hijos y ahora con mi hijo ella me da recomendaciones pero también dice que las cosas han cambiado y que hay que seguir las recomendaciones médicas, pero en general uno sigue las recomendaciones de la mamá" (GFB).

Estos testimonios evidencian la importancia de incluir a las personas que más influyen en las decisiones de las mujeres gestantes en los programas dirigidos a ellas y que por ejemplo, para las consultas prenatales, el curso de preparación para la maternidad y la paternidad y la cita de nutrición, se pueda contar con la asistencia de la madre de las gestantes, el compañero o alguien influyente en ella para ayudar a reforzar las recomendaciones del profesional de la salud.

Por otra parte, las participantes nos brindaron testimonios claves que explican por qué no siguen las recomendaciones de los profesionales de la salud, así como elementos que podrían ser útiles para utilizar en la estrategia dirigida a los médicos, enfermeras y nutricionistas: "Si el médico explicara bien las cosas de pronto se le haría más caso. Los médicos solo dan órdenes y no dan ejemplo. Ellos dicen: no fume porque le va a dar cáncer de pulmón y ellos salen y fuman" (GFB). "Ellos le dicen a uno no tome coca cola ni empanada y ellos salen y comen eso. Uno no les cree lo que dicen" (GFS). "Si los médicos explican mejor las cosas y dejan de dar órdenes, se podrían seguir sus recomendaciones." (GFB)."Si el doctor me dice que coma algo, yo trato de hacerle caso, pero sólo me como lo que me gusta" (GFS). "El doctor me decía coma pescado pero a mí no me gusta, le hacía caso en lo que me gustaba" (GFB).

Esto permite considerar que se deben realizar acciones con los profesionales de salud para que puedan comunicar de manera asertiva y coherente las recomendaciones alimentarias dadas a las gestantes y sus familias.

En conclusión, los anteriores resultados evidencian el uso de algunas páginas de internet y redes sociales para buscar información saludable y aunque los resultados no fueron masivos, evidencian que el medio más usado dentro de este grupo es mediante el buscador Google (27\%) seguido de You Tube con un 20\% y finalmente WhatsApp con un $19 \%$. 
Es interesante resaltar que, aunque las diferencias en uso no son muy grandes, sí la hay en cuando a los temas a consultar: Google es preferiblemente utilizado para buscar recetas, YouTube para buscar información sobre alimentación saludable y finalmente WhatsApp para consultar a otras personas en temas relacionados con alimentación y enfermedad.

Se destaca también el alto número de encuestadas que tienen Facebook y WhatsApp y aunque el tiempo que dedican al día o las veces que lo consultan no es tan alto, si son unas redes de uso masivo que podrían ser unas herramientas adecuadas para transmitir mensajes claves de forma rápida y visual.

En cuanto al uso de las redes sociales retomamos en estas conclusiones las opiniones expresadas por las participantes en los grupos focales con relación al medio preferido para recibir información sobre alimentación saludable: "El medio más efectivo sería un canal en YouTube, para ver cómo se prepara un alimento, es lo más fácil, y puede servir porque son fáciles" (GFB). "Prefiero ver un video y no leer algo" (GFS). "Yo en realidad, prefiero ver video prácticos" (GFB). "Por face si hay información interesante, se podría compartir, pero tendría que ser algo atractivo para mamás para mirarlo, seguirlo y compartirlo: mamás y cuidado." (GFB). "Yo me fijaría en la información y video: si hay imágenes con fondo blanco y hablando es aburrido, debe ser atractivo para que se quiera ver." (GFS) "Por WhatsApp, no me gustaría mucho mensajes, mejor recibir una imagen con un mensaje corto, como un meme. Seria atractivo y le pongo más cuidado" (GFB). "Uno de mamá está ocupado y no tiene tiempo de ponerse a leer, ir a la biblioteca, no se ven oraciones o textos largos, llega más un mensaje directo y gráfico" (GFS). "Me gustaría que me llegara información por WhatsApp y Facebook porque es más sencillo que llegue, no hay que buscarla, sólo llega." (GFB).

Como se había mencionado, los resultados de las encuestas demuestran que los medios más utilizados para recibir información sobre alimentación saludable son la televisión, el internet y las redes sociales. Sin embargo, debido al alto costo de producción de piezas y de transmisión de la primera, se analizará la viabilidad del uso de internet y redes sociales para la promoción de la alimentación saludable, y definir sí dado el casi de su uso, Facebook y WhatsApp sean los más aconsejables debido a que la mayoría de las mujeres los tienen y los usan de manera frecuente. 
Así mismo es importante tener en cuenta los resultados de la Encuesta Nacional de Calidad de Vida 2017 (DANE, 2017), que en el componente de tecnología referencia uso de computador e internet:

"El 44,3\% de los hogares manifestaron tener algún tipo de computador (computador de escritorio, portátil o tableta). La conexión a Internet pasó de 45,8\% en 2016 a 50,0\% en 2017. Del total de hogares que manifestaron tener computador $(44,3 \%)$, el 23,3\% tenía computador de escritorio, mientras que la tenencia de portátil fue $28,1 \%$ en 2017 . El uso de computador en cualquier lugar de las personas de 5 años y más, a nivel nacional alcanzó el 48,0\% en 2017. En las cabeceras el uso de computador fue de 53,4\% y en los centros poblados y rural disperso fue $28,8 \%$. Las personas de 5 años y más que reportaron usar internet en cualquier lugar y desde cualquier dispositivo, para el total nacional alcanzaron el $62,3 \%$ en 2017. En las cabeceras fue $69,4 \%$ y en los centros poblados y rural disperso 37,0\%. En 2017, del total de personas de 5 años y más que usaron internet $(62,3 \%)$, el 81,7\% lo hizo a través de teléfono celular, superior a $2016(70,4 \%)$. El 47,5\% lo hizo mediante computador de escritorio, el 33,7\% accedió a través de portátil y el $11,2 \%$ mediante tableta".

Finalmente, es importante destacar la relevancia de incluir a las madres, compañeros o suegras de las gestantes en la estrategia de comunicación debido a su importancia en las decisiones alimentarias para las embarazadas, así como también dirigir acciones a los profesionales de salud para que por medio de una comunicación asertiva sus recomendaciones sean seguidas. 


\section{Capítulo IV}

\section{Estrategia de comunicación para la promoción de la alimentación saludable}

En Colombia, casi el 50\% de las mujeres gestantes tienen algún tipo de malnutrición (Ministero de Salud, 2010), ya sea por exceso como sobrepeso u obesidad como por déficit cómo bajo peso para la edad gestacional, lo cual tiene grandes implicaciones para la salud tanto de ella como de su hijo, a corto y largo plazo.

Dado lo anterior, en el marco de la investigación realizada por el Instituto Nacional de Salud sobre prácticas alimentarias de un grupo de mujeres gestantes beneficiarias de la Secretaría de Integración Social de Bogotá, se recolecta información sobre el consumo de los alimentos, donde se evidencian falencias con relación al consumo de alimentos claves para la provisión de micro y macronutrientes durante la gestación y se recopila información relacionada con el consumo de medios, resultando importante el uso de la televisión, el internet y las redes sociales, para luego validar y conocer las causas de ciertos comportamientos por medio de grupos focales y se hace una propuesta de estrategia de comunicación estableciendo fases, actores claves, ejes que incluye y momentos que la integran. El proceso tuvo como marco teórico y metodológico las características de la Comunicación Estratégica de Sandra Massoni (Massoni, 2011), las cuales se describen a continuación:

- En el proceso no nos fijamos solo en el inadecuado estado nutricional de las gestantes, sino en qué alimentos consumen y porqué lo hacen.

- Los procesos se centran en diálogos y concertaciones, realizados a través de grupos focales. Los resultados muestran la alta influencia de las mamás, abuelas y suegras de las gestantes en la decisión del consumo de alimentos, por lo cual será importante incluirlas en todos los procesos.

- En la comunicación estratégica no hay una receta infalible para mejorar el consumo de alimentos saludables de las gestantes. Cada mujer es diferente, su situación económica, familiar y social, es diferente, además influyen en ellas aspectos como los gustos, antojos, mitos, entre otros y así mismo, las estrategias 
propuestas, deberán ser diferente acorde a la realidad que las rodea. Además de lo anterior, en esta propuesta de comunicación estratégica, es importante tener en cuenta que las gestantes tienen esa característica de "gestantes" por un tiempo corto, aproximadamente entre 7 y 8 meses de su vida, para luego pasar a ser lactantes o madres. Por esto varias de las acciones planteadas están dirigidas a los actores que sí estarán en su rol por un tiempo largo: profesional de la salud, líder social, abuela, los cuales podrán impactar e influenciar a muchas gestantes.

- Los procesos aceptan las características de las gestantes sin buscar "la gestante ideal”. El centro son las personas, sus capacidades y fortalezas y a partir de allí se busca cómo pueden contribuir al mejoramiento de los problemas. Pretende iniciar transformaciones internas, desde el centro de cada persona y no cambios en el otro. El cambio de hábitos alimentarios es algo que requiere tiempo, constancia y no es algo rápido ni fácil de hacer, sin embargo, como vimos anteriormente, el tiempo de la gestación es uno de los pocos momentos de la vida en que se pueden lograr ciertos cambios y que perdurarán en el tiempo, esto dado por el interés de la mujer a brindar el mejor alimento para obtener mejores resultados en la salud del binomio madre-hijo.

- Este tipo de estrategias se basa en el dialogo pero luego continuar avanzando hacia el "actuar", hacia el "hacer", hacia las acciones concertadas que pueden contribuir al mejoramiento de ciertas situaciones. Es por esto que la estrategia contiene acciones prácticas, viables y medibles con los diferentes actores reales, buscando que ésta que no sea solo una propuesta, sino que pueda ser implementada por las comunidades o las instituciones.

Dado lo anterior, es importante partir del diagnóstico resultante del objetivo uno y dos de la presente investigación donde se establecieron las prácticas alimentarias y prácticas del uso de los medios por parte de una muestra de gestantes pertenecientes a un programa de apoyo distrital, las cuales se caracterizaron socialmente por:

- Edad promedio: 19 a 34 años

- Viven en las 20 localidades de Bogotá, principalmente en estrato 2

- Viven, aproximadamente el $53 \%$ con su esposo o compañero y las restantes con familiares

- Más de la mitad, 52.2\%, tienen educación básica incompleta, el 40\% media completa y tan solo el 2,7 tiene estudios profesionales. 
- La mayoría trabaja en oficios del hogar o estudian y solo aporta una persona al hogar, contando con un promedio de ingreso mensual de $\$ 713.570$, los cuales son usados principalmente para la compra de alimentos, servicios públicos, productos de aseo, transporte y alquiler.

Diagnóstico del consumo de alimentos:

En su mayoría, las mujeres gestantes entrevistadas consumen una gran cantidad de carbohidratos, aportados por alimentos como arroz, pastas, tubérculos y plátanos así como productos de panadería que son consumidos a diario. Los lácteos, carnes, frutas y verduras son poco consumidos a diario. La mayoría de las gestantes no consume de manera habitual grasas saturadas como embutidos, margarina o mantequilla, ni comidas rápidas, sin embargo les gusta consumir frecuentemente alimentos fritos. El huevo, fue un alimento ampliamente consumido por las gestantes pero se presentó un bajo consumo de vísceras.

Con relación a la frecuencia, pocas gestantes consumen una alimentación fraccionada, es decir, 5 veces al día. Las demás consumen entre 3 y 4 veces. Los tiempos de comida consumidos con mayor frecuencia de manera diaria fueron el almuerzo y el desayuno. Las medias nueves y onces son los tiempos de comida menos consumidos.

También, se evidenció que el consumo de alimentos mejora durante la gestación, por la intención de cuidar su salud y la de su hijo, pero no siempre cumple con las recomendaciones dadas por los profesionales de la salud y prefieren guiarse por sus hábitos alimentarios, recomendaciones de sus familiares, costo de los alimentos y preferencias o ganas de comer ciertos alimentos particulares durante el embarazo.

Lo anterior, evidencia que las mujeres gestantes no cumplen las recomendaciones nutricionales especiales para las mujeres gestantes, lo cual se evidencia en el sobrepeso o la baja ganancia de peso gestacional repercutiendo en su salud y la del bebé, por lo cual es necesario comprender su realidad y a partir de ésta, plantear estrategias viables con ellas y los actores claves para aportar al mejoramiento real de su situación nutricional actual y en busca de transformaciones en los hábitos alimentarios de la población.

Diagnóstico del uso de medios:

Aunque la televisión es sin duda el medio más usado por las mujeres incluidas en el estudio, no será parte de la estrategia por ser un medio costoso y poco sostenible para la 
llegar a la población gestante de Bogotá. El segundo medio más usado es el internet y las redes sociales, donde páginas como, Google es preferiblemente utilizado para buscar recetas, YouTube para buscar información sobre alimentación saludable y finalmente WhatsApp para consultar a otras personas en temas relacionados con alimentación y enfermedad. La mayoría de las mujeres tiene fácil acceso a celulares donde usan Facebook y WhatsApp a diario, dedicándole un tiempo considerable, resultando un medio interesante para la transmisión de mensajes claves a las gestantes. Sin embargo, independiente del medio que se use, las mujeres consideran muy importante las características de los mensajes, ya que estos deben ser: cortos, atractivos, visuales, gráficos, con información clara y fácil de utilizar, que hable de alimentos disponibles. También es importante destacar la relevancia de incluir a las madres, compañeros o suegras de las gestantes en las acciones propuestas ya que son muy influyentes en el consumo de alimentos de las gestantes, así como también tener en cuenta a los profesionales de salud para que por medio de una comunicación asertiva, pueden hacer que sus recomendaciones sean realmente usadas para mejorar la alimentación de las gestantes.

Estos diagnósticos de las prácticas alimentarias y del consumo de medios, son dos herramientas estratégicas útiles para planificar de manera integrada acciones integrales dirigidas a los diferentes actores, para contribuir al mejoramiento de la salud de las mujeres y los niños. No se busca cambiar a las personas, busca junto con ellas, gestionar cambios en la forma de hacer las cosas, transformaciones en sus hábitos y comportamientos, los cuales pueden estar perjudicando a corto y largo plazo su salud.

Estos resultados permiten conocer el contexto social, alimentario y comunicativo de mujeres gestantes, las cuales entran a esta etapa de la vida y se mantienen por unos pocos meses y luego pasan a otra etapa, pero esto las hace especiales durante un pequeño espacio del tiempo, el cual es fundamental para el resto de sus vidas haciendo que las posibilidades de transformaciones y cambios reales sean viables mediante estrategias integrales, donde estén acompañadas por sus actores claves y por una institucionalidad que las comprenda, escuche, tenga en cuenta y construya junto con ellas.

Particularmente, en esta estrategia se busca fortalecer capacidades de los profesionales y líderes que las acompañan durante la gestación, para que partiendo de habilidades de escuchar, observar y generar confianza puedan generar empatía y les permitan brindar a las mujeres sugerencias útiles para su situación particular y empoderar a las gestantes para 
que ellas, informadas, sean quienes realmente deciden sobre su alimentación. De igual manera se pretende, mediante una planificación integrada, diseñar estrategias de comunicación que contribuyan a la transmisión y refuerzo de mensajes claves que mejoren el conocimiento, los saberes y el comportamiento de los actores involucrados en esta, partiendo siempre del conocimiento de su contexto y su realidad: qué comen, porqué lo comen, cómo se informan y porqué.

\section{Fases para la construcción de la estrategia:}

Primera fase: Caracterización de las prácticas alimentarias de las mujeres gestantes, para poder orientarlas sobre pautas de alimentación saludable. Era importante partir de su realidad, de sus gustos, sus motivaciones para decidir qué consumen y sus razones para consumir uno u otro alimento, así como conocer quién es la persona que más influye en la decisión del consumo de alimentos. Esto quiere decir, partir de su realidad alimentaria.

Segunda fase: Caracterización del consumo de medios de las mujeres gestantes.

Se indagó sobre las preferencias de este grupo poblacional para obtener información general y sobre alimentación, tanto en medios masivos como en internet y redes sociales, entendiendo que estos pueden ser herramientas de información valiosas en este tipo de procesos. Los resultados obtenidos permitieron establecer los medios más convenientes para usar en la propuesta de comunicación mediática dirigida a las mujeres embarazadas, contribuyendo así a garantizar que se van a usar medios frecuentados por ellas.

Tercera fase: Análisis de resultados, establecimiento de actores claves y elaboración de la propuesta de comunicación estratégica acorde a las realidades institucionales que actualmente acoge a esta población y a las preferencias en relación a piezas comunicativas. Dicha propuesta está compuesta por unos ejes, en los cuales se establecen componentes mediáticos y no mediáticos en los diferentes actores para incidir en las transformaciones relacionadas con comportamientos alimentarios de las mujeres gestantes.

De igual manera, en esta fase se definieron algunas recomendaciones para mejorar el impacto de la estrategia y conclusiones resultantes del proceso, esto dado que en el marco del trabajo de grado de la Maestría de Comunicación, Desarrollo y Cambio Social, el alcance era hasta la elaboración de la propuesta. 
Cuarta fase: En esta última fase se propusieron acciones de monitoreo, seguimiento y evaluación de la estrategia como una iniciativa para el establecimiento de una mejora continua en el proceso comunicativo y de transformación de comportamientos alimentarios.

A continuación se presentan los actores claves, ejes de la estrategia y componentes de la misma, propuestos para contribuir al mejoramiento de las prácticas alimentarias de las gestantes:

\section{Actores claves}

Durante todas las fases se pudo establecer los diferentes actores que influencian la decisión de cómo alimentarse durante la gestación. Igualmente se pudo relacionar, cuales son las personas que están con la mujer durante el embarazo y aunque tienen el conocimiento, muchas veces no influyen directamente en los comportamientos alimentarios.

En primera medida el actor principal siempre será la gestante, es la protagonista de la estrategia y así mismo es agente de su propio cambio. En este mismo grupo están las personas que más influyen en la conducta alimentaria, la madre, abuela, suegra o compañero. El segundo actor a describir son los líderes comunitarios con su función intermediadora entre las gestantes y la institucionalidad y el tercer actor, los profesionales de las instituciones estatales a los cuales está vinculada la gestante, así como los profesionales de la salud que acompañan a las mujeres durante los meses del embarazo. 


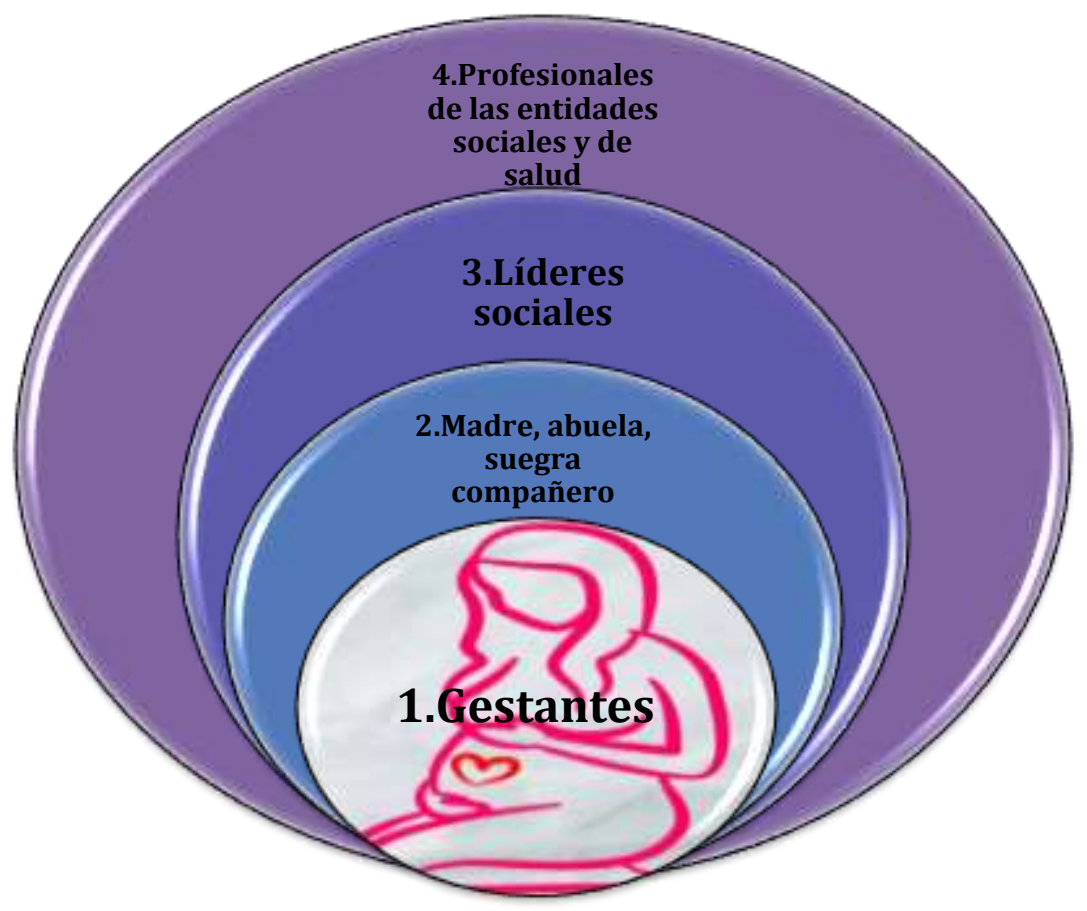

Ilustración 42. Mapa de Actores de las Mujeres Gestantes

\section{Primer actor: Gestantes}

Son las personas centrales de la estrategia. Las que participaron en el estudio son en su mayoría mujeres jóvenes o adultas jóvenes que están embarazadas, situación que trae cambios y expectativas en todos los aspectos de su vida, incluyendo su alimentación. Acorde a algunos estudios revisados, es una de las épocas de la vida donde se hacen cambios en los hábitos alimentarios debido al interés por alimentarse bien para el bienestar del bebé. Sin embargo y a pesar de las recomendaciones nutricionales dadas por los profesionales de la salud, su alimentación se caracteriza por no cumplir con los requerimientos necesarios dadas las necesidades específicas de la gestación. Ellas recurren a los consejos de sus familiares, especialmente de su madre, abuela o suegra o a las recomendaciones de su pareja, las cuales no siempre son adecuadas ya que están basadas en mitos y creencias adquiridas a través del tiempo.

\section{Segundo actor: Madre, abuela, suegra, hermana, amiga y/o compañero}

Los actores influyentes de este grupo, madre, abuela y suegra tienen la experiencia de ser madres, para aconsejar a las gestantes sobre cómo deben alimentarse, y por eso son autoridad alimentaria para las embarazadas. Esto se evidencia en algunos de los testimonios dados por las gestantes participantes en los grupos focales donde daban 
mayor credibilidad a lo recomendado por estos actores que por los profesionales de la salud, por ejemplo:

"Le hago caso a mi mama y abuela, porque los profesionales dicen cosas a las que uno no está acostumbrado, entones uno le pregunta a la mama y a la abuela y si ella lo aprueba uno lo hace" (GFB).

En la siguiente opinión, valía más la experiencia de la abuela al haber criado 11 hijos que el conocimiento del profesional:

"Mi abuela crio once hijos y ahora con mi hijo ella me da recomendaciones pero también dice que las cosas han cambiado y que hay que seguir las recomendaciones médicas, pero en general uno sigue las recomendaciones de la mamá” (GFS)

Los siguientes, hermana y compañero pueden aconsejar y ser escuchados por la afinidad sentimental que los une. Son personas importantes en la estrategia ya que son a quienes las mujeres escuchan siguiendo las recomendaciones dados por estos y en otros casos son quienes deciden lo que la gestante debe comer.

\section{Tercer actor: Líderes Institucionales}

En esta categoría se encuentran personas de la comunidad que trabajan actualmente con la Secretaría Distrital de Integración Social dentro del proyecto Creciendo en familia. Son ellos quienes hacen el enlace de las diferentes actividades educativas individuales y grupales o apoyo en el proceso de la entrega de los bonos a las mujeres gestantes. Además participan en los procesos de inscripción de las mujeres nuevas en el programa y en la guía u orientación de las usuarias sobre la vinculación a las ofertas institucionales que se ofrece según la vulnerabilidad de las mujeres.

Este grupo es un intermediario entre las mujeres gestantes y la Secretaría Distrital de Integración Social que deben ser incluidos en la estrategia por su papel fundamental entre la institucionalidad y la comunidad, además porque cada mes realizan encuentros educativos con las gestantes, teniendo momentos de oportunidad para transmitir mensajes claves y asesorar a las mujeres en temas puntuales.

\section{Cuarto actor: Profesionales de las instituciones}

Acá se ubica a los profesionales de la Secretaría Distrital de Integración Social, que es la entidad distrital que por competencias institucionales brinda apoyo a las mujeres 
gestantes con problemas de malnutrición y es la institución que tenía vinculadas a las mujeres que fueron incluidas en el estudio.

Esta institución está orientada a la promoción del desarrollo integral desde la gestación hasta la adolescencia, con prioridad en las personas que tienen situaciones de vulnerabilidad social o económica. Específicamente para los mil primeros días (desde la gestación hasta los dos años de vida) cuentan con un programa denominado "Creciendo en familia" a través del cual brinda orientación individual y grupal en temas de crianza, cuidado, protección y desarrollo infantil en el hogar y espacios comunitarios, asesoría nutricional para casos de malnutrición de gestantes y apoyo alimentario a gestantes con bajo peso gestacional y esto lo hace mediante acciones profesionales de nutrición, enfermería, psicología y pedagogía.

En este grupo también se incluyen otras instituciones que de una u otra manera contribuyen con el bienestar de las gestantes como son: Secretaría Distrital de Salud que, a través de los médicos y enfermeras, apoya aspectos relacionados con el consumo de micronutrientes en la gestantes y se encarga de garantizar la atención en salud a través de las Instituciones Prestadoras del Servicio de Salud, especialmente de los controles prenatales, del curso de preparación de la maternidad y la paternidad y de la atención del parto, el posparto y los controles posteriores. Otra entidad distrital competente es el Jardín Botánico, con agrónomos brindando asesoría en los temas de agricultura urbana y la Secretaria de Cultura con las salas de lectura para la primera infancia, el Instituto Distrital de las Artes - Idartes y el Instituto Distrital de Recreación y Deporte, quienes con educadores físicos, realizan actividades de recreación y uso del tiempo libre, específicas para este grupo poblacional.

Muchos de los profesionales nombrados de las entidades vinculadas, pueden ser escuchados pero no seguidos, ya que es una persona no familiar, habla sin saber sobre los determinantes sociales de cada gestante, y da órdenes que muchas veces ni siquiera ellos siguen. Esto acorde a los testimonios dados por varias gestantes en los grupos focales realizados durante la investigación. Por ejemplo:

"Los médicos solo dan órdenes y no dan ejemplo. Ellos dicen: no fume porque le va a dar cáncer de pulmón y ellos salen y fuman” (GFS)

Es así como se cuenta con 4 grupos de actores claves para la propuesta de estrategia de comunicación: gestantes, su círculo cercano de familiares, los líderes sociales de Secretaría de Integración y los Profesionales de las diferentes entidades que realizan 
acciones con las gestantes. A continuación se presentan los ejes propuestos para abordar en cada uno de los cuatro actores:

Eje comunicativo: Comprende acciones de Información, Educación y ComunicaciónIEC, con los diferentes actores para promover adecuados hábitos alimentarios mediante el cambio de comportamientos. Para esto se requiere participación activa de todos los actores (Profesionales de las instituciones, actores sociales, gestantes y actores influyentes), requiere fomentar y propiciar la construcción participativa de las estrategias mediante metodologías efectivas como por ejemplo "aprender haciendo". De igual manera, las herramientas pedagógicas que se utilicen con las mujeres gestantes deben ser pensadas con la comunidad. Este tipo de intervenciones, son a largo plazo y, acorde a las recomendaciones de la FAO, para su efectividad y sostenibilidad deben ser parte de programas institucionales. (FAO, 2012)

Este tipo de estrategias requiere de un líder, el cual debe ser parte de la Secretaría Distrital de integración Social, como entidad que tiene dentro de sus funciones el bienestar integral de la población vulnerable, para este caso, las gestantes pertenecientes a programas sociales, y es seleccionado porque es un sujeto motivador, tiene experiencia en ser planificador, diseñador y ejecutor de actividades de IEC, a la vez que puede articular acciones de las diferentes entidades competentes y comanda el proceso de seguimiento y evaluación de la estrategia. A continuación se detallan los componentes de la IEC:

Tabla 13. Resumen de los componentes del proceso de Información, Educación y Comunicación

\section{Componentes del Eje comunicativo}

\begin{tabular}{|l|l|l|}
\hline \multicolumn{1}{|c|}{ Información } & \multicolumn{1}{c|}{ Educación } & \multicolumn{1}{c|}{ Comunicación } \\
\hline $\begin{array}{l}\text { Buscar, organizar y analizar } \\
\text { datos de la población estudio: } \\
\text { Características } \\
\text { socioeconómicas }\end{array}$ & $\begin{array}{l}\text { Conocimientos que } \\
\text { permiten proponer acciones } \\
\text { de fortalecimiento de } \\
\text { Capacidades y búsqueda de } \\
\text { Consumo de Medios } \\
\begin{array}{l}\text { Hábitos de consumo } \\
\text { Percepciones }\end{array}\end{array}$ & $\begin{array}{l}\text { Mediante la comunicación se } \\
\text { motiva la acción para la solución de } \\
\text { problemáticas. } \\
\text { soluciones a partir de los } \\
\text { sujetos participantes } \\
\text { estas organizaciones deben aportar } \\
\text { propuestas para el cambio y } \\
\text { participan en el diseño y elaboración } \\
\text { de herramientas pedagógicas. } \\
\text { Se promueve la interacción con } \\
\text { otras instituciones para concertar } \\
\text { alianzas estratégicas. }\end{array}$ \\
\hline
\end{tabular}


A partir de los elementos anteriores, se debe organizar la estrategia en el eje comunicativo estableciendo los objetivos, los mensajes, las herramientas pedagógicas y los indicadores, teniendo como objetivo principal de la acción la promoción de conductas específicas en los diferentes actores y no solo la trasmisión de conocimientos. De igual manera se deben encaminar acciones hacia el empoderamiento de los actores para lograr cambios reales a partir del fortalecimiento de habilidades y destrezas, lo cual se pretende realizar mediante el establecimiento de alianzas estratégicas o redes de articulación basadas en la estrategia IEC, con las diferentes instituciones distritales que trabajan por el bienestar de las gestantes.

Eje comunico educativo: Este eje permite complementar el componente comunicativo mediante la propuesta del diseño de herramientas mediáticas dirigidas a los diferentes actores y que fortalecerán las acciones propuestas en el marco de la Información, Educación y Comunicación (IEC). Implica por lo tanto la propuesta del uso de los diferentes canales de fácil acceso, piezas y contenido que pueden ser utilizadas para la divulgación de la información que acorde a las características del consumo de medios resultantes en este estudio y según los mensajes que deben ser reforzados para contribuir al mejoramiento de la situación nutricional de las gestantes.

A continuación se describirá, al proceso a través del cual se definieron estos medios y piezas y no otras, siempre contando con las preferencias tanto de las mujeres gestantes como de los actores clave:

En los grupos focales, varias mujeres opinaron que preferirían recibir información por Facebook: "Por face me gustaría recibir información porque se podría compartir, pero tendría que ser algo atractivo para mamás para mirarlo, seguirlo y compartirlo: mamás y cuidado." (GFB)

Varias opinaron que les gustaría mucho poder ver videos y recibir información de esta forma: "Prefiero ver un video y no leer algo" (GFS), "Yo en realidad, prefiero ver video prácticos" (GFB) y prefieren que las características de los videos sean las siguientes:

"Yo me fijaría en la información y video: si hay imágenes con fondo blanco y hablando es aburrido, debe ser atractivo para que se quiera ver." (GFS)

Esto implica que las piezas que se transmitan deben bien diseñadas visualmente para que las mujeres las vean y las compartan, no es suficiente solo con el contenido. 
Con relación a WhatsApp, algunas opinaron: "Por WhatsApp, no me gustaría mucho mensajes, mejor recibir una imagen con un mensaje corto, como un meme. Sería atractivo y le pongo más cuidado" (GFB). Esto significa que les gustaría recibir información por este medio pero no que sean mensajes escritos, la preferencia es imágenes:

"Uno de mamá está ocupado y no tiene tiempo de ponerse a leer, ir a la biblioteca, no se ven oraciones o textos largos, llega más un mensaje directo y grafico" (GFS)

"Me gustaría que me llegara información por WhatsApp y Facebook porque es más sencillo que llegue, no hay que buscarla, solo llega." (GFB)

En conclusión, acorde a estos comentarios, la preferencia para recibir información por redes sociales sería por Facebook y WhatsApp, por medio de formatos cortos, atractivos, con imágenes y pocas palabras.

Por otra parte, para establecer el tipo de piezas que se debería utilizar, se presentaron a las gestantes y sus acompañantes, los siguientes modelos:

1. Videos

2. Infografías

3. Mensajes

\section{Videos}

Opción 1: Video de Profesional hablando con una mujer gestante, donde se muestran ejemplos de los alimentos que se deben comer durante el embarazo y explicando por qué son importantes durante el embarazo

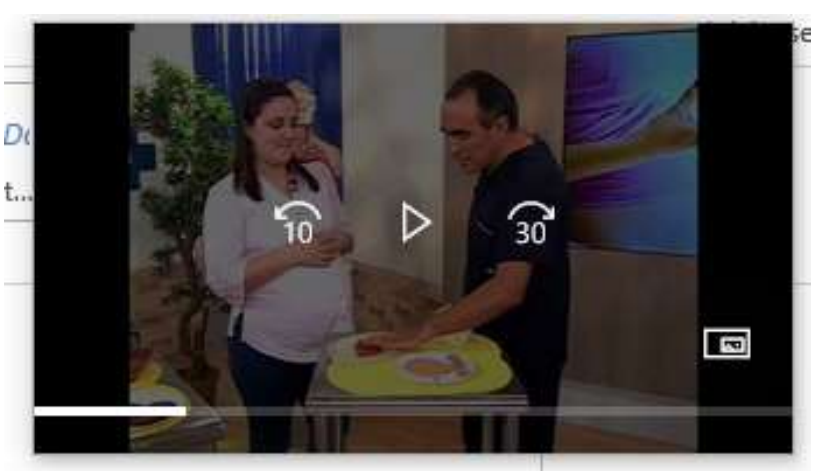

Fuente: https://www.youtube.com/watch?v=GWIWeojW7H8
Tiempo de duración: 7 Minutos

Nivel de tecnicidad: El Doctor usa terminologías técnicas como: E coli, Salmonella, unidades de retinol, pasteurizados y luego explica en términos comunes a qué se refiere.

La gestante contaba si comía o no los alimentos y porqué lo hacía.

En los grupos focales, algunas mujeres opinaron que este formato es sencillo, práctico y acorde a un bajo presupuesto. Otras dijeron que el profesional daba información 
interesante y explicaba bien a que se refería, además respetaba la opinión de la gestante participante.

Opción 2: Video de una YouTuber gestante donde muestra lo que come en un día y da recomendaciones sobre alimentación

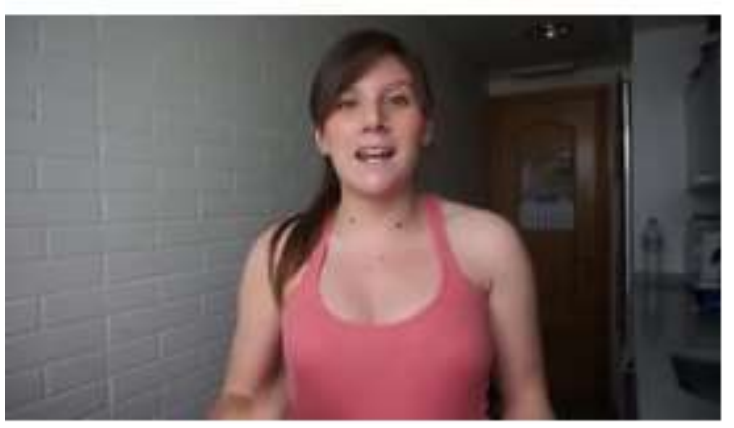

Fuente:https://www.youtube.com/watch?v=y8Ap88xdQkk
Tiempo de duración: 10 minutos

Nivel de tecnicidad: La gestante habla en términos comunes, contando sus gustos, sus cambios en el embarazo para bienestar de la salud de ella, su hijo y su familia. No utiliza términos técnicos, solo cuenta su experiencia y da consejos acorde a lo que ella ha investigado sobre la alimentación en la gestación.

Con relación a esta pieza las opiniones dadas por las participantes del grupo focal fueron varias. Algunas manifestaron que le creerían más si tuviera también la participación de un profesional de la salud, que hablaba mucho y no iba al grano. Sin embargo, otros participantes opinaron que fue muy agradable cómo se expresaba la YouTuber y que la seguirían en su canal para saber cómo le fue con el resto del embarazo.

Opción 3: Video de una sección de un programa tipo "Buenos días" donde entrevistan a un profesional mientras los presentadores preparan una receta.

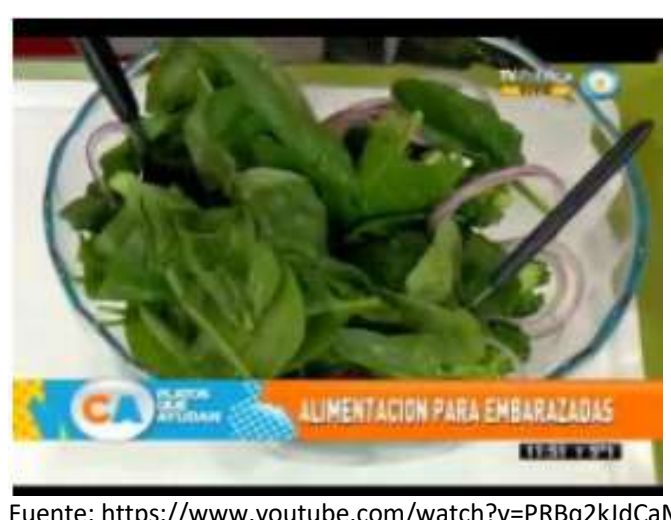

Fuente: https://www.youtube.com/watch?v=PRBq2kJdCaM
Tiempo de duración: 13 minutos

Nivel de tecnicidad: El médico utiliza terminología técnica como por ejemplo: ingesta, metabolismo, cuerpos cetónicos, hematocrito, etc.

Sin embargo, esto es aclarado por los presentadores quienes si utilizan términos coloquiales y van mostrando cómo preparar una ensalada para las gestantes. 
Con relación a esta última pieza, a las personas que les gustó argumentaron que la información era práctica y la receta que prepararon era fácil de hacer y aunque el médico usaba tecnicismo, luego explicaba a qué se refería y se hacía entender.

Adicionalmente, los participantes a los grupos focales opinaron sobre otras opciones que les parecen interesantes para ver recomendaciones sobre alimentación saludable: "Me gusta "Tasty” que en un minuto presenta una receta fácil de hacer y rápido" (GFS)

"Recetas de alimentación saludable con alimentos accesibles y rápidos y que sea bueno para la nutrición de la familia" (GFS)

"Es importante que en el video muestren que alimentos y la preparación" (GFB)

"Videos de un minuto, productos fácil de conseguir con el letrero que va dando los pasos" (GFB)

Varias mujeres estuvieron coinciden en no estar interesadas en qué contiene el alimento, como por ejemplo; contiene vitamina A, prefieren saber qué utilidad brinda, es decir, prefieren información como: la zanahoria es buena para los ojos. Lo anterior se constata en los siguientes testimonios "Me gustaría recibir información de recetas, no me interesa mucho saber qué contienen los alimentos, sino para qué sirve” (GFS)

"No quiero saber para qué sirve el pollo, quiero saber cómo preparar el pollo y para qué sirven los alimentos que se utilizan" (GFS)

En conclusión, las piezas de video deben tener las siguientes características:

a. video corto

b. Muestre una receta rica, preparada con alimentos de la región, accequibles y que sea fácil de preparar

c. Explique para qué sirven los alimentos utilizados y no necesariamente que se aclare cuáles nutrientes contienen

d. Utilice lenguaje fácil de entender sin tantos tecnicismos

Frente a la pregunta, sobre por cuál de los medios les gustaría recibir este tipo de videos, la mayoría están de acuerdo en recibirlos por WhatsApp o por Facebook. 


\section{Infografías}

Luego se presentó en el grupo focal dos ejemplos de afiches o infografías, por medio de los cuales se informa sobre alimentación saludable de la gestante. Se solicitó a los participantes que escogieran el que más les gusta y estos son los resultados:

Opción 1.

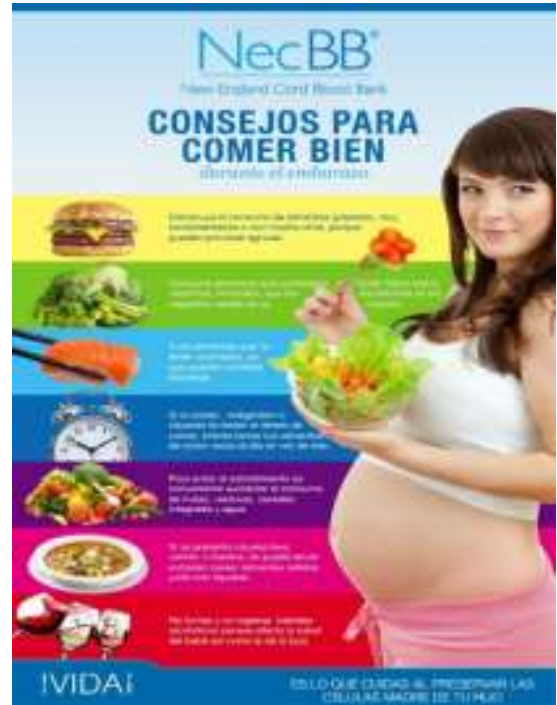

Varias de las mujeres opinaron que esta pieza no es atractiva ya que contiene mucho texto e imágenes que no llaman la atención.

Las mujeres argumentaron que no estarían muy interesadas en leerla y mucho menos en compartirla

Opción 2.

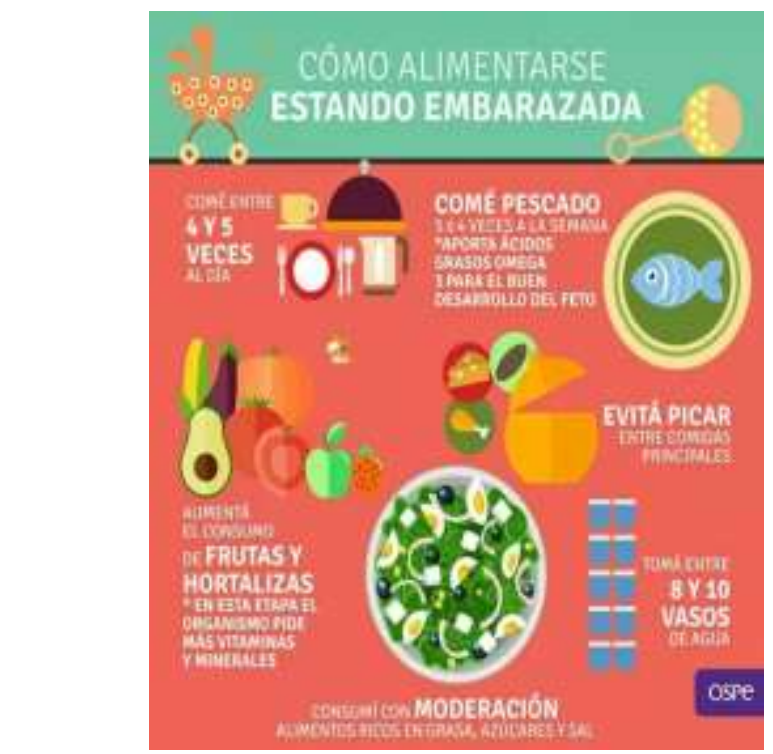

Este tipo de afiche es preferido por las participantes, las cuales refieren que tiene imágenes atractivas, información más sencilla:

"Me gusta la del lado derecho por el contenido básico, sin tantas palabras, se ve mejor, los colores e información directa" (GFS)

"La información es muy clara, especifica y explica para qué es" (GFB) 
Esto significa que prefieren información corta, concreta, clara con muchos dibujos y pocas letras, de buen tamaño y sin imágenes que simbolicen órdenes o aspectos rígidos como un reloj.

Medio preferido para recibir las infografías: En relación a este tema, la mayoría coincidieron en que prefieren recibirlas por WhatsApp o por Facebook:

"Si me gustaría que me llegaran infografías como la de la derecha por Facebook o whatsapp porque uno está metido entre esos dos aplicativos" (GFB)

"Todos los días usamos Facebook y whatsapp, entonces me parece bien que me llegue información por cualquiera de esas dos" (GFB)

Frecuencia del envío de los mensajes: Al indagar sobre la frecuencia, la mayoría opinan que sería ideal recibir mensajes de manera semanal porque todos los días es "aburrido":

"Un mensaje a la semana, "el mensaje de la semana" (GFS)

"Cada semana porque todos los días es aburrido" (GFB)

\section{Mensajes}

Con el objeto de validar mensajes, se presentan los dos ejemplos siguientes que les podrían llegar a las mujeres por diferentes medios:

Opción 1: ¿Has probado la papaya picada con queso? Mmmm es de lo mejor

Opción 2: ¿Sabías que las mujeres embarazadas no deben comer por dos sino para dos?

Las opiniones fueron las siguientes:

"Me gusta más el segundo, también sería interesante unirlas: si estas embarazada debes alimentarte mejor. Consume papaya con queso es deliciosa y ayuda a mejorar la visión" (GFB)

"La primera cuando uno está embarazada lo provoca a uno." (GFS)

"Las dos me gusta: la segunda es general y la primera les dice que comer" (GFS)

"Quisiera algo como: consume papaya que es buena para la visión y no consume papaya porque tiene vitamina A" (GFB)

"El dos porque en el primero pregunta, en el segundo asegura algo" (GFS)

Medio para recibir el mensaje: Luego se indaga sobre si le gustaría que le llegara por Whatsapp estos mensajes, ante lo cual responden: 
"Si me gustaría que me llegara el mensaje con una pequeña introducción o explicación: por ejemplo, el primero complementado con explicación sobre para qué sirve la papaya y el queso." (GFS)

"La sola pregunta no me dice nada: ¿has probado la papaya con queso? No me dice nada, prefiero que me diga para que sirve: por ejemplo: consume papaya con queso porque la papaya sirve para mejorar la visión.” (GFB)

"Si me dicen, la calabaza es rica, cómetela: no me la como, pero si me explican que la calabaza tiene algo muy bueno para mí y además me muestran cómo consumirla en receta práctica, sencilla y rica, me la como" (GFS)

"No me gusta la remolacha, pero cuando me explican los beneficios para la salud, la voy a preparar por mi cuerpo y mi salud. Me ha pasado eso con la sábila, con la remolacha, la zanahoria, no me gustaba pero por sus beneficios empecé a usarlos" (GFB)

En conclusión a las gestantes les gustaría recibir este tipo de mensajes donde se recomiende el consumo de ciertos alimentos explicando para que sirven.

Finalmente y a partir de la información recopilada durante las fases desarrolladas de recolección de información sobre prácticas alimentarias, preferencias de consumo de medios y validación cultural de los resultados, se estructura la siguiente estrategia de comunicación donde de integran los actores y los ejes con aspectos claves para contribuir a las transformaciones en los hábitos alimentarios de las gestantes:

\subsection{Propuesta de estrategia de comunicación}

\section{GESTANDO ANDO Y ME ALIMENTO BIEN}

Objetivo de la estrategia: Estructurar una estrategia de comunicación para la promoción de la alimentación saludable en las gestantes vinculadas al programa Creciendo en Familia de la Secretaría Distrital de Integración Social

Estructura general: La propuesta de la estrategia de comunicación está compuesta por 3 componentes en los cuales se integran los 4 actores (gestantes, actores cercanos claves, líderes sociales y profesionales institucionales) con los ejes establecidos (Comunicativo y comunico - educativo), estableciendo las actividades que se podrían desarrollar con 
cada uno de ellos, acorde a sus competencias y funciones y finalmente se proponen acciones de monitoreo, seguimiento y evaluación continua. La estrategia tendría entonces la siguiente estructura general:

Ilustración 43. Estructura general de la propuesta de la Estrategia de Comunicación

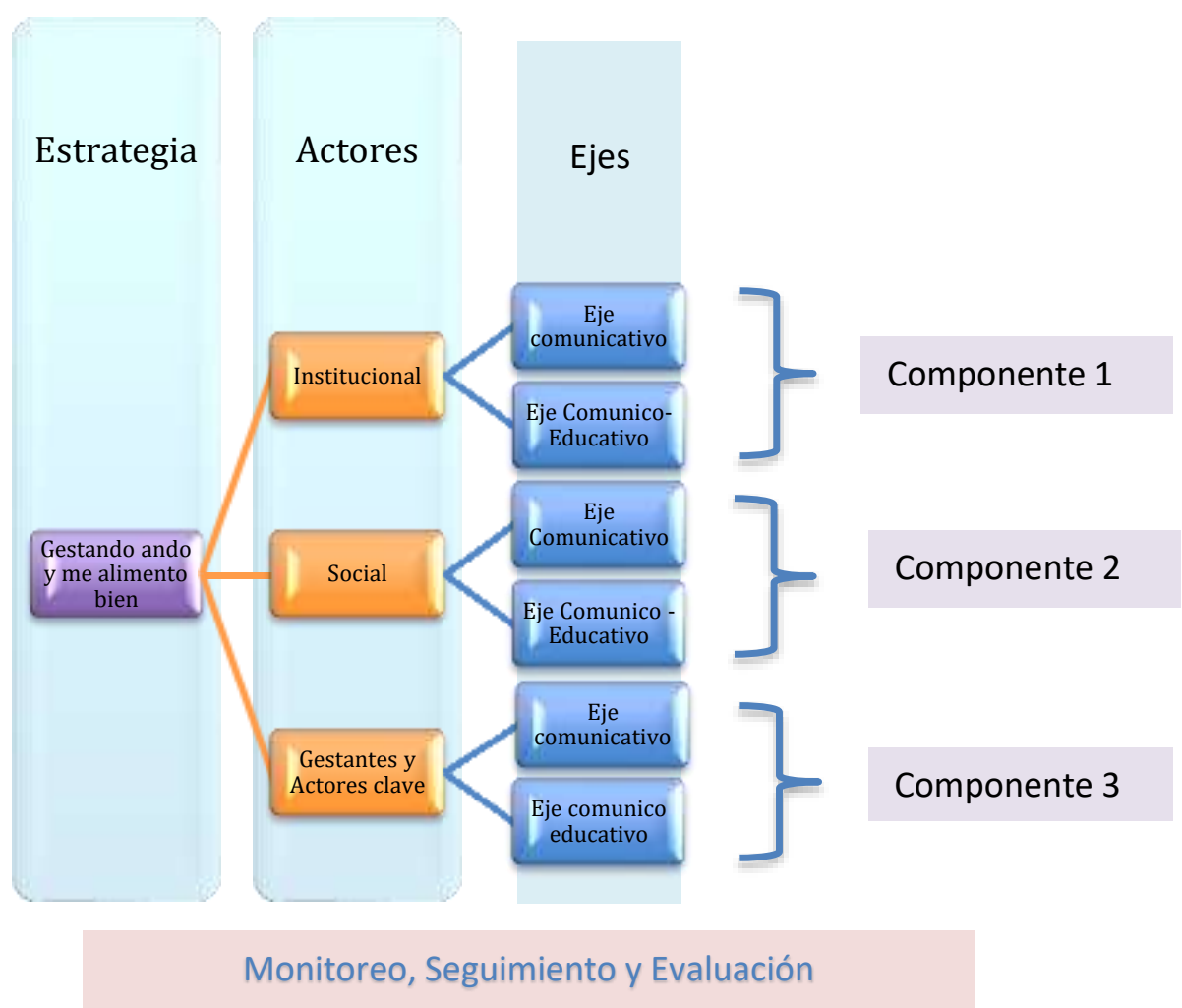

\section{Componente 1}

En este primer componente se integra el actor Institucional con el eje comunicativo y comunico educativo. Inicia con el establecimiento de un líder institucional que tenga la responsabilidad de coordinar la estrategia desde Secretaria Distrital de Integración Social y con las otras entidades competentes para activar acciones interinstitucionales. Este líder institucional debe ser un profesional que conozca muy bien las características de la población gestante, sus prácticas alimentarias, sus preferencias con relación a medios y las razones por las cuales sustentan su actuar, además debe conocer el funcionamiento institucional y específicamente del programa Creciendo en familia, en lo posible debe ser alguien que haya participado en el estudio. 
Es importante aclarar que el líder coordinará la estrategia pero no está solo, debe contar siempre con el equipo multidisciplinario de profesionales de la Secretaría que están trabajando a nivel local con las gestantes porque las acciones acá estipuladas tienen como objetivo, fortalecer las capacidades técnicas de los profesionales de la entidad y de otras instituciones, para poder guiar a las gestantes y sus familias sobre prácticas de alimentación saludable.

Lo anterior se sustenta en las opiniones dadas por varias gestantes, quienes aunque asisten a las sesiones educativas dadas en el programa y a los controles prenatales, consideran que la información dada por el profesional, es interesante pero muchas veces no es realista, no es agradable, entendible, por lo tanto sus recomendaciones sobre alimentación no siempre son acatadas. Las acciones de fortalecimiento de capacidades, está orientadas a brindar técnicas de consejería para que los profesionales tengan las habilidades para informar y hacer recomendaciones a las gestantes y sus familias y sean ellas quienes finalmente decidan, con la información pertinente, cómo deben alimentarse.

Por otra parte, en este componente se activarán acciones intersectoriales, con el objeto de integrar a las entidades oficiales, para accionar las diferentes líneas de la seguridad alimentaria de la mujer gestante:

Línea de Disponibilidad: Jardín Botánico con acciones de agricultura urbana Línea de Acceso: Secretaría de Integración con acciones sobre distribución adecuada de los recursos para menús saludables

Línea de Consumo: Secretaria de Salud con menús saludables, minutas variadas y control del incremento de peso de las mujeres gestantes.

Secretaria de Cultura: acciones para la promoción de la alimentación saludable a través del juego y las vivencias.

Línea de aprovechamiento Biológico: Secretaría de Salud con acciones de control del consumo de micronutrientes

En resumen, el primer componente tendría la siguiente estructura: 


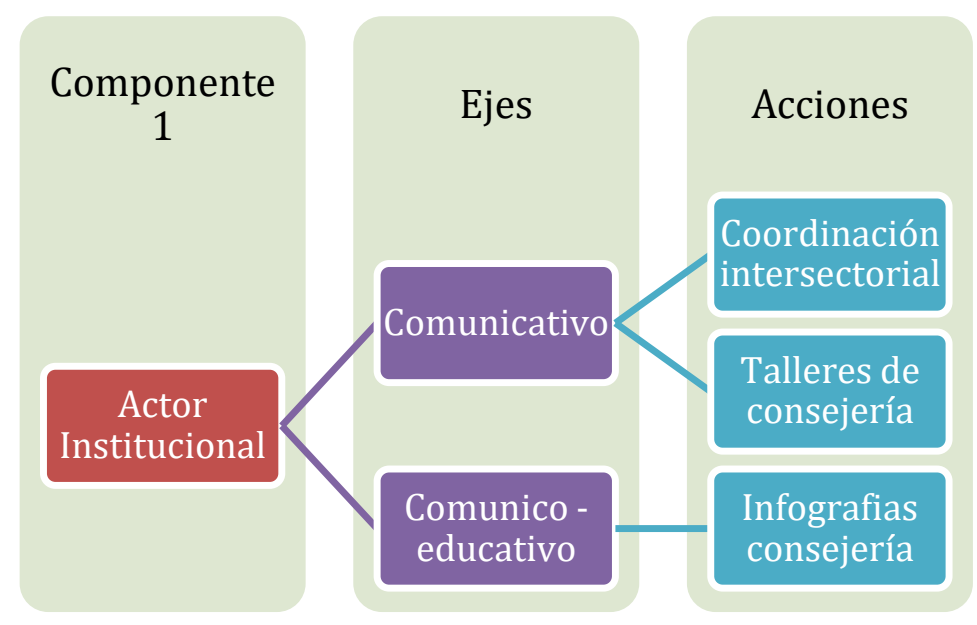

a. Comunicativo: En este eje se realizarán dos actividades: Coordinación de acciones intersectorial y fortalecimiento de capacidades mediante talleres de consejería:

Coordinación intersectorial: El líder institucional deberá organizar mesas técnicas de trabajo para articular acciones alrededor de la alimentación de las gestantes con las entidades públicas que actualmente realizan acciones con estas mujeres. La intención de esta actividad es garantizar seguridad alimentaria desde las diferentes líneas de la misma: disponibilidad, acceso, consumo y aprovechamiento biológico.

Fortalecimiento de capacidades mediante talleres de consejería: Se pretende capacitar a los profesionales de Secretaría de Integración y de las otras entidades públicas que trabajan directamente con las mujeres gestantes en técnicas de consejería. Esta es una técnica que ha sido propuesta por la Organización Mundial de la Salud para temas como VIH y alimentación infantil. Esto les brindará conocimientos sobre alimentación saludable, competencias para escuchar, observar, dialogar con las gestantes y habilidades para contribuir a generar confianza y brindar apoyo e información a las mujeres, empoderarlas y finalmente sean ellas quienes decidan qué es lo mejor en relación a la alimentación y cuidado de su bebe.

Las técnicas para escuchar y aprender estarán orientadas a:

a. Uso de lenguaje verbal no útil

b. Hacer preguntar abiertas

c. Emplear respuestas y gestos que demuestren interés

d. Parafrasear lo que las gestantes dicen 
e. Tener empatía, demostrando que comprende lo que la gestante siente

d. Evitar palabras que juzguen a las gestantes

Por otra parte, las técnicas de consejería para reforzar la confianza y dar apoyo, están compuestas por:

a. Aceptar los que la gestante piensa y siente

b. Reconocer y elogiar lo que la gestante está haciendo bien

c. Brindar ayuda práctica

d. Dar información pertinente

e. Usar lenguaje sencillo

f. Hacer una o dos sugerencias, no órdenes.

b. Comunico - educativo. Desde secretaria de integración se crearán y desarrollarán infografías para reforzar las técnicas aprendidas en el curso de consejería. Estas piezas deberán tener mensajes cortos, claros y atractivos, en lo posible, deben ser validados con un grupo de profesionales que hayan participado en el taller de consejería.

En este componente también se contempla la realización de talleres de medios, donde los profesionales participantes puedan aproximarse a la comunicación, la creación de piezas y mensajes claves para las gestantes usuarias con el objeto de fortalecer los procesos de enseñanza de alimentación saludable durante la gestación, esto mediante el fortalecimiento de las competencias para guiar el consumo de ciertos alimentos esenciales para la esta etapa de la vida.

\section{Componente 2}

En este segundo componente se integra el actor social o líder social con el eje comunicativo y comunico educativo. Estos actores son personas de la comunidad que han sido contratados por la Secretaría Distrital de Integración Social para poder articular acciones sectoriales con acciones sociales o comunitarias. Estas personas no son profesionales, pero si son reconocidas como líderes de la comunidad por lo cual pueden ser puente entre el actor institucional y las gestantes y sus familias, además tienen la credibilidad y confianza de las usuarias. 
Su función en el programa Creciendo en familia es principalmente guiar a las gestantes en las actividades a cumplir para poder ser y continuar en el programa y garantizar el cumplimiento de los requisitos de las nuevas integrantes. Además son unas personas importantes en la comunidad que pueden contribuir al fortalecimiento de capacidades de las gestantes en relación a la alimentación saludable, pero para esto es importante que ellas mismas sean capacitadas en habilidades y conocimientos de consejería, garantizando que puedan transmitir mensajes claves y estos sean aceptados por las gestantes y sus familias.

Este líder debe trabajar de la mano con los profesionales de la Secretaría Distrital de Integración Social del programa dirigido a gestantes, así como con otros profesionales de las diferentes entidades vinculadas y dado que el actor institucional coordina el proceso, este líder social colabora con las actividades que se requieran para una exitosa labor y afectar de manera positiva a las familias de las comunidades mediante el uso de técnicas de consejería que ayudan a que las recomendaciones dadas por el profesional, sean realmente adaptadas, acatadas y seguidas. Este componente también tienen eje comunico educativo para la creación y apropiación de mensajes claves para las partes.

En resumen, el segundo componente tendría la siguiente estructura:

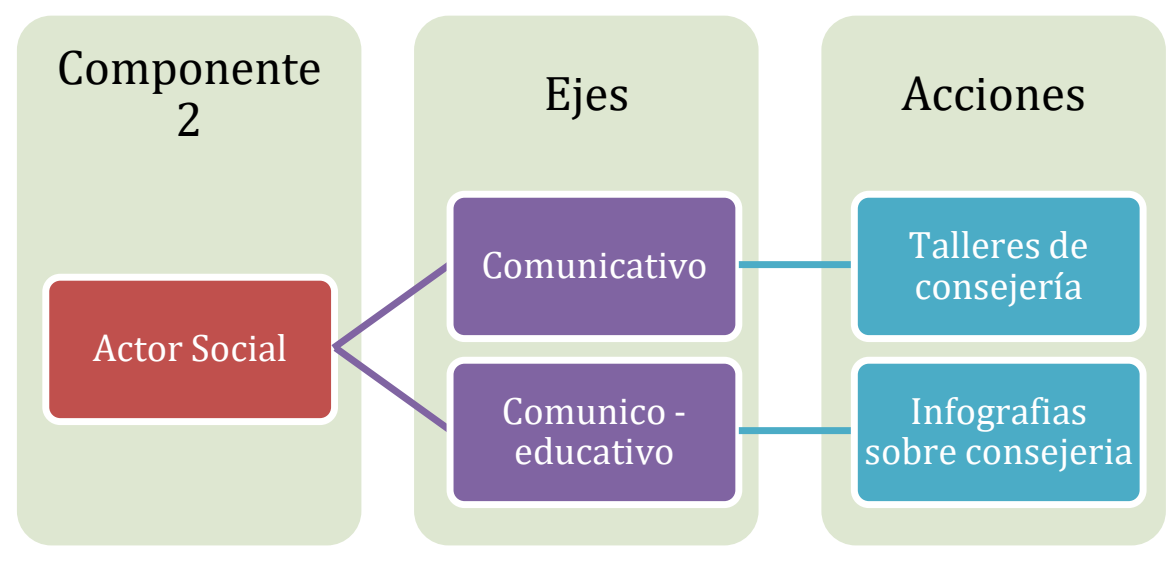

a. Comunicativo: Comprende el desarrollo de talleres de consejería en alimentación saludable de las gestantes, en los cuales los líderes sociales adquirirán los conocimientos necesarios para guiar a las gestantes y sus familias hacia la alimentación saludable y el consumo de alimentos esenciales para ellas, partiendo siempre de las practicas alimentarias características de estas mujeres así como de sus condiciones especiales 
durante la gestación: gustos, antojos, rechazos, susceptibilidad a las órdenes, así como también de las situaciones socio- económicas y culturales particulares.

Los talleres con estos actores incluirán tanto las estrategias para escuchar y aprender dadas a los anteriores actores como las técnicas para técnicas para reforzar confianza y dar apoyo:

Las técnicas para escuchar y aprender:

a. Uso de lenguaje verbal no útil

b. Hacer preguntar abiertas

c. Emplear respuestas y gestos que demuestren interés

d. Parafrasear lo que las gestantes dicen

e. Tener empatía, demostrando que comprende lo que la gestante siente

d. Evitar palabras que juzguen a las gestantes

Técnicas para reforzar confianza y dar apoyo:

a. Aceptar lo que la gestante o familiar piensa y siente.

b. Reconocer y elogiar lo que la gestante o familiar están haciendo bien.

c. Brindar ayuda práctica.

d. Brindar información pertinente.

e. Usar lenguaje sencillo.

f. Hacer una o dos sugerencias, no dé órdenes.

Aprender el uso de estas técnicas requiere de su práctica para que se conviertan en una habilidad, por lo cual requerirá de talleres prácticos y seguimientos a la utilización de los mismos en sus sesiones educativas con las gestantes en las localidades.

b. Comunico educativo: Este componente se fortalecerá con herramientas del eje comunico educativo, en el cual se crearán piezas tipo infografía dirigidas a los actores locales con el objeto de recordar las habilidades que les permitirán dar recomendaciones de alimentación a la gestantes y sus familia garantizando mayor apropiación y empoderamiento de su situación alimentaria. Estas piezas deben ser elaboradas con contenidos propuestos por los actores sociales en los talleres de consejería para que sean realmente apropiados, usados y contribuya al éxito de la estrategia. 
Al igual, que las infografías para las gestantes, estas deben ser con letra clara, información concreta y de fácil recordación e imágenes llamativas.

En este eje se realizarán talleres de medios para que los líderes sean las personas que luego puedan producir información, mensajes y piezas para las gestantes y sus familias.

\section{Componente 3}

En este tercer componente se integra el actor gestantes y familiares cercanos el eje comunicativo y comunico educativo. Las gestantes son actores principales de toda la estrategia, son el centro de atención porque el objetivo final es que puedan alimentarse lo mejor posible para el buen mantenimiento de su salud y la de su hijo. De igual manera, otros actores centrales son sus familiares, madre, abuela, suegra, amiga y compañero, debido a su gran influencia en la decisión del consumo de alimentos durante el embarazo.

En este componente se usan todos los procesos de caracterización realizados durante la investigación, cuáles son las prácticas alimentarias de las gestantes y cuáles son las prácticas en relación al consumo de alimentos en articulación con las razones culturales, económicas y sociales de su comportamiento, ya que solo entendiendo la razón original de su comportamiento, podemos entablar un proceso de dialogo para luego hacer recomendaciones usando su lenguaje y finalmente sea la gestante quien decida cómo debe alimentarse.

Es así como durante este primer momento se crearan acciones en el marco de los ejes dirigidas a las gestantes con la información que ya ellas nos han proporcionado y más adelante, en el proceso de seguimiento y evaluación ellas podrán volver a participar y ayudar a la creación de mensajes y piezas y estrategias de ellas para las futuras gestantes. De igual manera pasa con los familiares cercanos, ahora solo reciben información pero se espera que luego sean artífices de los contenidos, los medios y las piezas, conformando hasta una red comunitaria que contribuya a que otras mujeres y sus familias mejoren sus hábitos alimentarios, no solo durante la gestación sino, también a lo largo de los momentos del curso de vida: primera infancia, infancia, adolescencia, juventud, adultez y vejez.

El componente tres se esquematiza de la siguiente manera: 


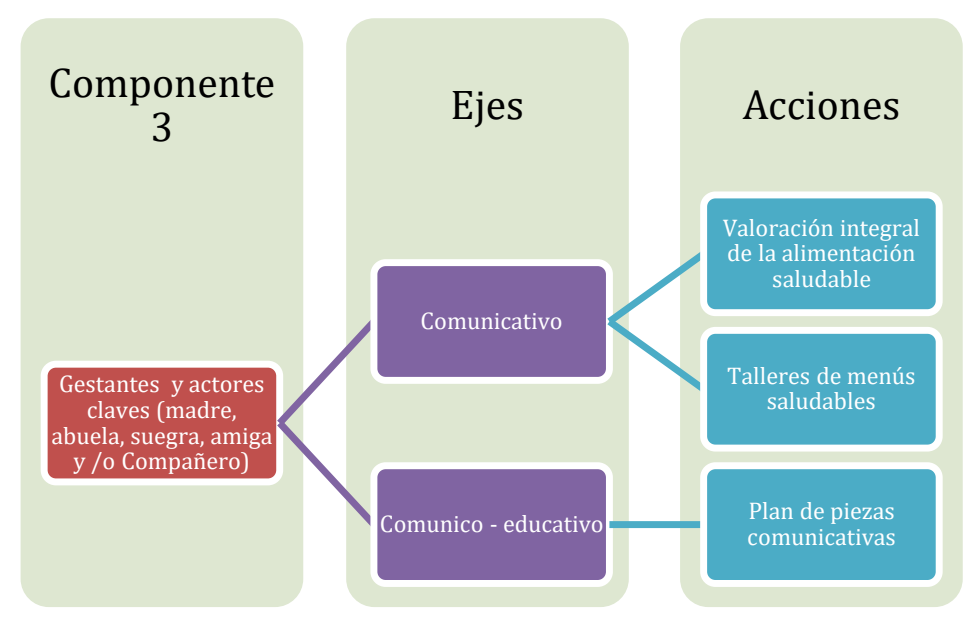

a. Comunicativo: Comprende acciones de formación y fortalecimiento de las gestantes y sus familiares para que de manera informada puedan decidir su consumo saludable de alimentos. Se realizará a partir de la información de la caracterización del consumo de alimentos y de medios y será desarrollado por los profesionales de las entidades participantes formados como consejeros por la Secretaría Distrital de Integración social.

La primera actividad considerada está relacionada con procesos de valoración integral de la alimentación saludable donde los profesionales que la realicen, sean médicos, enfermeros o nutricionistas, psicólogos o educadores, usan sus habilidades en consejería para escuchar de manera atenta a la embarazadas y sus familias y luego a partir de la información dada por ellas, se dan una o dos recomendaciones viables, se elogia a la gestante, se empodera de su momento de vital, como ser generador de vida y finalmente es ella quien decide cómo debe continuar alimentándose, haciendo cambios permanentes que beneficiaran también a su familia.

En un segundo momento, las líderes comunitarias realizarán talleres de menús saludables, los cuales le brindarán elementos técnicos para la planeación de su alimentación diaria. Los líderes deben poner en consideración el costo de los alimentos, los alimentos en cosecha, los alimentos cultivados en casa, los gustos de las mujeres, los alimentos preferidos o rechazados por las gestantes y su origen cultural. Esta información deberá ser trabajada tanto con los profesionales del programa como con las mujeres y sus familias, de manera que los menús propuestos no sean impuestos sino creados por las gestantes en los talleres. 
En estas sesiones de trabajo, los líderes sociales deberán poner en práctica las técnicas de consejería aprendidas y practicadas, logrando finalmente que sean las gestantes y sus familias quienes decidan sobre el consumo de alimentos acorde a las recomendaciones dadas por los profesionales y apoyadas por los familiares de ellas, quienes deben participar en los procesos de formación de manera permanente.

\section{b. Comunico educativo}

Comprende la difusión de las piezas y los mensajes creados a partir del proceso de caracterización desarrollado con las gestantes y sus familias en esta investigación integrando tanto los alimentos que consumen, el consumo crítico o excesivo de algunos de ellos, como los medios preferidos y viables para transmitir la información y la frecuencia recomendada por las gestantes participantes en las encuestas realizadas.

En el plan de medios se presenta el objetivo general del proceso, las características de los mensajes y hacia donde se debe orientar el contenido. En la siguiente tabla se propone el ciclo de envío de los mensajes y el contenido que se debe desarrollar en cada uno de ellos, resultando un ciclo de 6 semanas, en el cual se envía un mensaje a la semana, para luego hacer seguimiento al proceso, reformulación del contenido e inicio del siguiente ciclo de seis semanas más donde se refuerzan los temas enviados a través de los mensajes, reforzando el contenido de los mismos.

Finalmente, se presenta un ejemplo de cómo serían los mensajes y el contenido de los mismos, tanto para las gestantes como para sus familiares o actores clave:

En las siguientes matrices, se presenta el plan de medios propuesto para las gestantes y sus familiares:

\section{Gestantes}

Tabla 14. Plan general de medios

\begin{tabular}{|l|l|l|}
\hline \multicolumn{3}{|c|}{ MATRIZ DEL PLAN DE MEDIOS DIRIGIDO A LA GESTANTE } \\
\hline Objeto & Características de los mensajes & Contenido \\
\hline $\begin{array}{l}\text { Envío de } \\
\text { mensajes } \\
\text { semanales por } \\
\text { WhatsApp }\end{array}$ & $\begin{array}{l}\text { Mensajes cortos } \\
\text { Atractivos } \\
\text { Con información sobre alimentos de la región, } \\
\text { accesibles y ricos } \\
\text { Con recomendaciones y no ordenes } \\
\text { Información sobre la importancia para la salud de } \\
\text { consumir alimentos y no sólo sobre el contenido } \\
\text { nutricional del mismo }\end{array}$ & $\begin{array}{l}\text { Los mensajes deben dirigirse } \\
\text { a orientar el incremento del } \\
\text { consumo diario de vísceras, } \\
\text { frutas, verduras, huevo, } \\
\text { carne o pollo y lácteos. }\end{array}$ \\
\hline
\end{tabular}




\begin{tabular}{|l|l|l|}
\hline $\begin{array}{l}\text { Envío de } \\
\text { infografías } \\
\text { semanales por } \\
\text { Facebook }\end{array}$ & $\begin{array}{l}\text { Uso de gama de colores } \\
\text { Uso de letra grande } \\
\text { Imágenes atractivas } \\
\text { Mensajes claves y pocos }\end{array}$ & $\begin{array}{l}\text { Disminución del consumo } \\
\text { de alimentos fuente de } \\
\text { carbohidratos como arroz, } \\
\text { pasta, papa, plátano, yuca, } \\
\text { pan y productos de } \\
\text { pastelería. Así como de } \\
\text { azucares, miel y panela. }\end{array}$ \\
\hline $\begin{array}{l}\text { Envío de video } \\
\text { semanal de } \\
\text { receta saludable } \\
\text { por Facebook }\end{array}$ & $\begin{array}{l}\text { Video de receta tipo “Tasty" } \\
\text { Corta duración } \\
\text { Uso de alimentos de la región } \\
\text { Recetas ricas y fáciles de preparar } \\
\text { Participación de expertos del tema y presentadoras } \\
\text { agradables }\end{array}$ & $\begin{array}{l}\text { Aumentar la frecuencia del } \\
\text { consumo de alimentos a 5 } \\
\text { tiempos diarios. }\end{array}$ \\
\hline \multicolumn{2}{|l|}{$\begin{array}{l}\text { Asista acompañada a los controles prenatales de manera cumplida y acompañada por alguien } \\
-\quad \text { Asista acompañada a los cursos de preparación de la maternidad y la paternidad }\end{array}$} \\
\hline
\end{tabular}

Tabla 15. Ciclo de envío de la información a las gestantes

\begin{tabular}{|c|c|c|c|c|c|}
\hline \multicolumn{6}{|c|}{ CICLO DE 6 SEMANAS PARA ENVIO DE MENSAJES EN MEDIOS } \\
\hline 1 Semana & 2 Semana & 3 Semana & 4 Semana & 5 Semana & 6 semana \\
\hline $\begin{array}{l}\text { Mensaje de } \\
\text { expectativa }\end{array}$ & $\begin{array}{l}\text { Mensaje por } \\
\text { WhatsApp con } \\
\text { información } \\
\text { sobre consumo } \\
\text { de frutas }\end{array}$ & $\begin{array}{l}\text { Video corto con } \\
\text { información } \\
\text { sobre consumo } \\
\text { de verduras }\end{array}$ & $\begin{array}{l}\text { Infografía sobre } \\
\text { la frecuencia de } \\
\text { los tiempos de } \\
\text { comida }\end{array}$ & $\begin{array}{l}\text { Mensaje sobre } \\
\text { consumo de } \\
\text { leche y lácteos }\end{array}$ & $\begin{array}{l}\text { Mensaje sobre } \\
\text { consumo de } \\
\text { carnes y } \\
\text { visceras }\end{array}$ \\
\hline
\end{tabular}

Tabla 16. Ejemplo del desarrollo del plan de medios dirigido a las gestantes

\begin{tabular}{|l|l|l|l|l|}
\hline $\begin{array}{c}\text { Que } \\
\text { necesita } \\
\text { Saber }\end{array}$ & \multicolumn{1}{|c|}{ Ejemplo de la pieza } & $\begin{array}{c}\text { Canal de } \\
\text { comunicación }\end{array}$ & Características del mensaje & Frecuencia \\
\hline $\begin{array}{l}\text { Mensaje de } \\
\text { expectativa }\end{array}$ & $\begin{array}{l}\text { ¿Hambre o ganas de comer? } \\
\text { ¿Quieres saber cómo } \\
\text { alimentarte bien? }\end{array}$ & WhatsApp & $\begin{array}{l}\text { Mensajes que no den } \\
\text { información técnica, solo que } \\
\text { dejen en suspenso para recibir } \\
\text { información en el siguiente } \\
\text { envío }\end{array}$ & $\begin{array}{l}\text { Solo al } \\
\text { comenzar } \\
\text { el ciclo de } \\
\text { mensajes } \\
\text { de } 6 \\
\text { suntos podemos aprender.... }\end{array}$ \\
\hline $\begin{array}{l}\text { Incremente } \\
\text { el consumo } \\
\text { de frutas }\end{array}$ & $\begin{array}{l}\text { Las frutas ayudan a prevenir } \\
\text { las gripas, ¿Quieres comer dos } \\
\text { diferentes cada día? } \\
\text { iSeguro te sentirás muy bien! }\end{array}$ & WhatsApp & $\begin{array}{l}\text { Mensajes cortos } \\
\text { Atractivos } \\
\text { Con información sobre } \\
\text { alimentos de la región, } \\
\text { accesibles y ricos } \\
\text { Con recomendaciones y no } \\
\text { ordenes } \\
\text { Información sobre la } \\
\text { importancia para la salud de } \\
\text { consumir el alimentos y no del } \\
\text { contenido nutricional del mismo }\end{array}$ & $\begin{array}{l}\text { Segunda } \\
\text { Semana }\end{array}$ \\
& & & & \\
\hline
\end{tabular}




\begin{tabular}{|c|c|c|c|c|}
\hline $\begin{array}{c}\text { Que } \\
\text { necesita } \\
\text { saber }\end{array}$ & Ejemplo de la pieza & $\begin{array}{c}\text { Canal de } \\
\text { comunicación }\end{array}$ & Características del mensaje & Frecuencia \\
\hline $\begin{array}{l}\text { Incremento } \\
\text { del } \\
\text { consumo } \\
\text { de } \\
\text { verduras } \\
\text { crudas }\end{array}$ & $\begin{array}{l}\text { Video donde se presenta } \\
\text { receta de ensalada verde con } \\
\text { ajonjolí. } \\
\text { 1. Se presentan los } \\
\text { ingredientes ya listos con } \\
\text { mensajes en las imágenes: Por } \\
\text { ejemplo: una taza de lechuga } \\
\text { rasgada, un tomate picado en } \\
\text { cuadros, una cucharada de } \\
\text { ajonjolí. } \\
\text { 2. Se muestra la forma de } \\
\text { mezclarlos } \\
\text { 3. Se da alternativa de agregar } \\
\text { gotas de alguna fruta } \\
\text { 4. Se dan mensajes rápidos } \\
\text { sobre las ventajas para la salud } \\
\text { de consumir este tipo de } \\
\text { verduras, es decir, al final el } \\
\text { mensaje se orienta a la función } \\
\text { de las verduras y no a los } \\
\text { componentes de la misma. Por } \\
\text { ejemplo: } \\
\text { Sería muy saludable consumir } \\
\text { todos los días ensaladas } \\
\text { frescas, especialmente si } \\
\text { quieres evitar el estreñimiento }\end{array}$ & $\begin{array}{l}\text { Facebook } \\
\text { Nutri videos }\end{array}$ & $\begin{array}{l}\text { Video de receta } \\
1 \text { minuto } \\
\text { Videos cortos de recetas con } \\
\text { alimentos de la región. } \\
\text { Cortos } \\
\text { Coloridos } \\
\text { Ricas recetas } \\
\text { Atractivo } \\
\text { Fáciles de preparar }\end{array}$ & $\begin{array}{l}\text { Tercera } \\
\text { semana }\end{array}$ \\
\hline $\begin{array}{l}\text { Aumento } \\
\text { de la } \\
\text { frecuencia } \\
\text { de tiempos } \\
\text { de comidas }\end{array}$ & $\begin{array}{l}\text { Infografía donde se recuerda } \\
\text { el consumo de al menos } 5 \\
\text { tiempos de comida al día. } \\
\text { Por ejemplo: } \\
\text { Menú saludable para una } \\
\text { mujer gestante } \\
\text { 1. Se muestra dibujo de } \\
\text { desayuno con una fruta, } \\
\text { proteico, un cereal y un lácteo } \\
\text { 2. Medias nueves: porción } \\
\text { grande de fruta } \\
\text { 3. Almuerzo con Proteína, } \\
\text { leguminosa, ensalada de } \\
\text { verduras y cereal, más agua y } \\
\text { una fruta } \\
\text { 4. Onces: Lácteo y cereal } \\
\text { 5. Comida: Proteico, ensalada } \\
\text { de verduras y cereal. Más } \\
\text { pequeño que el almuerzo } \\
\text { 6. Un lácteo }\end{array}$ & $\begin{array}{l}\text { Facebook y } \\
\text { whatsapp }\end{array}$ & $\begin{array}{l}\text { Infografía colorida, con letra } \\
\text { grande, dibujos reales y } \\
\text { bonitos. Poco texto }\end{array}$ & $\begin{array}{l}\text { Cuarta } \\
\text { semana }\end{array}$ \\
\hline $\begin{array}{l}\text { Incremente } \\
\text { el consumo } \\
\text { de leche y } \\
\text { derivados } \\
\text { lácteos }\end{array}$ & $\begin{array}{l}\text { ¿Sabías que durante el } \\
\text { embarazo la leche y los } \\
\text { lácteos ayudan a fortalecer tus } \\
\text { huesos? Te recomiendo } \\
\text { consumir al menos dos } \\
\text { porciones cada día. }\end{array}$ & Whatsapp & $\begin{array}{l}\text { Mensaje corto, atractivo, } \\
\text { indicando para qué sirve el } \\
\text { alimento y no que nutriente } \\
\text { contiene. } \\
\text { Dar recomendaciones y no } \\
\text { órdenes }\end{array}$ & $\begin{array}{l}\text { Quinta } \\
\text { semana }\end{array}$ \\
\hline
\end{tabular}




\begin{tabular}{|c|c|c|c|c|}
\hline $\begin{array}{c}\text { Que } \\
\text { necesita } \\
\text { saber }\end{array}$ & Ejemplo de la pieza & $\begin{array}{c}\text { Canal de } \\
\text { comunicación }\end{array}$ & Características del mensaje & Frecuencia \\
\hline $\begin{array}{l}\text { Incremente } \\
\text { el consumo } \\
\text { de carnes } \\
\text { rojas y } \\
\text { vísceras } \\
\text { como } \\
\text { hígado o } \\
\text { pajarilla }\end{array}$ & $\begin{array}{l}\text { ¿Has comido Hígado cocinado } \\
\text { en cebolla y tomate? !Es una } \\
\text { preparación fácil, económica y } \\
\text { muy nutritiva! Te invito a } \\
\text { probarla ésta semana. }\end{array}$ & Whatsapp & $\begin{array}{l}\text { Mensaje corto, atractivo, } \\
\text { indicando para qué sirve el } \\
\text { alimento y no que nutriente } \\
\text { contiene. } \\
\text { Dar recomendaciones y no } \\
\text { órdenes }\end{array}$ & $\begin{array}{l}\text { Sexta } \\
\text { semana }\end{array}$ \\
\hline
\end{tabular}

2. Mensajes dirigidos al círculo cercano de la gestante: Madre, abuela, suegra, hermana, compañero y/o amiga

Tabla 17. Plan de medios para familiares

\begin{tabular}{|c|c|c|}
\hline \multicolumn{3}{|c|}{$\begin{array}{l}\text { MATRIZ DE PLAN DE MEDIOS DIRIGIDA AL CÍRCULO CERCANO: MADRE, ABUELA, } \\
\text { SUEGRA, HERMANA, COMPAÑERO Y/O AMIGA }\end{array}$} \\
\hline Objeto & Características de los mensajes & Contenido \\
\hline $\begin{array}{l}\text { Envío de } \\
\text { mensajes } \\
\text { semanales por } \\
\text { WhatsApp }\end{array}$ & $\begin{array}{l}\text { Mensajes cortos } \\
\text { Atractivos } \\
\text { Con información sobre cómo orientar a la } \\
\text { mujer gestante a que consuma una } \\
\text { alimentación saludable. } \\
\text { La información sobre alimentos debe ser con } \\
\text { productos de la región, accesibles y ricos } \\
\text { Orientar al círculo cercano para que de } \\
\text { sugerencias o recomendaciones y no órdenes }\end{array}$ & \multirow{3}{*}{$\begin{array}{l}\text { Los mensajes de esta fase deben } \\
\text { dirigirse a orientar a la familia sobre } \\
\text { cómo guiar a la mujer gestante a } \\
\text { consumir una alimentación saludable, } \\
\text { haciendo recomendaciones sobre la } \\
\text { importancia de consumir ciertos } \\
\text { alimentos esenciales para el bienestar } \\
\text { de la embarazada. } \\
\text { Dada la alta influencia de este grupo } \\
\text { de personas, se deben fortalecer los } \\
\text { mensajes relacionados con: } \\
\text { Aumento del consumo de frutas, } \\
\text { verduras, lácteos, vísceras y } \\
\text { alimentación fraccionada. }\end{array}$} \\
\hline $\begin{array}{l}\text { Envío de } \\
\text { infografías } \\
\text { semanales por } \\
\text { Facebook }\end{array}$ & $\begin{array}{l}\text { Coloridas } \\
\text { Uso de letra grande } \\
\text { Imágenes atractivas } \\
\text { Mensajes claves y pocos }\end{array}$ & \\
\hline $\begin{array}{l}\text { Envío de video } \\
\text { semanal de } \\
\text { receta saludable } \\
\text { por Facebook }\end{array}$ & $\begin{array}{l}\text { Video de receta tipo "Tasty" } \\
\text { Corta duración } \\
\text { Uso de alimentos de la región } \\
\text { Recetas ricas y fáciles de preparar }\end{array}$ & \\
\hline \multicolumn{3}{|c|}{$\begin{array}{l}\text { Mensajes complementarios } \\
\text { - } \quad \text { Asiste acompañada a los controles prenatales } \\
\text { - } \quad \text { Asistamos a los cursos de preparación de la maternidad y la paternidad }\end{array}$} \\
\hline
\end{tabular}

Tabla 18. Ciclo de envío de la información a los familiares

\begin{tabular}{|c|l|l|l|l|l|}
\hline \multicolumn{7}{|c|}{ CICLO DE 6 SEMANAS PARA ENVIO DE MENSAJES EN MEDIOS } \\
\hline 1 Semana & 2 Semana & \multicolumn{1}{|c|}{ 3 Semana } & \multicolumn{1}{|c|}{ 4 Semana } & \multicolumn{1}{|c|}{ 5 Semana } & \multicolumn{1}{|c|}{ semana } \\
\hline Mensaje de & Mensaje por & Video corto con & Infografía sobre la & Mensaje sobre & Mensaje \\
expectativa & WhatsApp & información sobre & recomendación de & cómo & sobre cómo \\
& con & como recomendar & las frecuencias de & recomendar el & recomendar \\
& información & el consumo de & tiempos de & incremento del & el \\
& sobre como & verduras a las & comida en las & consumo de & incremento \\
& recomendar & gestantes & gestantes, es & leche y lácteos & del consumo \\
\hline
\end{tabular}




\begin{tabular}{|l|l|l|l|l|l|}
\hline & $\begin{array}{l}\text { el consumo } \\
\text { de frutas a } \\
\text { las gestantes }\end{array}$ & $\begin{array}{l}\text { decir, } \\
\text { alimentación } \\
\text { fraccionada }\end{array}$ & $\begin{array}{l}\text { en las mujeres } \\
\text { gestantes }\end{array}$ & $\begin{array}{l}\text { de carnes y } \\
\text { vísceras en } \\
\text { las gestantes }\end{array}$ \\
\hline
\end{tabular}

Tabla 19. Ejemplo del desarrollo del plan de medios dirigido a los familiares

\begin{tabular}{|c|c|c|c|c|}
\hline $\begin{array}{c}\text { Que } \\
\text { necesita } \\
\text { saber }\end{array}$ & Ejemplo de la pieza & $\begin{array}{c}\text { Canal de } \\
\text { comunicación }\end{array}$ & $\begin{array}{l}\text { Características de } \\
\text { los mensajes }\end{array}$ & Frecuencia \\
\hline $\begin{array}{l}\text { Mensaje de } \\
\text { expectativa }\end{array}$ & $\begin{array}{l}\text { ¿Te gustaría ayudar a la } \\
\text { gestante a alimentarse mejor? } \\
\text { ¡Juntos podemos apoyarla! } \\
\text { ¡Te animas? }\end{array}$ & WhatsApp & $\begin{array}{l}\text { Mensajes que no den } \\
\text { información técnica, } \\
\text { solo que dejen en } \\
\text { suspenso para recibir } \\
\text { información en el } \\
\text { siguiente envío }\end{array}$ & $\begin{array}{l}\text { Solo al } \\
\text { comenzar el } \\
\text { ciclo de } \\
\text { mensajes de } \\
6 \text { semanas }\end{array}$ \\
\hline $\begin{array}{l}\text { Recomendar } \\
\text { el consumo } \\
\text { de frutas }\end{array}$ & $\begin{array}{l}\text { El consumo diario y variado } \\
\text { de frutas ayuda a la buena } \\
\text { salud de las gestantes. } \\
\text { ¿Podrías hoy llevarle una fruta } \\
\text { para que consuma a las onces? }\end{array}$ & WhatsApp & $\begin{array}{l}\text { Mensajes cortos } \\
\text { Atractivos } \\
\text { Con información } \\
\text { sobre alimentos de la } \\
\text { región, accesibles y } \\
\text { ricos } \\
\text { Con } \\
\text { recomendaciones y } \\
\text { no ordenes } \\
\text { Información sobre la } \\
\text { importancia para la } \\
\text { salud de consumir el } \\
\text { alimentos y no del } \\
\text { contenido nutricional } \\
\text { del mismo }\end{array}$ & $\begin{array}{l}\text { Segunda } \\
\text { Semana }\end{array}$ \\
\hline $\begin{array}{l}\text { Recomendar } \\
\text { el } \\
\text { incremento } \\
\text { del consumo } \\
\text { de verduras } \\
\text { crudas }\end{array}$ & $\begin{array}{l}\text { Video donde se presenta } \\
\text { receta de remolacha, } \\
\text { zanahoria, huevo, cilantro y } \\
\text { crema de leche } \\
\text { 1. Se presentan los } \\
\text { ingredientes ya listos con } \\
\text { mensajes en las imágenes: Por } \\
\text { ejemplo: media taza de } \\
\text { zanahoria cocinada picada, } \\
\text { media taza de remolacha en } \\
\text { cuadros picada, un huevo } \\
\text { cocido y picado y cilantro } \\
\text { picado, además de media } \\
\text { cucharada de crema de leche y } \\
\text { una pizca de sal. } \\
\text { 2. Se muestra la forma de } \\
\text { mezclarlos } \\
4 . \text { Se dan mensajes rápidos } \\
\text { sobre las ventajas para la salud } \\
\text { de consumir este tipo de } \\
\text { verduras, es decir, al final el } \\
\text { mensaje se orienta a la función } \\
\text { de las verduras y no a los } \\
\text { componentes de la misma. Por } \\
\text { ejemplo: Para tener una piel }\end{array}$ & $\begin{array}{l}\text { Facebook } \\
\text { Nutri videos }\end{array}$ & $\begin{array}{l}\text { Video de receta } \\
1 \text { minuto } \\
\text { Videos cortos de } \\
\text { recetas con } \\
\text { alimentos de la } \\
\text { región. } \\
\text { Cortos } \\
\text { Coloridos } \\
\text { Ricas recetas } \\
\text { Atractivo } \\
\text { Fáciles de preparar }\end{array}$ & $\begin{array}{l}\text { Tercera } \\
\text { semana }\end{array}$ \\
\hline
\end{tabular}




\begin{tabular}{|c|c|c|c|c|}
\hline $\begin{array}{c}\text { Que } \\
\text { necesita } \\
\text { saber }\end{array}$ & Ejemplo de la pieza & $\begin{array}{c}\text { Canal de } \\
\text { comunicación }\end{array}$ & $\begin{array}{l}\text { Características de } \\
\text { los mensajes }\end{array}$ & Frecuencia \\
\hline & $\begin{array}{l}\text { sana durante el embarazo, } \\
\text { recomiéndale a la gestante } \\
\text { consumir ensaladas todos los } \\
\text { días. ¡Te lo agradecerá! }\end{array}$ & & & \\
\hline $\begin{array}{l}\text { Recomendar } \\
\text { el aumento } \\
\text { de la } \\
\text { frecuencia } \\
\text { de tiempos } \\
\text { de comidas }\end{array}$ & $\begin{array}{l}\text { Infografía donde se dan } \\
\text { mensajes para que las } \\
\text { personas más influyentes en } \\
\text { las gestantes les recuerden el } \\
\text { consumo de al menos } 5 \\
\text { tiempos de comida al día. } \\
\text { Por ejemplo: } \\
\text { ¡Oye i Tú que tanto } \\
\text { experiencia tienes!, recuérdale } \\
\text { a la gestante que su cuerpo } \\
\text { necesita comer, además de } \\
\text { desayuno, almuerzo y comida, } \\
\text { por lo menos } 2 \text { refrigerios } \\
\text { entre las comidas. } \\
\text { Ella te escucha y sigue tus } \\
\text { pasos. } \\
\text { Gracias por ayudarnos a tener } \\
\text { unas gestantes muy sanas. } \\
\text { En la infografía puede ir una } \\
\text { imagen de talonario donde los } \\
\text { médicos escriben los } \\
\text { medicamentos, con una } \\
\text { imagen de menú diario y } \\
\text { firmado: } \\
\text { Con amor... mamá y ahora } \\
\text { abuela } \\
\text { Con amor.... Esposo y ahora } \\
\text { papá } \\
\text { Con amor... hermana y ahora } \\
\text { tía } \\
\text { Con amor ... amiga y ahora } \\
\text { madrina }\end{array}$ & $\begin{array}{l}\text { Facebook y } \\
\text { whatsapp }\end{array}$ & $\begin{array}{l}\text { Infografía colorida, } \\
\text { con letra grande, } \\
\text { dibujos reales y } \\
\text { bonitos. Poco texto }\end{array}$ & $\begin{array}{l}\text { Cuarta } \\
\text { semana }\end{array}$ \\
\hline $\begin{array}{l}\text { Mensajes } \\
\text { sobre } \\
\text { recomendar } \\
\text { el consumo } \\
\text { de leche y } \\
\text { derivados } \\
\text { lácteos }\end{array}$ & $\begin{array}{l}\text { Gracias a la leche y a los } \\
\text { lácteos la mujer embarazada } \\
\text { puede tener huesos sanos y } \\
\text { fuertes. ¿Podrías invitarla a } \\
\text { comer alguno de estos } \\
\text { alimentos? }\end{array}$ & Whatsapp & $\begin{array}{l}\text { Mensaje corto, } \\
\text { atractivo, indicando } \\
\text { para qué sirve el } \\
\text { alimento y no que } \\
\text { nutriente contiene. } \\
\text { Dar recomendaciones } \\
\text { y no órdenes }\end{array}$ & $\begin{array}{l}\text { Quinta } \\
\text { semana }\end{array}$ \\
\hline $\begin{array}{l}\text { Recomendar } \\
\text { el } \\
\text { incremento } \\
\text { el consumo } \\
\text { de carnes } \\
\text { rojas y } \\
\text { visceras } \\
\text { como hígado } \\
\text { o pajarilla } \\
\end{array}$ & $\begin{array}{l}\text { ¿Te gustaría en el almuerzo } \\
\text { consumir un hígado en bistec } \\
\text { al caballo? Seguro que a la } \\
\text { gestante también, te invito a } \\
\text { prepararle un trozo y a } \\
\text { sentarse juntos a la mesa. } \\
\text { ¡Seguro se sorprenderá de lo } \\
\text { bien que cocinas! }\end{array}$ & Whatsapp & $\begin{array}{l}\text { Mensaje corto, } \\
\text { atractivo, indicando } \\
\text { para qué sirve el } \\
\text { alimento y no que } \\
\text { nutriente contiene. } \\
\text { Dar recomendaciones } \\
\text { y no órdenes }\end{array}$ & $\begin{array}{l}\text { Sexta } \\
\text { semana }\end{array}$ \\
\hline
\end{tabular}




\section{Fase: Monitoreo y evaluación}

Con el objeto de contribuir a que la estrategia sea eficaz y efectiva, se requiere de un proceso de seguimiento al cumplimiento de los objetivos, las actividades y los resultados de la estrategia de comunicación. Este proceso de monitoreo debe estar acompañado por un proceso de evaluación, el cual se debe hacer antes, durante y después de la estrategia para medir los impactos y transformaciones generadas en las gestantes participantes.

Se deben definir indicadores cuantitativos y cualitativos y establecer la metodología que permitirá hacer el monitoreo y evaluación de la estrategia. La finalidad del proceso es asegurar que lo planeado está bien y que en caso de requerir ajustes, estos se pueden hacer a tiempo. Además permite medir la estrategia para establecer aspectos positivos que puedan usarse más adelante en otras estrategias.

Esta fase deberá ser coordinada por el profesional de la Secretaría Distrital de Integración Social que lidera el proceso, pero no lo puede realizar solo, se requiere de la participación de los diferentes actores involucrados: profesionales, líderes sociales, gestantes, familiares, ya que ellos podrán aportar importantes opiniones para el mejoramiento del proceso, así como ideas nuevas para el siguiente periodo de la estrategia. De igual manera, se busca que las personas que participaron puedan aportar para la construcción de nuevas piezas, nuevos diseños y nuevos contenidos, acorde a la experiencia que ellos han tenido. A continuación, se hace un consolidado de elementos orientadores propuestos para el monitoreo y la evaluación de la estrategia:

Tabla 20. Proceso de monitoreo y evaluación

\begin{tabular}{|c|c|c|}
\hline \multicolumn{3}{|c|}{ Monitoreo y evaluación de la estrategia } \\
\hline Indicadores & Variables & Preguntas orientadoras \\
\hline De proceso & $\begin{array}{l}\text { Cumplimiento de las } \\
\text { actividades con las gestantes } \\
\text { De cobertura } \\
\text { Calidad de los mensajes }\end{array}$ & $\begin{array}{l}\text { ¿El número de gestantes a las que se } \\
\text { planeó llegar es el mismo número al } \\
\text { que se llegó? } \\
\text { ¿Se está mejorando? } \\
\text { ¿Que se está haciendo para mejorar? }\end{array}$ \\
\hline
\end{tabular}

Cumplimiento de actividades El número de profesionales y líderes con los profesionales sociales a los que se planeó llegar es el institucionales y con los líderes mismo número al que se llegó? sociales ¿Se está mejorando?

¿Que se está haciendo para mejorar? 


\begin{tabular}{|c|c|c|}
\hline \multirow[t]{3}{*}{$\begin{array}{l}\text { De } \\
\text { resultado }\end{array}$} & $\begin{array}{l}\text { Piezas comunicativas } \\
\text { Los medios de comunicación }\end{array}$ & $\begin{array}{l}\text { ¿El lenguaje es apropiado? ¿El medio } \\
\text { seleccionado fue el apropiado y es } \\
\text { sostenible? } \\
\text { ¿Qué se ha logrado? ¿Cómo estábamos } \\
\text { antes y cómo estamos ahora? }\end{array}$ \\
\hline & Talleres de consejería dirigidos & ¿La metodología es apropiada? \\
\hline & $\begin{array}{l}\text { a profesionales y líderes } \\
\text { sociales }\end{array}$ & $\begin{array}{l}\text { ¿Qué se ha logrado? } \\
\text { ¿Cómo estábamos antes y cómo } \\
\text { estamos ahora? }\end{array}$ \\
\hline \multirow[t]{7}{*}{ De impacto } & La estrategia en general & ¿Se ha logrado el impacto esperado? \\
\hline & Cambio de prácticas, actitudes & ¿La estrategia ha cambiado prácticas, \\
\hline & y comportamientos & actitudes $\quad \mathrm{y}$ \\
\hline & $\begin{array}{lll}\text { relacionados } & \text { con } & \text { la } \\
\text { alimentación } & & \end{array}$ & $\begin{array}{l}\text { relacionados } \quad \text { con } \quad \text { prácticas } \\
\text { alimentarias. }\end{array}$ \\
\hline & Sostenibilidad de la estrategia & $\begin{array}{l}\text { ¿Los medios de comunicación son los } \\
\text { más eficientes? }\end{array}$ \\
\hline & & $\begin{array}{l}\text { ¿Las estrategias propuestas son las } \\
\text { mejores para trabajar con profesionales } \\
\text { y líderes sociales? }\end{array}$ \\
\hline & & $\begin{array}{l}\text { ¿Qué cambio? ¿Este cambio será } \\
\text { permanente? }\end{array}$ \\
\hline
\end{tabular}




\section{Conclusiones}

Llegue a la maestría de Comunicación, Desarrollo y Cambio Social de la Universidad Santo Tomás buscando aprender cómo, mediante la comunicación, lograr acciones efectivas para la promoción de la salud y prevención de la enfermedad. Esto debido a que a partir de mi experiencia personal como profesional de la salud he evidenciado que, a pesar de las diferentes campañas que se realizan para mejorar es estilo de alimentación de la población, continúa siendo el principal problema, las enfermedades crónicas no transmisibles como la enfermedad coronaria y la hipertensión arterial, las cuales son evitables mediante una adecuada alimentación durante el transcurso de la vida, la cual inicia con la gestación, continua con la lactancia materna y la alimentación complementaria.

Durante los dos años del transcurso de los 4 semestres, aprendí qué es comunicación y comprendí cómo puede ser una herramienta para el desarrollo y el cambio social, muy lejos de lo que yo me imaginaba que era. Finalmente realizó mi trabajo de grado en buscar cómo promover efectivamente la alimentación saludable de la gestante, periodo en el cual las mujeres están dispuestas a hacer cambios en sus hábitos alimentarios, buscando el bienestar y la salud tanto de ellas como de sus hijos y este trabajo se vincula a una investigación longitudinal sobre prácticas alimentarias desde la gestación hasta los dos años, que está realizando el Instituto Nacional de Salud, Colciencias y la Secretaría de Salud y se espera que este producto pueda ser un instrumento de planeación útil para que desde la salud pública, se pueda realmente contribuir a generar transformaciones, cambios e impactos que beneficien la salud de la población Colombiana.

Es así como resultado de este proceso, puedo presentar a continuación las siguientes conclusiones:

Esta investigación permitió conocer las características sociales, alimentarias y de consumo de medios de una muestra de mujeres diversas: la mayoría se encuentran entre los 19 y los 37 años de edad; viven, aproximadamente la mitad, con su esposo o conyugue y las demás con un familiar, la mayoría tiene educación básica incompleta o media completa; casi todas son estrato 2, trabajan en oficios del hogar o estudian. Con relación 
a sus ingresos, en más de la mitad de los hogares, solo una persona aporta dinero, obteniendo un promedio mensual de $\$ 713.570$, valor que está por debajo del salario mínimo mensual y es usado principalmente para compra de alimentos, servicios, arriendo y productos de aseo. Además de estas características comunes, las une estar en una etapa de la vida especial, corta, pero que genera un impacto para el resto de la vida de una mujer y una familia: la gestación, durante la cual, la mujer presenta cambios físicos, mentales y hormonales que la preparan para la maternidad.

A partir del primer objetivo, se pudo caracterizar cuales son las prácticas alimentarias de las gestantes incluidas en el estudio: estas mujeres presentan un alto consumo de alimentos fuente de carbohidratos, azúcares y leches, un consumo medio de huevos, carnes y pollo y un bajo consumo de frutas, verduras y vísceras y un esquema de alimentación de tres tiempos de comida frente a lo recomendado de 5 o 6 tiempos de comida y todo esto influenciado por las recomendaciones de las madres de estas mujeres, sus abuelas, hermanas, tías, pareja y en último lugar aceptan las recomendaciones del profesional de la salud. Aunque las gestantes son conscientes de algunos de sus malos hábitos alimentarios, por encima de las recomendaciones de los profesionales de la salud, están sus gustos, sus antojos, su presupuesto para alimentación, pero sobretodo sus hábitos alimentarios. Se requiere de un trabajo articulado donde ellas sean protagonistas, actores y creadoras junto con sus familias, sus líderes comunitarios y los profesionales que mes a mes acompañan su gestación para que se logren poco a poco generar empoderamiento y transformaciones reales que contribuyan a mejorar sus hábitos alimentarios y por ende su estado de salud.

Con relación al segundo objetivo, se buscó reconocer cuáles eran los medios más utilizados para recibir información sobre alimentación saludable, y se encontró que es la televisión, el internet y las redes sociales. Sin embargo, debido al alto costo de producción de piezas y de transmisión y sostenibilidad de la televisión, se indaga sobre el uso de internet y redes sociales para la promoción de la alimentación saludable, resultando que los medios más viables y usados son Facebook y WhatsApp debido a que la mayoría de las mujeres los tienen y los usan de manera frecuente. Es importante aclarar que aunque el consumo de medios fue importante caracterizarlo, no es el centro de la estrategia, ya que se propuso una iniciativa con ejes comunicativos y comunico educativos donde los medios son una herramienta y no el fin último. Esto dado que la comunicación para la salud avanzó hacia la búsqueda de superación de los problemas, los cambios reales y 
permanentes, la formación de redes, la movilización para su puesta en la agenda pública y no solo en la creación de piezas para transmitir en los medios de comunicación.

Con esta información se puso en marcha el propósito de unir dos ciencias: ciencias de la salud y ciencias sociales, es decir: nutrición y comunicación. Dos ciencias diferentes pero que unidas se complementan. Considero que los profesionales de la salud deberíamos tener conocimientos más profundos sobre la comunicación porque pensamos que comunicar es solo que un emisor envíe mensajes a un receptor utilizando para ello unos medios. La promoción de la alimentación saludable es una acción compleja porque incluye un gran componente cultural que ha sido trasmitido de generación en generación, que se relaciona con cuáles son los alimentos que se producen, cuáles están disponibles, cuánto cuestan, cuanto tengo para comprarlos y si quiero consumirlos o prefiero otros. Es acá cuando el profesional de la salud debe unir sus conocimientos a la comunicación transversal para la salud: cómo, a partir de la realidad de una comunidad, los empodero, brindo información importante para ellos y juntos organizamos y desarrollamos acciones de promoción de la alimentación que contribuyan a transformar y cambiar hábitos alimentarios inadecuados que perduren realmente en el tiempo y mejoren su situación nutricional, recordando que podemos utilizar herramientas como los medios, pero partiendo de aquellos que realmente utilizan frecuentemente.

De igual manera, el profesional de la salud cuando se une al campo de la comunicación y lo hace a partir de la realidad alimentaria de la comunidad y de la concepción de alimentación saludable de ellos, puede contribuir a autogenerar estrategias que lleven a cambios viables, es decir, puede contribuir al desarrollo porque la comunidad comparte información sobre alimentación y significados de su situación alimentaria, lo cual conlleva al refuerzo de la construcción común de soluciones, a la participación, a una mejor toma de decisiones, a partir de capacidades propias que permitan ampliar opciones y oportunidades de mejora. En esta propuesta de comunicación no se propone un estilo de comunicación horizontal, dominante, homogenizador, donde mediante el uso de unos medios se transmite información a conveniencia, sino una comunicación que permita contribuir a frenar la desigualdad, que incluye participación de actores sociales y locales, promueve el empoderamiento, la movilización, la toma de decisiones de la comunidad, todo enfocado al desarrollo. Es por esto que se buscó tanto información sobre su realidad alimentaria como su realidad del consumo de medios, lo cual luego fue corroborado 
mediante grupos focales donde participaban las gestantes y sus familias, encontrando información valiosa sobre porqué tienen ciertos comportamientos alimentarios y concluyendo el importante papel de los actores claves como las abuelas y suegras, mientras que las recomendaciones de los profesionales no son tan importantes.

La propuesta de estrategia para la promoción de la alimentación saludable está basada en usar la comunicación como un proceso movilizador, donde el dialogo, el conocimiento de la realidad alimentaria y el reconocimiento de los actores claves es la base para el cambio social y el mejoramiento de sus hábitos alimentarios. En esta propuesta tanto las gestantes como los actores claves no son objeto de intervención, son sujetos que construyen sus propias herramientas, a partir de información y apoyo técnico brindado por la institución. Se busca también, generar cambios, por medio del dialogo, de los profesionales y los líderes comunitarios, reconociendo sus conocimientos, miedos, habilidades y debilidades. Esta estrategia pretende fortalecer las habilidades de consejería de los profesionales de las instituciones y de los líderes para que escuchen a las gestantes y sus familias, para que generen confianza y luego puedan brindar apoyo efectivo a estas mujeres para el mejoramiento de su alimentación, contribuyendo así a la salud de ellas y sus bebés.

La estrategia para la promoción saludable debe ser sostenible en el tiempo, debe monitorearse y evaluarse continuamente para en conjunto, entre todos los actores, aportar a su mejoramiento. Acá el dialogo y el debate es fundamental, partir de lo que piensa y puede aportar el otro, propiciar la apropiación comunitaria de la estrategia, con pertinencia cultural, alimentaria y la generación de contenidos para la promoción de la alimentación saludable de la gestantes. Por esto y para propiciar el cambio social, la estrategia debe tener contenidos locales y propiciar la formación de redes que permitan que otras gestantes y sus familias, en pocos meses, también sean beneficiarias y participes de su transformación alimentaria.

Es así como se propone una estrategia de comunicación donde se incluyen los tres grupos de actores claves que más influyen en las gestantes: profesionales de las instituciones, líderes sociales, y gestantes y sus familias. Con cada uno de ellos se estipula trabajar en dos ejes, uno comunico- educativo que está enfocado en fortalecer habilidades de consejería para poder generar confianza en las mujeres gestantes, conocer sus problemas alimentarios y luego poder brindar información clave para contribuir al mejoramiento y 
otro eje comunicativo para reforzar, a través del uso de redes sociales, lo aprendido en las sesiones de consejería. Esto busca que el apoyo que se brinde a las mujeres sea basado en el dialogo, en su realidad, en sus concepciones y no a partir de transmisión de teorías que no generaran cambios e impactos en los hábitos alimentarios de las mujeres y sus familias. Con el tercer grupo, mujeres gestantes y sus familias, los ejes están dirigidos al fortalecimiento de capacidades a partir de talleres prácticos de menús saludables donde se parte del conocimiento de los hábitos alimentarios para fortalecer y mejorar el consumo de alimentos en la gestación y luego utilizando las redes sociales, se refuerzan los conocimientos brindados en los talleres y se hace recordatorio de temas claves para la alimentación. Finalmente se plantean talleres de medios para que las mujeres creen sus propios mensajes, los cuales será útiles para las gestantes que continuaran en el programa.

Esto se enmarca en la metodología de Información, Educación y Comunicación, IEC, la cual fortalece la capacidad de los individuos para incidir directamente en su desarrollo orientando procesos locales de prácticas adecuadas de alimentación saludable, generando cambios en conocimientos, actitudes y prácticas. La IEC no impone procesos, ideas, teorías o formas, en cambio se elaboran a partir de la participación activa de los actores, los cuales, con información correcta y orientación institucional, crean sus propios procesos.

En todo lo anterior, la comunicación estratégica nos guío sobre la mejor forma de estructurar la propuesta, permitió entender que no hay una fórmula única, un modelo a seguir o una estructura aplicable para la promoción de la alimentación saludable de las mujeres gestantes. Esta estrategia requiere un trabajo continuo en equipo, incluyendo a los actores claves que pueden influenciar de manera positiva a las gestantes en relación a la adecuada alimentación, aprovechando las capacidades de cada uno para lograr mejores resultados y proponiendo metodologías pedagógicas y el uso de medios para mayores impactos que perduren y se sostengan en el tiempo. Lo más útil de la comunicación estratégica es su concepción a partir de las realidades de las gestantes, no se puede planear acciones de promoción de la alimentación saludable sin conocer cómo y porque consumen cierto tipo de alimentos, menos proponer uso de medios si no sabemos que escuchan, ven, leen y mucho menos sin saber quiénes son aquellos que realmente influyen en las decisiones alimentaria. Está comunicación pone en el centro a las gestantes, son aceptadas y no pretende cambiar sus hábitos sino mejorarlos, para lo cual se trabaja con ellas mismas, además implica a los actores clave tanto para la construcción como para el 
desarrollo de las estrategia motivándolos siempre a ser agentes de cambio. Se centra en las situaciones, en los movimientos, no hay nada estático, estandarizado ni tampoco verdades únicas, así como también, en el proceso, se dan opciones de cambios, pero no soluciones definitivas porque las realidades son cambiantes y finalmente identifica las fortalezas, roles y oportunidades de los actores para adaptar situaciones y obtener transformaciones en el marco de la alimentación.

Para terminar concluyo mi investigación considerando que la comunicación es un proceso participativo, dialógico, conjunto, progresivo que debe ser parte de procesos de transformación para garantizar su sostenibilidad promoviendo el desarrollo de comunidades empoderadas y garantizando procesos de cambio social que realmente garanticen mejor calidad de vida a las poblaciones actuales y sus próximas generaciones y la promoción de la alimentación saludable en las mujeres que están gestando a los niños del mañana no pueden ser ajenas a los procesos de comunicación, desarrollo y cambio social. Si se invierten esfuerzos físicos y recursos económicos en promover una adecuada alimentación con estrategias efectivas, sostenibles, que partan de la realidad de los contextos e incluye a los actores claves, los resultados pueden ser más favorables, que si se hacen estrategias dirigidas a alguien sin tener en cuenta a ese alguien y su entorno. 


\section{Recomendaciones}

Al finalizar este proceso investigativo y acorde a las experiencias tenidas en el mismo, puedo realizar las siguientes recomendaciones a quien esté interesado en la promoción de la alimentación saludable de la mujer gestantes y sus familias:

- Para poder hacer una propuesta de estrategia de comunicación de la alimentación saludable en cualquier población, se debe tener en cuenta la realidad de la comunidad, partir de sus características socios culturales, sus tradiciones, sus hábitos y claro ésta haciéndolos parte del proceso. Al vincular a la población como sujetos y no como objetos de intervención se inician procesos de transformación social que contribuyen a la solución real de los problemas, de igual manera se potencializan las fortalezas y capacidades para el bien común y para la generación de mayores oportunidades.

- Los medios de comunicación no deben ser el centro de las estrategias, son herramientas que ayudan a difundir información, pero cuando se usan solos no generan procesos de cambio de comunidades, ni empoderamiento, y mucho menos impacto en el desarrollo de la población. Sin embargo, es útil generar mensajes complementarios a la estrategia por medio de las redes sociales, las cuales son utilizadas por la mayoría de las personas, de manera frecuente y su divulgación es a bajo costo. Lo importante es realizar piezas cortas, atractivas, con poco texto y mensajes claves con lenguaje sencillo que estén orientadas a ser compartidas.

- La información resultante del consumo de alimentos de las mujeres del programa de familias en acción de la Secretaría Distrital de Integración Social, debería ser cruzada con los resultados de la Encuesta Nacional de Situación Nutricional 2015, con el objeto de hacer cruces de la información distrito y nación y comparaciones en relación al estado nutricional de las madres y el peso al nacer de los hijos.

- Es fundamental para un país promover la alimentación saludable en las mujeres gestantes para garantizar insumos a nivel nutricional y de salud de las futuras 
generaciones, contribuyendo así al desarrollo humano. Para esto se requiere poner en el centro a las gestantes y sus familias, planeando acciones con ellas y para ellas, teniendo en cuenta sus gustos, necesidades, inquietudes y sus hábitos alimentarios.

- Los profesionales que trabajen con las gestantes y sus familias deben realizar recomendaciones usando técnicas de consejería, eso significa, poniéndose en lugar de las gestantes, escuchándolas, revisando su contexto, entorno y ámbito, propiciando un dialogo y hacer luego una o dos recomendaciones para que ellas sean quienes decidan qué es lo mejor para su salud y la del bebé.

- Es importante tener en cuenta a los líderes sociales o referentes comunitarios, ya que son personas cercanas a las mujeres y que pueden ser escuchadas y seguidas de mejor manera que los profesionales de las instituciones. Sin embargo, estas personas también requieren procesos de fortalecimiento de capacidades que contribuyan a que sus recomendaciones sobre alimentación saludable sean las mejores y acordes a las sugerencias técnicas de los profesionales.

- Acorde a los principios de Sandra Masonni, se requiere que se piense menos en el problema y más en soluciones de fondo, pasando a actuar lo antes posible, realizando procesos de evaluación continua para mejorar los procesos. De igual manera se recomienda en este marco, no pretender una fórmula secreta para promover la alimentación saludable de la población, no hay un modelo o una única estructura aplicable a todos los casos. La comunicación estratégica busca aprovechar las capacidades de los actores, potencializarlos, empoderarlos, dialogar y buscar posibles acciones con la comunidad, construir estrategia, dar opciones de mejora y finalmente contribuir al cambio social por medio de transformaciones reales, efectivas y sostenibles.

- El trabajo intersectorial que se pueda lograr, en el marco de una mesa de trabajo liderada por la Secretaria Distrital de Integración Social es fundamental para procurar la seguridad alimentaria de las gestantes, revisando y proponiendo acciones a nivel de la disponibilidad, el acceso, el consumo y el aprovechamiento biológico de los alimentos.

- Las acciones de promoción de la alimentación saludable deberían realizarse en el marco de la comunicación, el desarrollo y el cambio social, ya que se sale de propuestas realizadas sin tener en cuenta la opinión, sugerencias o participación de los actores que sufren el problema, busca hacer transformaciones a partir del 
empoderamiento, teniendo en cuenta sus recursos, intereses, capacidades y potencialidades.

- Este tipo de propuestas deben ser tenidas en cuenta por las instituciones públicas o privadas que realizan actividades de promoción con las mujeres gestantes y sus familias, ya que se parte de sus realidades y su cultura para proponer acciones viables para el bienestar alimentaria de ellas, sus hijos y sus familias.

- Se recomienda poder implementar este tipo de estrategias pero incluir el componente de monitoreo, seguimiento y evaluación permanente, de manera que se puedan medir cambios, mejoras e impacto de las diferentes acciones sobre los hábitos alimentarios, frecuencia del consumo de alimentos, estado nutricional de la mujer y estado nutricional del bebé.

- La estrategia de comunicación no es estática, cambia acorde a las circunstancias locales y del medio, por lo cual sus líderes institucionales deberán contemplar acciones de dialogo que conlleven a mejorar los procesos basados siempre en el dialogo con los actores, su participación activa y propositiva y generar espacios de discusión y construcción conjunta.

- Por último considero que todas las facultades de la salud deberían fortalecer su currículo con estudios de comunicación, pero más allá de una perspectiva mediática; debe ser en el marco del desarrollo y el cambio social, donde el centro sean las personas con sus realidades, sus propuestas, sus acciones, empoderadas y conscientes de su importante papel y propiciando transformaciones que perduren a pesar de tiempo. 


\section{Bibliografía}

Alarcón, C. (01 de 2013). La iniciativa de comunicación. Obtenido de Comunicación y medios para el desarrollo de América Latina y el Caribe: http://comminit.com/la/content/de-cero-siempre

Bernabeu-Peiró, Á. (2015). La divulgación radiofónica de la alimentación y la nutrición. El ejemplo de radio 5 Todo Noticias. Revista de Comunicación y Salud, Vol. 5., $36-53$.

Cifuentes, D., \& Reyes, J. (2014). Aproximación a los hábitos de consumo de contenido mediatico por parte de los niños y las niás en Colombia. Bogotá: Ministerio de Cultura.

DANE. (2017). Encuesta Nacional de Calidad de Vida . Bogotá.

Erwin Hernández-Rincón, D. S.-B.-M.-S.-F.-M. (2015. ). Promoción de alimentación saludable en hogares comunitarios infantiles del municipio de Sopó (Cundinamarca. Colombia) bajo la estrategia de Atención Primaria en Salud. Revista Científica Salud Uninorte, Vol 31 No. 03.

FAO. (2012). Estrategia de Informaciín, Educación y Comunicación en Seguridad Alimentaria y Nutricional para Colombia en el marco del PDSP. Bogotá: FAO.

Fatima, E., Luordes, C., \& Leticia, S. (2017). Conocimientos sobre el riesgo de embarazo. Salud Pública de México.

Hernandez, M. (2014). Ganancia del peso gestacional como factor de riesgo para desrrollar complicaciones obstétricas. Revista de Perinatología y Reproducción Humana.

Krause A, K. L. (1995). Nutrición y dietoterapia. Pensylvania, USA: Interamericana Mc Graw Hill.

Latham, M. (2002). Nutrición Humana en el Mundo en Desarrollo. Bogotá: Organización de las Naciones Unidas para la Agricultura y la Alimentación.

Martinez, M. (2012). Comunicación y Desarrollo. Prácticas comunicativas y empoderamiento local. Gedisa.

Massoni, S. (2011). Comunicación estratégica: Comunicación para la innovación. Rosario, Argentina.

Ministero de Salud, P. I. (2010). Encuesta Nacional de Situación Nutricional, ENSIN. Bogotá.

MinSalud. (2012). Sistematización de la estrategia de movilización social.

Molina, Y. M. (2001). El Mercadeo Social en Colombia. Medellín. 
Mosquera, M. (2003). Comunicación en Salud: Conceptos, Teorías y Experiencias. Bogotá.

Niljand, M. (2008). Prenatal origins of adult disease. Texas. EUA.

Onofrio, M. I. (2012). Revista comunitaria No. 7315. Obtenido de Universidad de Cadiz: file://G:/2018/maestria/Bibliografia\%202018/resumen\%20marcelo\%20martinez $\% 20 y \% 20$ sierra.pdf

Organización de las Naciones Unidas para la alimentación y la agricultura, F. (2015). Estrategia de Información, Educación y Comunicación en seguridad alimentaria y nutricional para Colombia". FAO.

Perczek, R., \& Corredor, N. (2014). Plan de acción en salud 1000 primeros días. Colombia $2012-2021$.

R. Wildman, D. (2000). Advanced human nutrition: Nutrition and human reproduction. London: CRS Press pp 399-403.

Rym El Rafei. (2015). Association of Pre-Pregnancy Body Mass Index and GestationalWeight Gain with Preterm Births and Fetal Size: an ObservationalStudy from Lebanon. Paediatric and Perinatal Epidemiology.

Salud, M. d., Profamilia, \& ICBF. (2010). ENSIN.Encuesta Nacional de la Situación Nutricional en Colombia. Bogotá.

Sanchez, L. C. (2012). El bienestar empieza en casa. Fundación Alpina.

Sánchez-Jiménez, B., Sámano, R., Pinzón, I., Balas, M., \& Perichart, O. (2010). Factores Socioculturales que Influyen en las prácticas alimentarias de gestantes con y sin obesidad. Revista salud pública y Nutrición.

Tamara R. Cohen, H. P. (2010). Are Canadian Women Achieving a Fit Pregnancy? A Pilot Study. Canadian Journal and Public Health, 87 -91.

Torrez, V. A., \& Chavez, R. (2008). La comunicación en los programas de promoción y prevención de la salud en bogotá.

Tufte, T. (2015). Comunicación para el cambio social. Barceloa, España: Icaria Editorial SA.

Urrea, S. (2003). https://es.scribd.com/doc/9504850/Teoria -de-la-difusionde.innovaciones-rogers.

Zigla Consultores. (17 de Enero de 2013). ZIGLA. Obtenido de http://www.ziglablog.com.ar/el-mapeo-de-actores-como-herramienta-visualpara-el-diagnostico-de-un-programa/ 
Hernández, M. (2014). Ganancia de peso gestacional como factor de riesgo para desarrollar complicaciones obstétricas. Revista de Perinatología y reproducción humana.

Latham, M. (2002). Nutrición Humana en el Mundo en Desarrollo. Ithaca, New York: Organización de las Naciones Unidas para la Agricultura y la Alimentación.

Martínez, M. (2012). Comunicación y desarrollo. Prácticas comunicativas y empoderamiento local. Gedisa.

Massoni, S. (2011). Comunicación estratégica: comunicación para la innovación. Buenos Aires: Homo Sapiens Ediciones.

Mosquera, M. (2003). Comunicación en Salud: Conceptos, teorías y experiencias. Son de Tambora.

Muñoz, M., Martínez, J., \& Quintero, A. (2010). Validación de la Escala Latinoamericana y Caribeña de Seguridad Alimentaria en gestantes adolescente. Avances en enfermería, 173 - 183.

Organización de las Naciones Unidas para la Alimentación y la Agricultura, F. (2016). Estrategia de Información, Educación y Comunicación en Seguridad Alimentaria y Nutricional para Colombia. Bogotá: FAO.

Perczek, N. C. (2014). Plan de Acción de Salud 1000 primeros días. Colombia 2012 2021.

Profamilia. (2010). Encuesta Nacional de Situación Nutricional en Colombia. Situación Nacional, Bogotá.

Salud, M. d. (2010). Plan Decenal de Lactancia Materna, 2010 - 2020. Bogotá.

Salud, O. M. (2007). Consejería para la alimentación del lactante y del Niño Pequeño. Washington.

Sánchez, E. A. (2007). Gestación y prácticas de cuidado. Avances en enfermería, 50-57.

Sarmiento, O., Ramírez, A., Samper, B., Paula Pinzón, S. G., \& Olarte, A. (2001). Nutrición en mujeres gestantes en Colombia. Nutrición Salud Pública, 1 - 9.

Social, M. d. (2012). Manual para la extracción, conservación, transporte y suministro de la leche materna. Bogotá.

Tarazona, M. C. (2013). Factores tempranos definitivos en la programación del metabolismo. Revista de la asociación Colombiana de Ciencia y Tecnología de Alimentos, 3- 10. 
Tufte, T. (2004). Eduentretenimiento en la comunicación para el VIH SIDA, más allá del mercadeo, hacia el empoderamiento. Investigación y desarrollo Volumen 12. Núm. 1, 24 - 43.

Urrea, S. C. (2003). https://es.scribd.com/doc/9504850/Teoria-de-la-Difusion-deInnovaciones-Rogers\#.

http://www.integracionsocial.gov.co/index.php/servicios-sociales/servicio-infancia$\underline{\text { sdis? } \text { start }=3}$ 